ANDRÉA LOPES RAMIRES KAIRALA

HIPOMINERALIZAÇÃO MOLAR INCISIVO (MIH): UMA CORRELAÇÃO DE FATORES POSSIVELMENTE DESENCADEANTES

BRASÍLIA

2015 


\author{
UNIVERSIDADE DE BRASÍLIA \\ FACULDADE DE CIÊNCIAS DA SAÚDE \\ PROGRAMA DE PÓS-GRADUAÇÃOEM CIÊNCIAS DA SAÚDE
}

ANDRÉA LOPES RAMIRES KAIRALA

HIPOMINERALIZAÇÃO MOLAR INCISIVO (MIH): UMA CORRELAÇÃO DE FATORES POSSIVELMENTE DESENCADEANTES

\begin{abstract}
Dissertação apresentada como requisito parcial para a obtenção do Título de Mestre em Ciências da Saúde pelo Programa de Pós-Graduação em Ciências da Saúde da Universidade de Brasília.
\end{abstract}

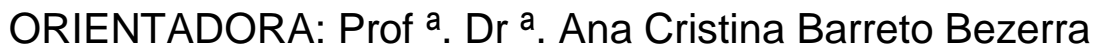




\title{
HIPOMINERALIZAÇÃO MOLAR INCISIVO (MIH): UMA CORRELAÇÃO DE FATORES POSSIVELMENTE DESENCADEANTES
}

\begin{abstract}
Dissertação apresentada como requisito parcial para a obtenção do Título de Mestre em Ciências da Saúde pelo Programa de Pós-Graduação em Ciências da Saúde da Universidade de Brasília.
\end{abstract}

Aprovada em de de 2015

BANCA EXAMINADORA

Prof $\stackrel{a}{\text {. Dr }} \stackrel{\text { a }}{ }$ Ana Cristina Barreto Bezerra - Presidente Universidade de Brasília - UnB - DF

Prof a . Dr a Erika Negrini Lia - Membro

Universidade de Brasília - UnB - DF

Prof a . Dr a Tatiana Degami Paes Leme Azevedo - Membro Universidade Católica de Brasília - UCB - DF

Prof. Dr. Orlando Ayrton de Toledo - Suplente Universidade de Brasília - UnB - DF 
Dedico esse trabalho com todo o meu amor ao meu esposo, Kairala Aos nossos queridos filhos, genros e nora E a nossa preciosa neta Maria Eduarda. Pelo incentivo e apoio em todas as minhas escolhas e decisões. Amo vocês. 


\section{AGRADECIMENTOS}

À Deus, muito obrigado por ter me fortalecido nos momentos em que mais precisei de forças e fé.

À minha orientadora Professora Dra. Ana Cristina Barreto Bezerra agradeço por proporcionar não só o conhecimento, mas também a convivência desses últimos anos e por ter-me feito aprender. É uma honra após anos voltar a ser sua aluna e orientanda. A palavra mestre, nunca fará justiça! Os meus eternos agradecimentos.

Ao Professor Dr. Orlando Ayrton de Toledo por ser um exemplo maravilhoso a ser seguido.

Ao meu grande amigo e amor da minha vida, Kairala José, pela paciência, incentivo e por sempre acreditar em mim.

Aos filhos Carol, Natalia, Thiago e Isabela que são a razão de toda a minha existência, agradeço pelo amor de vocês. Aos meus amores mais recentes José Maurício, Luiz Matheus e Lanna.

À minha neta Maria Eduarda que é a renovação da vida e do amor.

Aos meus pais responsáveis por toda a minha formação, pela minha personalidade e pelos meus princípios. Amo vocês!

As colegas Caroline Mohamed e Winnie Mandela pelo trabalho em equipe, pelos ótimos momentos juntas e pelo aprendizado em conjunto. Sem vocês esse momento não seria possível.

A amiga Dinair sempre disposta, muito obrigado pelo auxílio.

A todas as crianças e familiares que aceitaram participar deste estudo. A contribuição de vocês foi fundamental.

A todos que direta ou indiretamente fizeram parte da minha formação, o meu muito obrigado. 
"Que os vossos esforços desafiem as impossibilidades, lembrai-vos de que as grandes coisas do homem foram conquistadas do que parecia impossível. " 


\section{RESUMO}

INTRODUÇÃO: A hipomineralização incisivo-molar $(\mathrm{MIH})$ é definida como uma patologia de origem sistêmica, de etiologia desconhecida, caracterizada pela diminuição da mineralização dos primeiros molares permanentes, frequentemente associada com alterações nos incisivos permanentes. Entidade facilitadora de lesão de cárie, levando a hipersensibilidade, medo e ansiedade, além de problemas comportamentais, principalmente quando há envolvimento estético. Sua prevalência mundial varia entre 2,5 a 40,2\%. Há uma ampla variedade de fatores envolvidos no desenvolvimento da MIH. Estudos indicam como possíveis causas, comprometimento da saúde materna durante o último trimestre de gestação como infecção urinária e diabete; APGAR $<7$, baixo peso ao nascer (BP) e prematuridade; na primeira infância doenças respiratórias, exantemáticas e seus tratamentos, como utilização de amoxicilina e má nutrição. Período, esse, em que ocorre a mineralização do esmalte dentário no feto e no recém-nascido (RN). OBJETIVO: O objetivo desse trabalho é determinar a prevalência da $\mathrm{MIH}$ e conhecer os possíveis fatores etiológicos envolvidos na sua formação. MÉTODO: A amostra foi constituída por 168 crianças entre 6 e 8 anos de idade, frequentando escola pública no Gama, DF e nascidas no Hospital Regional do Gama, DF. A coleta de dados foi realizada através exame clínico oral, um questionário aplicado as mães e análise do prontuário médico. Durante a observação registrou-se a presença de opacidades demarcadas em primeiros molares e incisivos permanentes devido a acometimento por MIH. Através de questionário entregue as mães procurou-se uma relação entre fatores de agravo a saúde da mãe no final da gestação e da criança até o primeiro ano de vida, com a formação de MIH. Realizado pesquisa bibliográfica na base PUBMED de artigos publicados nos últimos dez anos. RESULTADOS: A prevalência de $\mathrm{MIH}$ em 168 crianças da regional do Gama /DF foi de N=9 ou 5,36\% (IC95\%: $1,95 \%$ - 14,1\%). Não foi encontrado significância estatística entre mães que referiram problemas médicos no período pré-natal com $\mathrm{MIH}$. A falta de acompanhamento médico durante a gestação mostrou porcentagem elevada, mas sem valor estatístico; dos indivíduos pesquisados que possuíam $\mathrm{MIH}(\mathrm{N}=9), 22,22 \%$ informaram não ter feito pré-natal ( $p$-valor 0,19; OR:3). Em relação a idade gestacional $11,11 \%$ das crianças com $\mathrm{MIH}$ eram prematuras ( $p$-valor=1 IC: $0,02-9,49$ - OR: 1,14). Das crianças com MIH, 66,7\% mamaram no seio materno mais do que 1 ano, ( $p$-valor $=0,05)(95 \%$ de confiança) mostrando uma relação estatisticamente significativa. Não foi encontrada relação entre $\mathrm{MIH}$ e doenças no primeiro ano de vida. Na amostra não foi detectado incisivos permanentes com MIH. CONCLUSÕES: As interferências na saúde materna no final da gestação e no primeiro ano de vida da criança podem estar associados com $\mathrm{MIH}$. Os fatores envolvidos na formação da $\mathrm{MIH}$, ainda são indefinidos, mas de acordo com uma corrente majoritária na literatura, são o nascimento prematuro e BP ao nascer os mais relacionados com essa entidade. No entanto, são necessários mais estudos clínicos para que se possam validar algumas dessas teorias.

Palavras-chave: Defeitos no esmalte; molar incisor hypomineralization; prematuridade; prevalência; etiologia. 


\begin{abstract}
:
INTRODUCTION: Incisor-molar hypomineralization $(\mathrm{MIH})$ is defined as a systemic source of disease of unknown etiology, characterized by decreased mineralization of permanent molars, often associated with changes in the permanent incisors. Facilitator of carious lesion, leading to hypersensitivity, fear and anxiety, and behavioral problems, especially when there are aesthetic involvement. Its worldwide prevalence varies between 2.5 and $40.2 \%$. There are a wide variety of factors involved in the development of $\mathrm{MIH}$. Studies indicate, as possible causes, maternal health commitment during the last trimester of pregnancy as urinary tract infection and diabetes; APGAR $<7$, low birth weight (BP) and prematurity; and early childhood respiratory diseases, rash and its treatments such as use of amoxicillin and malnutrition. Period, this, in which there is mineralization of enamel in the fetus and newborn (NB). AIM: of this study was to determine the prevalence of $\mathrm{MIH}$ and know the possible etiologic factors involved in its formation. METHODS: The sample consisted of 168 children between 6 and 8 years old, attending public school in Gama, DF and born in the DF Range Regional Hospital. Data collection was performed by oral clinical examination, applying a questionnaire mothers and analysis of medical records. During the observation there was presence of demarcated opacities in first molars and permanent incisors due to involvement by $\mathrm{MIH}$. Through a questionnaire delivered mothers looked for a relationship between injury factors the health of mother and child at the end of pregnancy to the first year of life the child with the formation of $\mathrm{MIH}$. Conducted literature search in PubMed base of articles published in the last ten years. RESULTS: The prevalence of MIH in 168 children in the regional Gama / DF was N $=9$ or $5.36 \%(95 \% \mathrm{Cl}: 1.95 \%-14.1 \%)$. It found no statistically significant difference between mothers who reported medical problems in the prenatal period with $\mathrm{MIH}$. The lack of medical care during pregnancy showed high percentage but without statistical value; of individuals surveyed who had $\mathrm{MIH}(\mathrm{N}=9), 22.22 \%$ reported not having done prenatal ( $\mathrm{p}$-value 0.19 ; OR: 3$)$. In relation to gestational age $11.11 \%$ of children with $\mathrm{MIH}$ were premature $(\mathrm{p}$-value $=1$ $\mathrm{Cl}: 0.02$ to 9.49 - OR: 1.14). Children with $\mathrm{MIH}, 66.7 \%$ were breastfed for more than one year ( $p=0.05$ ) (95\% confidence) showing a statistically significant relationship. No relationship was found between $\mathrm{MIH}$ and disease in the first year of life. The sample was not detected permanent incisors with MIH. CONCLUSIONS: Interference on maternal health in late pregnancy and the first year of a child's life may be associated with $\mathrm{MIH}$. The factors involved in the formation of $\mathrm{MIH}$ are still undefined, but according to a majority in the current literature, are premature birth and birth the BP more related to that entity. However, further clinical studies are needed so that they can validate some of these theories.
\end{abstract}

Index Terms - Dental enamel; molar incisor hypomineralisation; premature birth; prevalence; etiology. 


\section{LISTA DE FIGURAS}

Figura 1 - Estágios de mineralização dentária proposto por Nicodemos, Moraes e Médici Filho (1974).

Quadro 1 - Cronológica da mineralização dos dentes permanentes entre brasileiros (Nicodemos, Moraes e Médici Filho 1974), modificada.

Figura 2 - (A) incisivos (11 e 21) com MIH opacidade demarcada. (B) Incisivos (11 e 21) com fratura de esmalte.

Figura 3 - Diferentes manifestações clinicas do MIH. A: Opacidade difusa em incisivos centrais permanentes (ICP). B: Mancha escura em ICP. C: Opacidade demarcada em 1ํㅡㄹ Molar Permanente (1ํMP). D: Lesão escura com início de carie em (1ํMP).

Quadro 2 - Diagnóstico diferencial entre as anomalias do esmalte dentário

Quadro 3: Prevalência de MIH em diferentes estudos epidemiológicos

Figura 4: Fluxograma de procedimentos e critérios de exclusão da pesquisa

Gráfico 1 - Perfil da idade das crianças da amostra

Gráfico 2: Distribuição da amostra por sexo

Gráfico 3: Perfil da escolaridade materna

Gráfico 4: Realização de consultas de pré-natal

Gráfico 5: Intercorrências encontradas durante a gestação das mulheres estudadas

Gráfico 6: Intercorrências no período neonatal

Gráfico 7: Intercorrências encontradas durante o $1^{\circ}$ ano de vida da criança

Gráfico 8: Tempo de aleitamento materno

Gráfico 9: Perfil de cuidados com higiene oral

Gráfico 10: Relação entre a classificação do RN (peso x idade gestacional) e nível de MIH

Gráfico 11 - Dentes molares permanentes com MIH

Gráfico 12: Análise de acometimento de $\mathrm{MIH}$ por período 


\section{LISTA DE TABELAS}

Tabela 1 - Distribuição das crianças pesquisadas nas escolas quanto a ocorrência de $\mathrm{MIH}$

Tabela 2: Informações socioeconômica dos indivíduos com MIH

Tabela 3: Relação de MIH com intercorrências no período pré-natal

Tabela 4: Relação de MIH com intercorrências no período perinatal

Tabela 5: Relação de MIH com intercorrências no $1^{\circ}$ ano de vida

Tabela 6: Informações sobre a saúde oral e relação com MIH

Tabela 7: Distribuição dos indivíduos quanto aos dentes com MIH 


\section{LISTA DE ABREVIATURAS E SIGLAS}

1MI - Primeiro Molar Inferior

19MS - Primeiro Molar Superior

2PE - 2 2 Pré-Escola

BP - Baixo Peso ao Nascer

DC - Doença celíaca

DF - Distrito Federal

DMH - Deciduous Molars Hypomineralization

EAPD - European Academy of Paediatric Dentistry

FC - Fibrose Cística

HMI - Hipomineralização Incisivo Molar

HRG - Hospital Regional do Gama

IC - Intervalo de confiança

ICI - Incisivo Central Inferior

ICS - Incisivo Central Superior

ILS - Incisivo Lateral Inferior

ILS - Incisivo Lateral Superior

ITU - Infecção do Trato Urinário

MIH - Molar Incisor Hypomineralization

OMS - Organização Mundial de Saúde

OR - Odds Ratio

RA - Região Administrativa

RNPT - Recém-Nascido Pré Termo

RNT - Recém-Nascido a Termo

VEU - Vida Extrauterina

VIU - Vida Intrauterina 


\section{SUMÁRIO}

1 INTRODUÇÃO

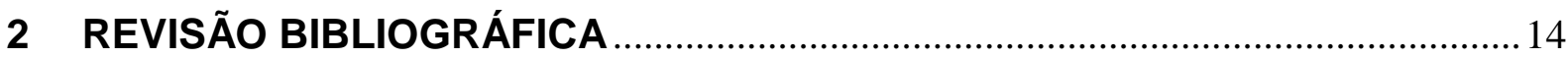

21 DEFINIÇÃO

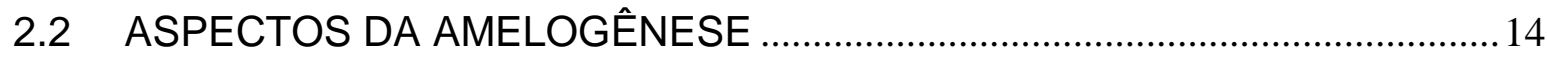

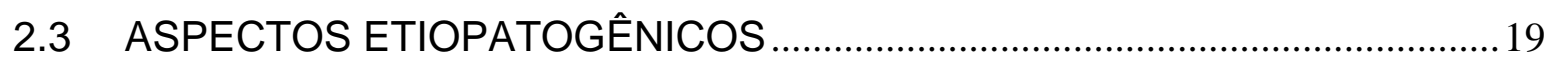

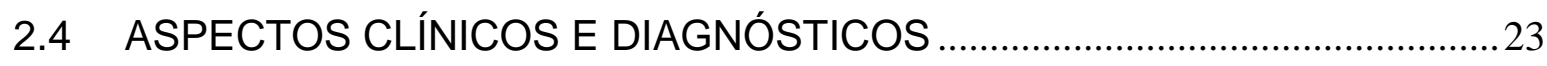

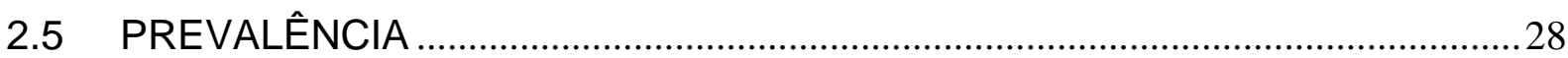

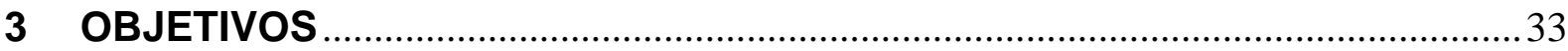

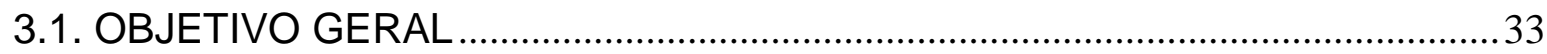

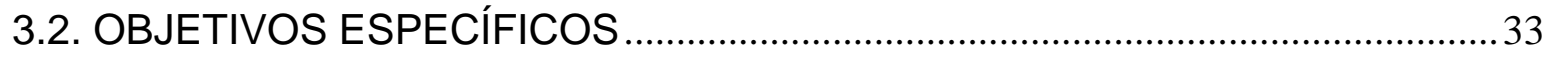

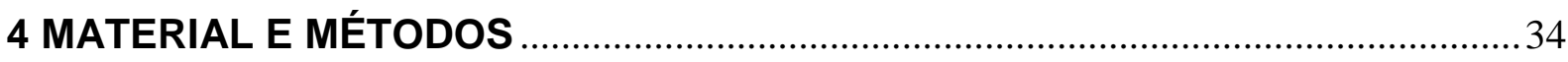

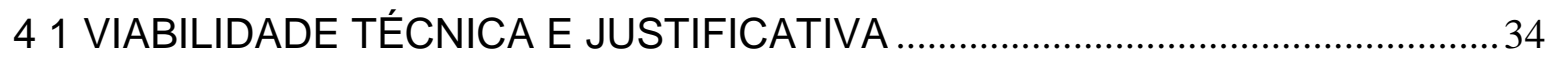

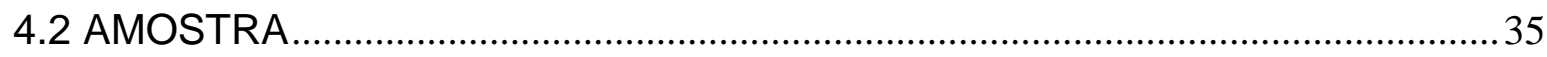

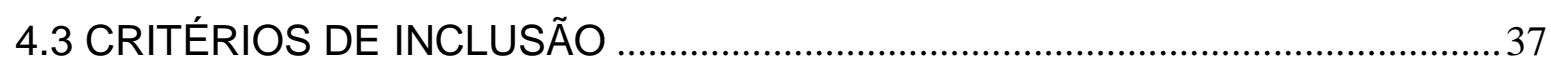

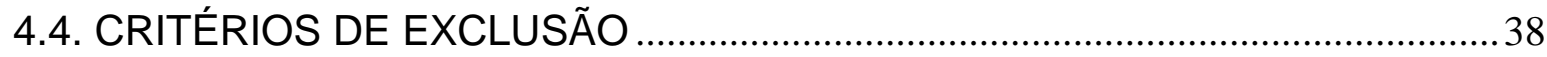

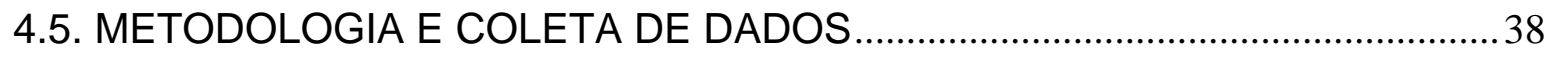

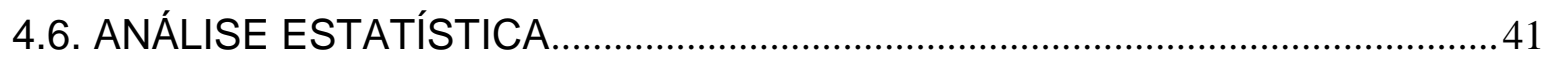

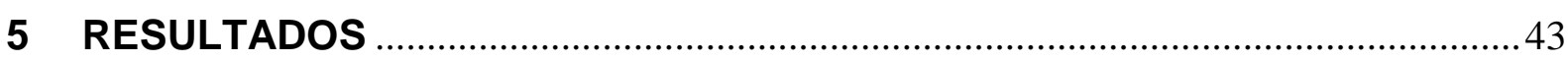

5.1 ANÁLISE DESCRITIVA DA AMOSTRA _.............................................................. 43

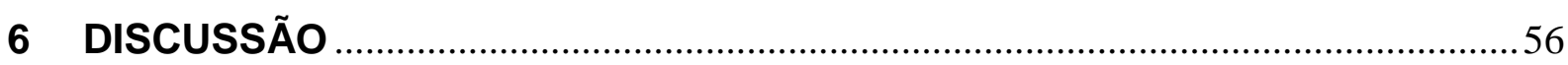

7 CONCLUSÔES

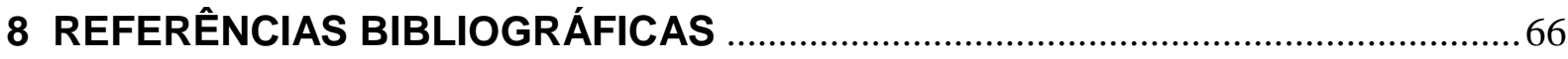

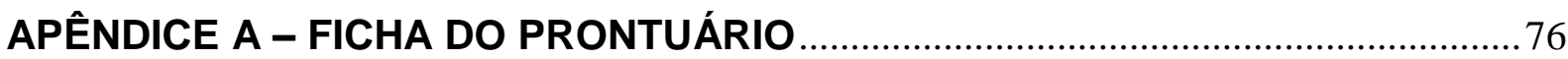

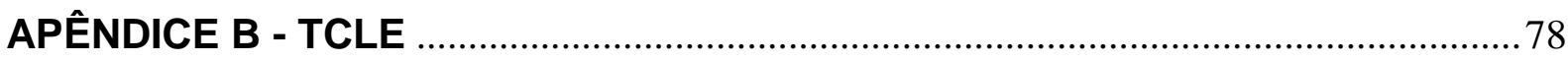

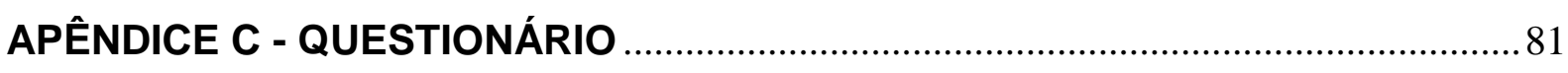

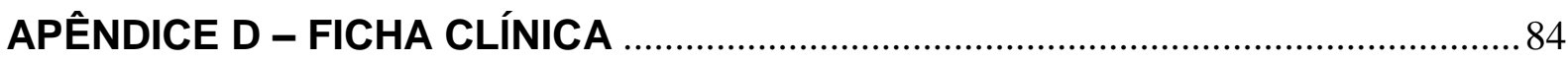

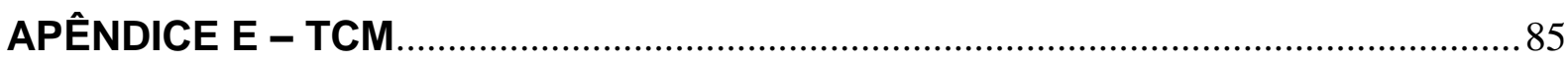

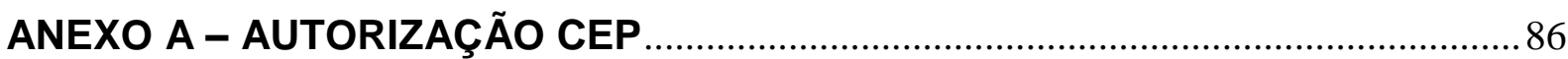




\section{INTRODUÇÃO}

A hipomineralização incisivo molar $(\mathrm{MIH})$ é definida como uma patologia de origem sistêmica caracterizada pela diminuição da mineralização de molares, frequentemente associada com alterações nos incisivos permanentes. (1)

A etiologia da $\mathrm{MIH}$ permanece com grandes indefinições e, ao que se sabe, é resultante de uma alteração da função do ameloblasto durante a amelogênese na fase tardia de mineralização, ocasionando um defeito do esmalte dentário, com uma diminuição significante de seu conteúdo proteico.

Apesar de ainda ser pouco conhecida, o que leva a frequentes diagnósticos equivocados, estudos europeus mostram que a $\mathrm{MIH}$ é significativamente prevalente em vários países $(2,3,4,5)$. No Brasil, os dados de reconhecimento desta patologia, bem como de sua prevalência na população, ainda são poucos $(6,7,8$, 9), mas o seu conhecimento aprofundado, com identificação precisa de sua etiologia, mostra-se relevante. Uma possível consequência de um esmalte defeituoso, por exemplo, é um rápido desenvolvimento de lesões de cárie, logo após a erupção dos molares permanentes, com necessidade de procedimentos clínicos e tratamentos recorrentes. $(10,11,12)$

Defeitos semelhantes aos da $\mathrm{MIH}$, em segundos molares decíduos, estão sendo descritos na literatura $(13,14)$, recebendo recentemente a nomenclatura de "Deciduous Molars Hypomineralization" (DMH), o que poderia ser traduzido como hipomineralização de molares decíduos. Esses defeitos estruturais levam a um aumento da sensibilidade devido à dentina exposta e/ou perda de elementos dentários muito precocemente, em um número significativo da população pediátrica. (10)

A escolha desse tema foi motivada pela premente necessidade de se estudar e mais bem compreender as alterações do esmalte dentário, buscando-se associar eventos ocorridos durante a gestação e no $1^{\circ}$ ano de vida, levando-se em consideração doenças de ordem sistêmica. Portanto, a finalidade é unir a Pediatria e a Odontopediatria. Essa busca pretende detectar e prevenir ocorrências que poderiam manifestar-se clinicamente somente em torno de 6 a 8 anos de idade, quando da erupção dos primeiros molares permanentes e, muitas das vezes, quando já estão presentes sinais e sintomas, como dor, processos inflamatórios e/ou 
infecciosos e alterações no padrão estético, que poderão acarretar comprometimento da saúde da criança, no seu sentido mais amplo, de acordo com a definição de saúde preconizada pela Organização Mundial de Saúde (OMS) desde 1948 : "Saúde é um completo estado de bem-estar físico, mental e social, e não meramente ausência de doença". Considerando-se que a MIH continua sendo um desafio do ponto de vista de sua etiologia, prevalência e fisiopatologia, procurou-se abordar os principais possíveis fatores etiológicos, fisiopatológicos e da investigação diagnóstica, mais frequentes envolvidos no surgimento de alterações do esmalte, com o objetivo prevenir ou minimizar o impacto da $\mathrm{MIH}$ através de uma compreensão mais acurada dos diversos aspectos envolvidos nessa entidade. 


\section{REVISÃO BIBLIOGRÁFICA}

Realizou-se, entre outubro e dezembro de 2014, pesquisa bibliográfica na base MEDLINE/PUBMED de artigos publicados nos últimos dez anos, tendo como palavras-chave: "molar incisor hipomineralization", "primary molars", "permanente molars", "children", "premature birth", "prevalence", "etiology". Foram impostos limites de pesquisa: artigos em língua inglesa ou espanhola. Foram analisados 358 artigos, dos quais 45 selecionados. Incluiu-se artigos de revisão e estudos epidemiológicos.

\section{DEFINIÇÃO}

O primeiro relato clínico de MIH data de 1970, porém com diversas nomenclaturas para molares e incisivos com opacidades de esmalte demarcadas, tais como hipomineralização idiopática, opacidade de esmalte não relacionadas ao flúor, hipoplasia interna do esmalte, manchamento não endêmico do esmalte, etc (15). Apenas em 2001, Weerheijm, Jalevick e Alaluusua (36) definiram a patologia como uma hipomineralização de origem sistêmica, que pode afetar 1, 2 ou os 4 primeiros molares permanentes, com alta prevalência de incisivos afetados, denominando-a "Molar-Incisor Hipomineralization" (MIH) (16) ou, em português, Hipomineralização Incisivo-Molar.

Mais recentemente, Crombie et al (55) passaram a considerar que, por vezes, os segundos molares permanentes e as cúspides dos caninos permanentes, também podem ser afetados por MIH (10).

\subsection{ASPECTOS DA AMELOGÊNESE}

As primeiras semanas de vida após a fecundação são caracterizadas por um período marcado por divisões e diferenciações celulares. Entre a $3^{\text {a }}$ e $8^{\underline{a}}$ semana de vida intrauterina (VIU), tem início a formação facial, sendo que na $6^{\stackrel{a}{ }}$ semana ocorre proliferação do epitélio oral, da maxila e da mandíbula, originando as lâminas dentárias (17). 
A odontogênese ocorre como resultado de mecanismos sinalizadores e sequenciais complexos entre o tecido epitelial de origem ectodérmica e o tecido ectomesenquimal originado da crista neural. Do ectoderma origina-se o órgão do esmalte, estrutura epitelial que modela todo o dente e a forma do esmalte do órgão dentário; do mesoderma deriva-se a papila dentária que mais tarde se diferencia em polpa dentária, formando o cemento, o ligamento periodontal e o osso alveolar.

A formação e o desenvolvimento do órgão dentário se realizam segundo um padrão histológico definido, obedecendo a vários estágios de desenvolvimento:

1. Iniciação

2. Histodiferenciação

3. Morfodiferenciação

4. Aposição

5. Calcificação

6. Erupção

Cada fase de desenvolvimento, à sua maneira, é sensível a múltiplos fatores externos que podem causar alterações de acordo com a fase onde houve a interferência. Em determinadas circunstâncias, podem ocorrer situações que modificam a fisiologia e morfologia dos tecidos, provocando desvios da estrutura da posição normal, podendo afetar partes externas ou internas. Estas alterações podem surgir por múltiplas causas, locais ou gerais, e às vezes por fatores indeterminados (18).

O início da odontogênese humana se dá por volta da $6^{\text {a }}$ semana de VIU, a calcificação dos dentes decíduos ocorre por volta do $4^{\circ}$ mês de VIU e no $6^{\circ}$ mês, todos os dentes já iniciaram a sua calcificação (19). A formação dos dentes permanentes ocorre entre a $20^{\underline{a}}$ semana de VIU e a $10^{\underline{a}}$ semana pós-natal. O esmalte estará completamente formado no momento da erupção dentária, mas sua superfície ainda será porosa e não completamente mineralizada.

A aposição, resultado de uma deposição de esmalte e de dentina pelos ameloblastos e odontoblastos que se alinham ao longo da futura junção amelodentinária e dentina-cemento, se dá no estágio de morfodiferenciação. Essas células serão responsáveis pela deposição sistemática e em ritmo definido de esmalte e dentina. Por outro lado, a calcificação ocorre em consequência da deposição de minerais e envolve a precipitação de sais inorgânicos na matriz depositada (20). 
O esmalte dentário é o tecido mais duro e mais mineralizado do corpo humano e sua formação, extremamente complexa, pode ser influenciada por fatores ambientais e genéticos, gerando alterações estruturais. As interferências ocorridas durante a formação do esmalte são permanentemente registradas. Os defeitos de esmalte são definidos como distúrbios na formação e mineralização dos tecidos duros durante a odontogênese (21). As influências no desenvolvimento dentário podem afetar quantitativa e qualitativamente o desenvolvimento tanto do esmalte quanto da dentina $(22,109)$.

A amelogênese envolve três fases: pré-secreção, secreção e maturação. $\mathrm{Na}$ pré-secreção ocorrerá a morfodiferenciação dos ameloblastos e a secreção da matriz orgânica do esmalte. Na segunda fase ocorre a secreção de esmalte prismático, interprismático e aprismático. Inicialmente essa matriz é constituída por dois tipos de proteínas, as amelogeninas em 90\% e não amelogeninas. Estudos indicam que as amelogeninas são responsáveis pela formação dos nós que direcionarão o crescimento dos primeiros cristais de esmalte. Após atingir sua espessura máxima, a matriz entrará no estágio de maturação, quando ocorre perda de proteínas e água e aumento dos cristais minerais. (23)

Vários trabalhos foram realizados com o objetivo de estudar o desenvolvimento dentário, fazendo uma associação com a idade cronológica da criança. No Brasil, utilizam-se os estudos de Nicodemo et al 1974 (24) para determinação da idade por meio da mineralização dos dentes permanentes, nos quais consideram-se oito estágios da mineralização (Figura 1). Autores tem se dedicado ao estudo de determinadas classes de dentes, entre eles Nicodemo, que estudou a mineralização dos terceiros molares, enquanto que Moraes (24) estudou os primeiros molares e incisivos permanentes, com Médici Filho (24) estudando os caninos, os pré-molares e os segundos molares permanentes. A partir da união desses autores, montou-se uma tabela de cronologia da mineralização de dentes permanentes, com uma relação entre os elementos dentários e os oito estágios de mineralização. (Quadro 1). Através desses estudos sobre a cronologia da calcificação dos dentes permanentes pode-se deduzir em que período da vida da criança, seja intra ou extrauterino, ocorreu o desequilíbrio na amelogênese capaz de alterar a constituição do esmalte dentário. 


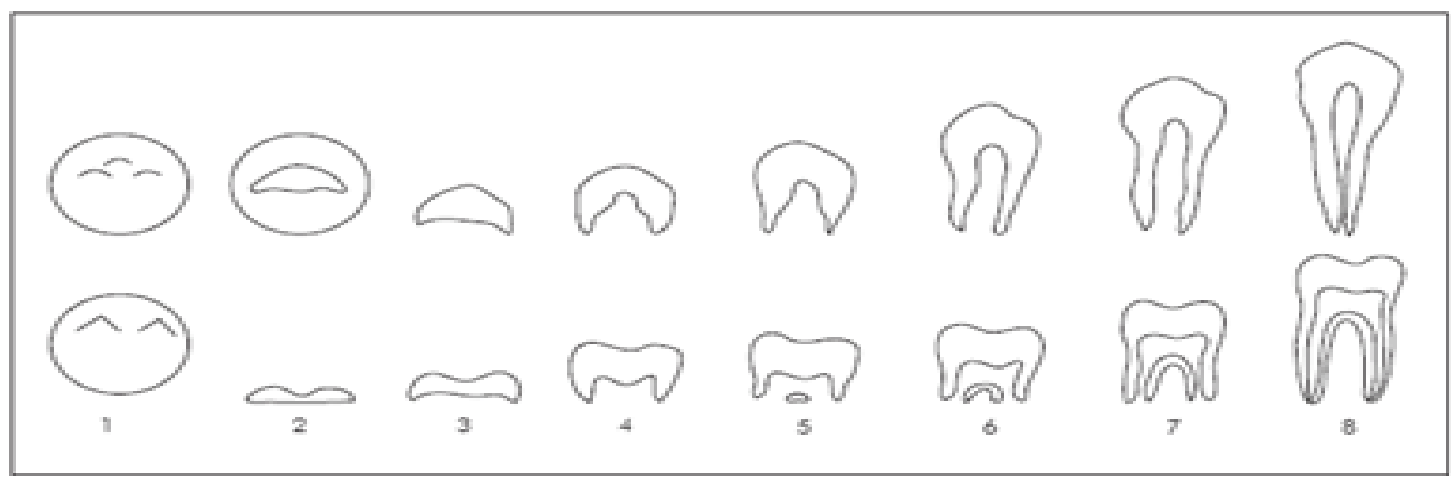

Figura 1- Estágios de mineralização dentária proposto por Nicodemos, Moraes e Medici Filho (1974)

\section{Estágios:}

1- Primeiras evidências de formação da coroa

2- Um terço da coroa

3- Dois terços da coroa

4- Coroa completa

5- Início da mineralização da raiz

6- Um terço da raiz

7- Dois terços da raiz

8- Término apical

Quadro 1 - Cronológica da mineralização dos dentes permanentes entre brasileiros (Nicodemos, Moraes e Médici Filho 1974), modificada. (Apenas molares e incisivos são de interesse para esse estudo)

\begin{tabular}{|c|c|c|c|c|c|c|c|c|}
\hline DENTE & $\begin{array}{c}\text { 10 evidência de } \\
\text { mineralização }\end{array}$ & $\begin{array}{c}1 / 3 \text { de } \\
\text { coroa }\end{array}$ & $\begin{array}{c}2 / 3 \text { de } \\
\text { coroa }\end{array}$ & $\begin{array}{c}\text { Coroa } \\
\text { completa }\end{array}$ & $\begin{array}{c}\text { Início da } \\
\text { formação } \\
\text { radicular }\end{array}$ & $\begin{array}{c}1 / 3 \text { da } \\
\text { raiz }\end{array}$ & $\begin{array}{c}2 / 3 \text { da } \\
\text { raiz }\end{array}$ & $\begin{array}{c}\text { Término } \\
\text { apical }\end{array}$ \\
\hline ICS & $5-7$ & $8-15$ & $18-30$ & $36-57$ & $60-78$ & $75-90$ & $87-108$ & $100-116$ \\
\hline ILS & $9-15$ & $24-30$ & $33-57$ & $54-72$ & $72-88$ & $84-102$ & $96-112$ & $105-117$ \\
\hline $1^{\circ} \mathrm{MS}$ & $1-6$ & $6-16$ & $18-30$ & $36-48$ & $54-66$ & $66-84$ & $75-96$ & $90-104$ \\
\hline ICI & $3,9-6,1$ & $9-12$ & $18-27$ & $28-45$ & $48-68$ & $60-78$ & $76-96$ & $90-102$ \\
\hline ILI & $4,5-5,8$ & $7-12$ & $18-30$ & $18-66$ & $54-78$ & $68-88$ & $80-99$ & $92-102$ \\
\hline $1^{\circ} \mathrm{MI}$ & $1-6$ & $6-12$ & $18-28$ & $18-45$ & $54-66$ & $57-81$ & $78-96$ & $90-104$ \\
\hline
\end{tabular}

Obs: Os dados referem-se a meses de vida extra-uterina (VEU).

ICS: Incisivo Central Superior.

ILS: Incisivo Lateral Superior.

1MS: Primeiro Molar Superior.

ICI: Incisivo Central Inferior.

ILS: Incisivo Lateral Inferior.

1ำMI: Primeiro Molar Inferior 
Defeitos de desenvolvimento de esmalte geralmente são denominados como hipoplasias (25), que não devem ser confundidas com hipomineralizações ou opacidades, que são definidas como defeitos qualitativos dos tecidos dentários, identificados visualmente, como uma anormalidade na sua translucidez, e se caracterizam por áreas de coloração branca, creme, castanha ou amarela, de superfície lisa e espessura normal de esmalte $(25,26)$. Nas hipoplasias, a falta de estrutura em alguma face dos dentes poderá ser observada. Esse é um defeito dito quantitativo.

Alterações em genes específicos sinalizadores, distúrbios sistêmicos, traumas, entre outros, poderão afetar os ameloblastos durante sua formação ou maturação. Interferências no período de secreção, por meio de interrupções ou inativação na aposição da matriz de esmalte resultam hipoplasia. Quando ocorrem distúrbios no período de maturação, o processo de absorção proteica poderá ser deficiente ocasionando, assim, em um esmalte com mineralização insuficiente (27, 109).

Desse modo, os defeitos de esmalte podem ser estudados como marcadores de muitos eventos biológicos adversos ocorridos durante o desenvolvimento, e isso pode ter aplicação em investigações clínicas, epidemiológicas e antropológicas (28). Tais defeitos representam uma alteração de estrutura dentária de grande significância na clínica odontológica pediátrica e são responsáveis por desordens estéticas, funcionais, desarticulações em fase adulta, sensibilidade dentária, predisposição ao desenvolvimento de lesão de cárie, com desenvolvimento de abscessos, tratamento extensos e perdas dentárias (29).

Assim, a cronologia de erupção dentária é um ponto certamente importante para o entendimento dos inúmeros fatores que podem levar a lesão ou destruição do esmalte dentário.

A evolução normal da dentição humana depende do equilíbrio fisiológico do organismo como um todo. Existem fatores pessoais e/ou ambientais que, sem influir no equilíbrio fisiológico, parecem acarretar variações na cronologia eruptiva dos dentes $(30,31)$.

Os dentes irrompem na cavidade oral com uma cronologia estabelecida, de uma maneira geneticamente determinada, de acordo com a espécie, mas existem fatores sistêmicos que podem alterar essa cronologia e ou retardar a erupção 
dentária. O entendimento desses processos cronológicos e a sequência de erupção tem uma grande importância na área de saúde, pois devemos considerar a erupção não como um fenômeno isolado, mas sim uma parte do desenvolvimento global da criança (32).

Existem várias doenças que podem causar um retardo na erupção dentária, dentre elas as deficiências hormonais como os da tireoide e hipófise (33.) Em relação à nutrição, vários estudos mostram que a oferta inadequada de nutrientes leva a atraso na erupção dos primeiros dentes decíduos (34). A prematuridade e o baixo peso (BP) ao nascer potencialmente trazem reflexos e podem ocasionar algum retardo na erupção dentária. O ganho diário de peso, a inclusão de suplementos vitamínicos, o tempo de intubação e a presença de apneias são fatores que interferem na erupção dos dentes (19).

\subsection{ASPECTOS ETIOPATOGÊNICOS}

A etiologia da MIH permanece com grandes indefinições e, o que se sabe, é que resulta de uma alteração da função do ameloblasto durante a amelogênese na fase tardia de mineralização, resultando em defeito do esmalte dentário com uma diminuição significativa de conteúdo proteico (11). Tal distúrbio na formação do esmalte poderia ser resultante de intercorrências ocorridas entre o segundo trimestre de gestação e o $4^{\circ}$ ano de vida (1). O desencadeamento desse processo é, muito provavelmente, multifatorial, restando a definição exata de quais e quantos sãos os fatores desencadeantes, assim como o potencial patogênico de cada um deles, além da janela em que a embriogênese dentária pode ser afetada. É importante lembrar que entre a $28^{\mathrm{a}}$ semana de gravidez e os primeiros dias de vida os ameloblastos iniciam a amelogênese dos primeiros molares permanentes (35).

A etiologia dessas alterações envolve múltiplos fatores, entre eles mudanças ambientais e problemas nos períodos pré-natal e perinatal. Um dos grandes desafios é a variabilidade de elementos desencadeantes e a correlação entre eles, o que impede de classificar um único fato como responsável pelas alterações presentes (36). 
Um defeito de origem sistêmica no esmalte dentário de primeiros molares e incisivos permanentes é a condição clássica que dá origem à denominada hipomineralização molar-incisivo (MIH).

São citados vários fatores, possivelmente associados à alteração e de natureza sistêmica, como doenças respiratórias de uma maneira geral e condições pré e perinatais $(15,37)$. Além disso, também são frequentemente citados como causas o baixo peso (BP) ao nascimento, hipóxia, desordens metabólicas do cálcio e fosfato e doenças da infância associadas à febre alta, sendo que alguns ainda sugerem que a exposição à dioxina, um subproduto industrial decorrente, dentre outros, da utilização de pesticidas e que se acumula no tecido adiposo humano poderia ser um fator de aumento de risco (38). Ambientalistas alertam para a crescente presença dessa substância no corpo humano, entre eles: Carey, Giesy, Hodson, Owens, dentre outros. No Brasil, destacam-se as varias pesquisas sobre 0 tema. $(8,9,21,69)$

Autores (39) afirmam que o ameloblasto é capaz e depositar toda a matriz de esmalte, mas o depósito seria perturbado pela inabilidade do mesmo em reabsorver as proteínas da matriz em função da baixa oferta de oxigênio, seja por complicações no parto, doenças respiratórias (40), ou devido a um inadequado suprimento de fosfato de cálcio provavelmente relacionado a problemas renais, diarreia, febre alta e desnutrição (41).

Muñoz et all (42) referem que $87 \%$ dos pacientes afetados por MIH alegam ter tido problemas médicos no período que vai do último trimestre de gestação, com atenção especial ao parto, até os 3 primeiros anos de vida da criança. Foi registrado como problema de saúde da mãe durante o último trimestre de gestação: diabetes gestacional, hipertensão arterial, pré-eclâmpsia, asma, infecção do trato urinário (ITU), ou frequente utilização de antibióticos e/ou salbutamol. Os antecedentes durante o parto detectados foram: sofrimento fetal, parto prolongado, cesaria, parto prematuro e asfixia. Os antecedentes médicos durante os 3 primeiros anos referemse a quadros febris inespecíficos, doenças exantemáticas, especialmente a varicela; enfermidades respiratórias como bronquite, otite, broncopneumonia e seus tratamentos antibióticos $(38,54,55,56)$.

Atenção especial parece merecer a diabetes gestacional, com vômitos prolongados e uso de medicação antiespasmódica utilizada no final da gestação. É 
sabido que há um quadro de hipocalcemia na mãe e pequenos períodos de hipóxia para o feto $(43,44)$ associadas à esta patologia.

Estudos tem descrito uma alta prevalência de defeitos do esmalte em crianças que nasceram prematuras (antes das 37 semanas de gestação) e com BP (peso de nascimento menor que $2.500 \mathrm{~g}$ ) $(45,46,47)$.

Recém-nascidos pré-termo (RNPT), e de BP apresentam, frequente e precocemente, algumas complicações inerentes à sua condição ou devido a terapêuticas e intervenções que se fazem necessárias nos seus primeiros dias de vida. As dificuldades mais frequentes são: anóxia ou hipóxia, distúrbios hidroeletrolíticos (como hipoglicemia e hipocalcemia), anemia de variados graus, distúrbios renais, metabólicos e cardiorrespiratórios (38). Nessas circunstâncias várias intervenções terapêuticas se fazem necessárias com o uso de drogas, assistência ventilatória e intubação orotraqueal. Comparando-se RNPT com recémnascido a termo (RNT) observou-se que aqueles têm mais defeitos de esmalte $(6,48)$.

Seow (45) encontrou uma prevalência superior de defeito de esmalte em primeiros molares permanentes em crianças RNPT e BP ao nascer (21\% e 11\%, respectivamente), quando comparados com crianças de um grupo controle, mas nessa publicação não foi utilizado o termo MIH e sim "defeitos do esmalte" (49). Outro estudo realizado na Suécia (50) revelou uma prevalência 2 vezes maior de $\mathrm{MIH}$ em crianças prematuras (38\%) quando comparado com crianças de grupo controle (16\%).

Em estudo com o objetivo de avaliar a prevalência de defeitos de esmalte em dentes decíduos, e determinar a possibilidade de fatores tais como a prematuridade, peso ao nascer, e variáveis sócio demográficas, estarem associadas a tais defeitos, mostrou que crianças com história de muito baixo peso apresentavam grande prevalência de defeitos de esmalte (51).

Cesáreas com período expulsivo demorado, nascimento prematuro e gemelaridade foram frequentemente relacionadas com o $\mathrm{MIH}$ (52). Quando comparado com o nascimento de parto normal, a cesárea tem um maior risco de levar a hipóxia (53). A utilização de anestesia raque espinhal em cesáreas pode levar a complicações tais como hipotensão, com ocasional hipóxia ao feto (44). 
A identificação desses fatores é de extrema importância, não só para adoção de medidas preventivas para os defeitos de esmalte, mas também para outros problemas sistêmicos com repercussão na cavidade bucal $(21,2845,54)$.

A asma é doença crônica das vias aéreas, caracterizada por bronco constrição, inflamação e hiper-reatividade brônquica a diferentes estímulos (57). Em estudo com 47 crianças, entre os 6 e 8 anos de idade, que usaram inalação com beta agonista e corticoide inalatório antes dos 3 anos de vida, observou-se que 15 (31,9\%) apresentavam opacidade demarcadas de algum tipo e 6 (12,8\%) presentavam perda de estrutura dentária relacionada a defeitos do esmalte. (58)

A fibrose cística (FC) é uma patologia caracterizada por inflamação crônica em vias aérea, alta produção de muco e infecções brônquicas com bactérias específicas (59). O tratamento da FC inclui o tratamento da inflamação brônquica e o uso de antibióticos para a infecção. Ferrazano et al, 2012 (60) encontrou alta prevalência (56\%) de defeitos de esmalte em crianças com FC em comparação com grupo controle sugerindo que esse fato pode ser o resultado do uso prolongado de terapia farmacológica, com antibióticos.

Em estudo com o objetivo de investigar a presença de defeitos de desenvolvimento de esmalte em crianças com doença celíaca (DC), e comparar os resultados obtidos com os de um grupo controle de crianças sem DC, observou-se que as primeiras possuem um risco maior (42,2\%) de apresentarem defeitos do esmalte dentário, em comparação com indivíduos saudáveis $(9,4 \%) p<0,001$ (61).

O uso de antibióticos, em particular a amoxicilina, durante os 3 primeiros anos de vida tem uma significância na etiologia da $\mathrm{MIH}$; esse fato pode estar diretamente relacionado ao efeito da droga sobre o ameloblasto ou pode ser atribuída a doença infecciosa que levou ao uso da medicação $(22,56,62)$.

Estudos identificaram uma associação entre desnutrição e defeitos de esmalte em primeiros molares permanentes sendo que estes dentes com defeitos possuíam o dobro de chances de apresentar cárie $(63,102)$. Outros afirmam que a má nutrição infantil, assim como a exposição a bifenilos policlorados podem estar associados a defeitos no esmalte $(56,102)$.

De acordo com Whitford et al (64), condições que afetam o pH da matriz de esmalte, como acidose respiratória, níveis de oxigenação anormais resultantes de hipoventilação, inibem a ação de enzimas proteolíticas e o desenvolvimento dos 
cristais de hidroxiapatita podem ser afetados resultando em um esmalte hipomineralizado $(7,64,65)$.

É possível encontrar na literatura uma convergência sobre a provável origem sistêmica da HMI (66), entretanto recente estudo realizado entre dentistas portugueses refere também uma possibilidade de susceptibilidade genética relacionada com a $\mathrm{MIH}$ (67). Outros pesquisadores sugerem a realização de estudos familiares para a obtenção de dados mais concretos (62). De fato, a susceptibilidade parece variar de indivíduo para indivíduo, pois pessoas expostas às mesmas condições podem não apresentar defeitos do esmalte ou mesmo a MIH (66).

Um dos grandes desafios é a variabilidade de elementos desencadeantes e a correlação entre eles, o que impede de classificar um único fato como responsável pelas alterações presentes (36).

\subsection{ASPECTOS CLÍNICOS E DIAGNÓSTICOS}

A MIH não parece ser uma condição nova e altas frequências de cárie em determinadas localidades podem indicar subnotificação do defeito de desenvolvimento do esmalte (1).

Clinicamente, o esmalte hipomineralizado pode ser liso ou poroso e apresentar diferentes padrões de cor que permeiam entre o amarelo e o marrom (37). O grande diferencial é que sempre apresentarão uma demarcação rugosa, perceptível fisicamente por meio de sonda. (Figura 2).

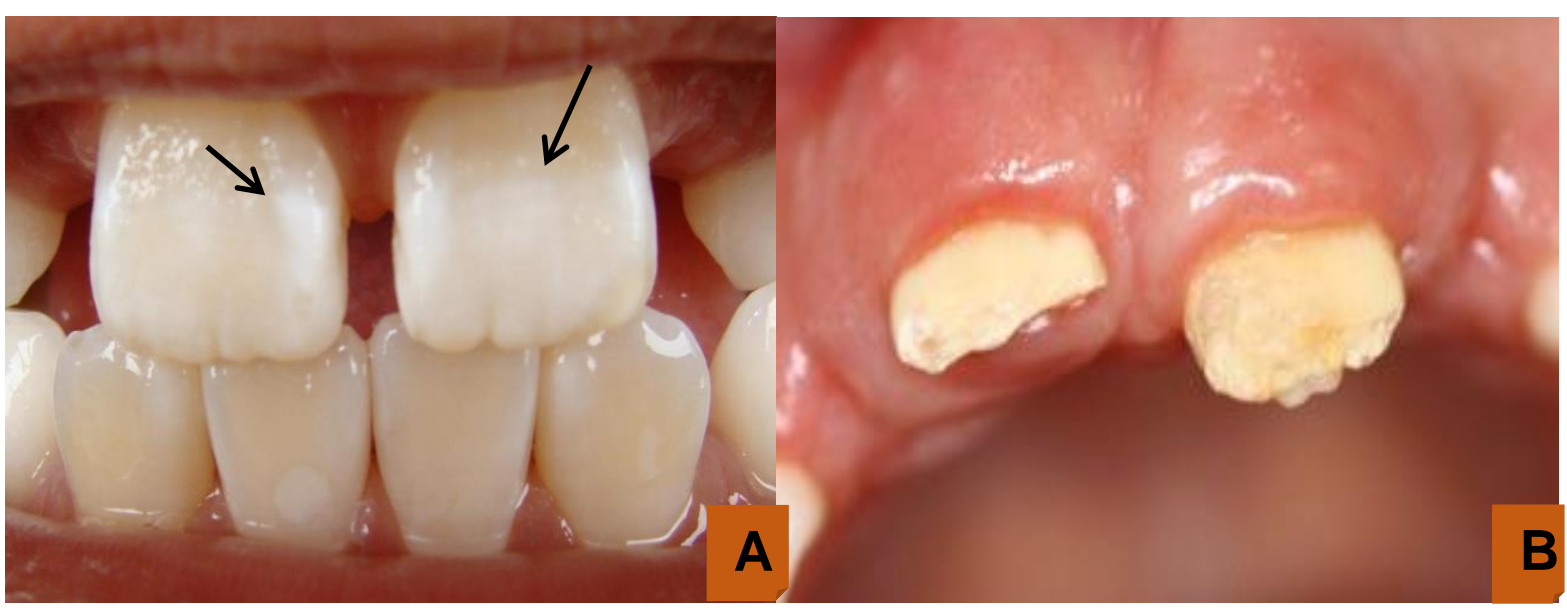

Figura 2 - (A) incisivos (11 e 21) com MIH opacidade demarcada. (B) Incisivos (11 e 21) com fratura de esmalte. (Arquivo particular) 
Uma classificação universalmente aceita até pouco tempo, era a utilização dos termos "suave", "moderada" e "severa" para distinguir os diferentes estágios de afecção dentária por MIH (68). Lesões mais escuras demonstram um aumento de severidade, com esmalte mais poroso do que o esmalte cujas lesões apresentam-se brancas/opacas (69).

Após a realização de seminário sobre MIH da EAPD (European Academy of Paediatric Dentistry) em 2003, os critérios de diagnóstico foram estabelecidos. Acordou-se que, para o exame, os dentes devem ser limpos, mas não ressecados, e que 8 anos é a idade ideal para realizar a observação. A idade dos 8 anos é um ótimo período para avaliação de lesões de $\mathrm{MIH}$, pois nesse período já ocorreu a erupção dos primeiros molares e incisivos permanentes e as perdas estruturais póseruptivas não são extensas. Deve-se verificar em cada dente a presença de opacidades demarcadas, a presença de restaurações atípicas, a presença de fraturas de esmalte pós-eruptivas, além de se averiguar a possibilidade de perda de primeiros molares em decorrência da MIH (68).

Em 2010, em outro seminário na Finlândia, os critérios foram revistos: o tamanho dos defeitos passou a ter relevâncias para a determinação do grau de severidade, variando entre leve e severa. Leve quando há opacidades demarcadas sem fratura de esmalte, com sensibilidade ocasional, e severa quando se apresentam opacidades demarcadas com fraturas, cárie e hipersensibilidade capaz de afetar a função. Quanto ao tamanho das opacidades, são consideradas pequenas (aproximadamente $2 \mathrm{~mm}$ ), médias (aproximadamente $3,5 \mathrm{~mm}$ ) e grandes (acima de $4,5 \mathrm{~mm}$ ) (70). As opacidades apresentam-se principalmente no terço cuspídeo ou incisal da coroa dos dentes afetados (68). (Figura 3).

Observa-se que existe alguma correlação entre dureza e a cor do esmalte afetado. $\mathrm{O}$ esmalte amarelado parece possuir menor resistência que o esmalte no espectro branco (69). 

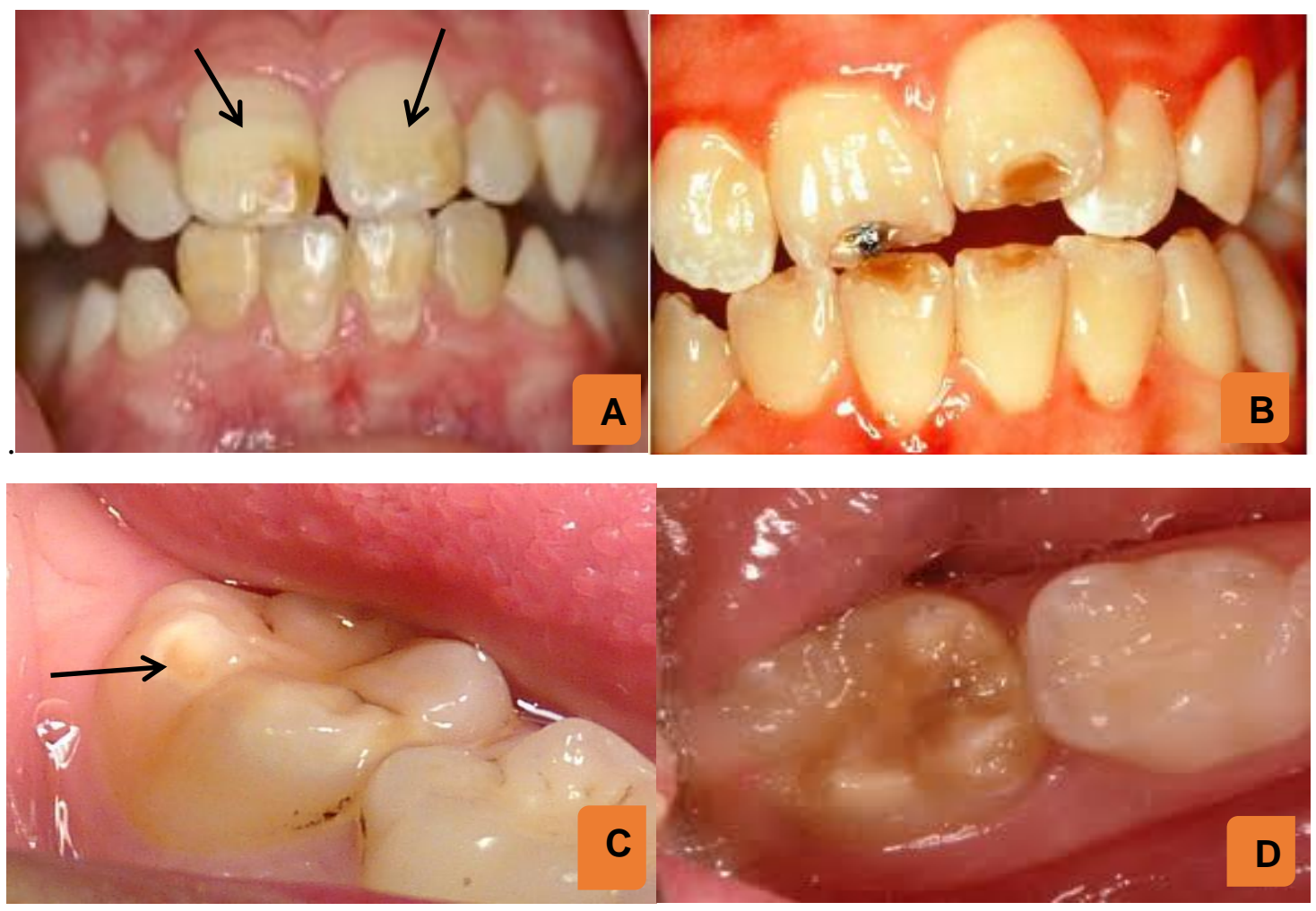

Figura 3 - Diferentes manifestações clinicas do MIH. A: Opacidade demarcada em incisivos centrais permanentes (ICP). B: Mancha escura em ICP. C: Opacidade demarcada em 1ำ Molar Permanente (1ํMP). D: Lesão escura com início de carie em (1ํMP). (Fotos arquivo particular).

A severidade da $\mathrm{MIH}$ varia não só entre os pacientes, mas também entre diferentes dentes de um mesmo paciente. Nem todos os primeiros molares permanentes apresentam o mesmo grau de comprometimento $(3,66,71)$. O risco de desenvolvimento de defeitos em incisivos aumenta quanto maior for o número de molares são afetados $(15,16)$.

Esse quadro não deve ser confundido com outras patologias (Quadro 2), tais como lesão de cárie inicial, fluorose ou amelogênese imperfeita. O diagnóstico diferencial, no caso da fluorose, é feito considerando-se que na MIH os molares não são igualmente comprometidos.

A amelogênese imperfeita é uma alteração de caráter hereditário, que afeta o esmalte dentário em ambas as dentições, sendo um distúrbio de natureza totalmente ectodérmica (72). Na Amelogênse Imperfeita do tipo hipoplásica revelam-se micro cavidades bem delimitadas em áreas amolecidas ou áreas aprismáticas, assim como 
porosidades e depressões. Isso pode ocorrer pela dissociação dos cristais e irregularidades na orientação dos prismas (73).

Quadro 2 - Diagnóstico diferencial entre as anomalias do esmalte dentário

\begin{tabular}{|l|l|}
\hline \multicolumn{1}{|c|}{$\begin{array}{c}\text { ANOMALIAS DO } \\
\text { ESMALTE DENTÁRIO } \\
\text { (AED) }\end{array}$} & \multicolumn{1}{|c|}{ CRITÉRIOS AUXILIARES PARA DIAGNÓSTICO } \\
\hline Hipoplasias & $\begin{array}{l}\text { Perda de estrutura dentária devido a defeitos qualitativos } \\
\text { (alteração na função secretora dos ameloblastos). } \\
\text { 1) Hipoplasia de Turner. Etiologia: Trauma ou infecção } \\
\text { local. Apresentação: falta parcial ou total de esmalte } \\
\text { sobre a dentina. } \\
\text { 2) Amelogênese Imperfeita. Etiologia: Fatores } \\
\text { hereditários. Apresentação: Pode afetar as duas } \\
\text { dentições (decídua e permanente) e todos os dentes. }\end{array}$ \\
\hline Hipomineralizações ou & $\begin{array}{l}\text { Alteração da translucidez do esmalte com modificação da } \\
\text { cor, devido a defeito quantitativo, ocorrem alterações na } \\
\text { microestrutura do esmalte na fase de sua maturação. } \\
\text { 1) MIH ou Opacidade Demarcada. Etiologia: fatores } \\
\text { sistêmicos (ainda desconhecidos). Apresentação: } \\
\text { superfície lisa, espessura normal, limites da lesão são } \\
\text { claros. } \\
\text { 2) Fluorose. Etiologia: exposição excessiva a fluoretos } \\
\text { durante a amelogênese. Apresentação: Translucidez de } \\
\text { vários graus, distribuída de forma continua, linear ou por } \\
\text { manchas, sem limites nítidos com o esmalte contíguo. }\end{array}$ \\
\hline
\end{tabular}

Clinicamente é difícil aferir a quantidade exata de perda de esmalte e o risco dessa ocorrência no dente acometido por $\mathrm{MIH}$, entretanto, existe alguma correlação entre dureza e a cor do esmalte afetado. O esmalte amarelado, como anteriormente mencionado, parece possuir menor resistência que o esmalte no espectro branco (69). 
Além da desintegração do esmalte dentário, frequentemente nas regiões de cúspides e margens incisais, os pacientes com MlH normalmente apresentam grande sensibilidade dentária, com dor espontânea ou quando o dente é exposto a diferenças de temperatura $(10,11,12,74)$. As crianças atingidas têm seu tratamento complicado pela dificuldade em se anestesiar os dentes afetados, gerando medo e ansiedade, além de problemas comportamentais, principalmente quando há envolvimento estético (67). Muitas vezes os tratamentos dentários são dolorosos, pois procedimentos comuns, como secar a região dentária, e a dificuldade do controle da dor, mesmo com uso de anestesia, podem gerar desconforto intenso ao paciente (74). Essa limitação, ocorrida durante a anestesia, está correlacionada à presença de uma inflamação subclínica das células da polpa causada pela porosidade do esmalte.

Crianças com dentes afetados por defeitos de esmalte geralmente recebem mais tratamentos dentários, comparadas àquelas que não possuem. Frequentemente, os tratamentos têm maior complexidade e, quando envolvem incisivos, tais defeitos tem o potencial de causar prejuízos psicológicos e sociais às crianças portadoras. O manejo dos dentes com MIH vai desde o diagnóstico precoce à extração dentária, necessitando de acompanhamento ortodôntico nos casos mais severos. As crianças atingidas, e suas famílias, necessitam de uma atenção especial e de orientações precisas sobre higienização bucal e o prognóstico em cada caso (75).

Os incisivos permanentes que se apresentam com defeito no esmalte parecem ter menor tendência a fraturas, mas comumente apresentam lesões mais extensas e com maior frequência em sua superfície vestibular (76).

O diagnóstico correto e o momento adequado para intervenções, com uma visão multidisciplinar, são primordiais, pois como anteriormente mencionado, os problemas causados pela $\mathrm{MIH}$ vão desde questões estéticas, impactando na autoestima, até problemas funcionais como dificuldade de mastigação, sensibilidade dentária, tratamentos mais complexos e ainda gastos financeiros (29). 


\subsection{PREVALÊNCIA}

Nos últimos anos, com a diminuição da prevalência e incidência da doença cárie, novos estudos estão sendo realizados sobre a prevalência e a etiologia da $\mathrm{MIH}$, entre outras doenças, que eram consideradas de menor importância no passado (52).

Sua prevalência, em diferentes estudos pelo mundo, é bastante variável, oscilando, por exemplo, de 2,5 \% na China a 40,2\% no Rio de Janeiro $(8,77)$. Contudo, não parece ser uma condição nova, com consenso entre os autores que o correto diagnóstico apresenta dificuldades, principalmente em locais de alta prevalência de cárie, pois o defeito de desenvolvimento do esmalte, seria um facilitador da cárie. (78).

Essa grande variação na faixa de prevalência pode ser devida por fatores tais como a falta de padronização nos critérios utilizados na realização de exames clínicos, à inclusão de crianças de diferentes faixas etárias, às diferenças de prevalência da MIH em distintos países, ou ainda à possibilidade dos altos índices de cárie poderem mascarar a existência de $\mathrm{MIH}(2)$.

Estudos epidemiológicos têm sido realizados em todo o mundo, sobre $\mathrm{MIH}$, principalmente em países europeus. O Brasil, no entanto, já aparece no cenário acadêmico mundial através de estudos bem fundamentados, por exemplo, em estudo realizado em $2014(6,7,8,28,51,79)$, pesquisa sobre os possíveis tratamentos restauradores em molares afetados pela $\mathrm{MIH}$. Não se pode esquecer que estudos realizados quando os critérios diagnósticos de $\mathrm{MIH}$ ainda não eram estabelecidos (antes de 2003), podem não apresentar resultados fidedignos da prevalência real da $\mathrm{MIH}$ (52).

Como pode ser observado no quadro abaixo, há uma demonstração de grande variabilidade na prevalência dos defeitos do esmalte, segundo diferentes autores em diversos locais do mundo, variação possivelmente relacionada ao número total de amostras entre os estudos e a diferenças de procedimentos de calibração entre os examinadores. (Quadro 3) 
Quadro 3: Prevalência de MIH em diferentes estudos epidemiológicos

\begin{tabular}{|c|c|c|c|c|c|}
\hline ESTUDO & PAÍS & IDADE & AMOSTRA & CALIBRAGEM & PREVALÊNCIA (\%) \\
\hline 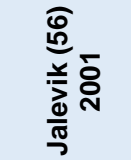 & Suécia & 8 anos & 519 & Sim & $18,4 \%$ \\
\hline 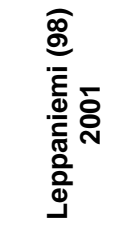 & Finlândia & $7-13$ anos & 488 & NR & $19,3 \%$ \\
\hline 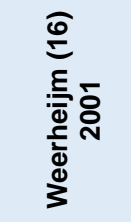 & Holanda & 11 anos & 497 & NR & $9,7 \%$ \\
\hline 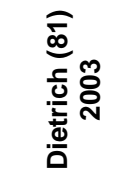 & Alemanha & $\begin{array}{c}8 \text { anos coorte } \\
10-17 \text { anos }\end{array}$ & 2.408 & Sim & $\begin{array}{c}2,4-11 \% \text { média } \\
5,6 \%\end{array}$ \\
\hline 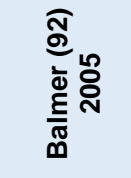 & Reino Unido & 8-16 anos & 25 & Sim & $40 \%$ \\
\hline 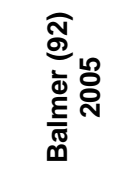 & Austrália & 8-16 anos & 25 & Sim & $44 \%$ \\
\hline 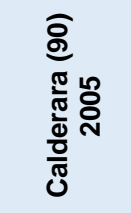 & Itália & 7-8 anos & 227 & Sim & $13,7 \%$ \\
\hline 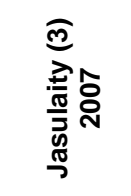 & Holanda & 9 anos & 442 & Sim & $14,3 \%$ \\
\hline 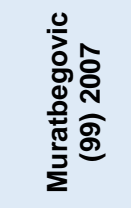 & Bósnia & 12 anos & 560 & NR & $12,3 \%$ \\
\hline 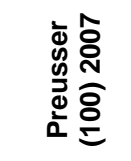 & Alemanha & 6-12 anos & 1.002 & Sim & $5,9 \%$ \\
\hline
\end{tabular}




\begin{tabular}{|c|c|c|c|c|c|}
\hline 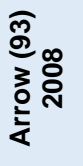 & Austrália & 7 anos & 511 & Sim & $22 \%$ \\
\hline $\begin{array}{l}\mathbb{E}_{\infty} \\
\text { 융 } \\
\text { ᄋ }\end{array}$ & Hong Kong & $11-14$ anos & 2.635 & Sim & $2,8 \%$ \\
\hline 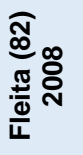 & Líbia & 7-9 anos & 378 & Sim & $9 \%$ \\
\hline 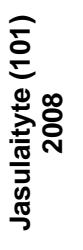 & Lituânia & 7-9 anos & 1.277 & Sim & $14,9 \%$ \\
\hline 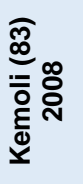 & Quênia & 6-8 anos & 3.591 & Sim & $13,7 \%$ \\
\hline 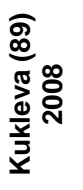 & Bulgária & $7-14$ anos & 2.960 & NR & $3,58 \%$ \\
\hline 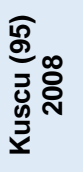 & Turquia & 7-9 anos & 147 & Sim & $14,9 \%$ \\
\hline 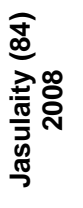 & Alemanha & 9 anos & 442 & & $14,3 \%$ \\
\hline 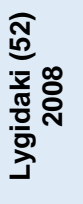 & Grécia & $5,5-12$ anos & 3.518 & Sim & $10,2 \%$ \\
\hline 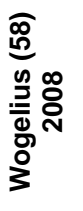 & Dinamarca & 6-8 anos & 647 & Sim & $37,5 \%$ \\
\hline 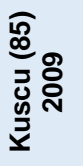 & Turquia & $7-10$ anos & 109 e 44 & Sim & $9,1 \% 9,2 \%$ \\
\hline
\end{tabular}




\begin{tabular}{|c|c|c|c|c|c|}
\hline 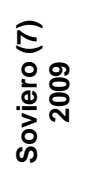 & Brasil & 7-13 anos & 249 & Sim & $40,2 \%$ \\
\hline 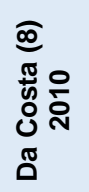 & Brasil & 6-12 anos & 918 & Sim & $19,8 \%$ \\
\hline 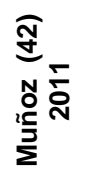 & Chile & $6-13$ anos & 334 & Sim & $16,8 \%$ \\
\hline 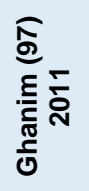 & Iraque & 7-9 anos & 823 & Sim & $21,5 \%$ \\
\hline 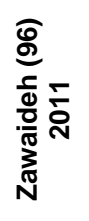 & Jordânia & 7-9 anos & 3.666 & Sim & $17,6 \%$ \\
\hline 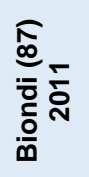 & Argentina & 11,3 anos & 1.098 & & $15,9 \%$ \\
\hline 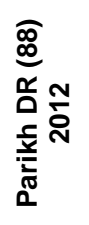 & Índia & 8-12 anos & 1.366 & Sim & $9,12 \%$ \\
\hline 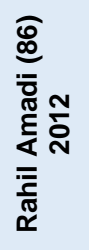 & Irã & 7-9 anos & 433 & Sim & $12,7 \%$ \\
\hline 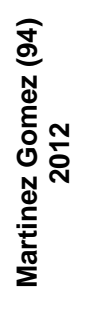 & Espanha & 6-14 anos & 505 & Sim & $17,7 \%$ \\
\hline 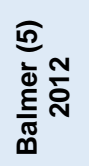 & Inglaterra & 12 anos & 3.233 & Sim & $15,9 \%$ \\
\hline
\end{tabular}




\begin{tabular}{|c|c|c|c|c|c|}
\hline 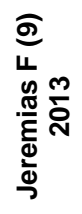 & Brasil & 6-12 anos & 1.157 & Sim & $12,3 \%$ \\
\hline 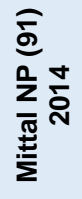 & Índia & 6-9 anos & 1.792 & Sim & $6,31 \%$ \\
\hline
\end{tabular}




\section{OBJETIVOS}

\subsection{OBJETIVO GERAL}

Determinar a prevalência de MIH em crianças entre 6 e 8 anos de idade, estudantes de escola pública da região do Gama em Brasília- Distrito Federal.

\subsection{OBJETIVOS ESPECÍFICOS}

- Identificar possíveis casos de MIH em crianças nascidas no HRG/DF e correlacionar os dados à história clínica das progenitoras durante o último trimestre de gestação, período neonatal e primeiro ano de vida como possíveis agentes etiológicos da patologia estudada.

- Analisar os prontuários e correlacionar as intercorrências durante o pré-natal e período perinatal de mães acompanhadas durante a gestação no Hospital Regional do Gama (HRG) /DF para correlação de possíveis fatores causais da HMI. 


\section{MATERIAL E MÉTODOS}

\section{VIABILIDADE TÉCNICA E JUSTIFICATIVA}

Em um exame preliminar de bibliografia especializada, buscou-se aclarar o quadro atual das possíveis etiologias da $\mathrm{MIH}$. Entretanto, surge uma questão importante nos trabalhos já publicados tornando difícil uma análise detalhada das questões levantadas em cada artigo, devido tanto a escolhas de metodologias diferentes, quanto à composição amostral, com grupos étnicos e realidades socioeconômicas bastantes diversas.

A originalidade do projeto não está em seu conteúdo propriamente dito, mas na proposta de se levantarem dados de uma comunidade brasileira e brasiliense, relacionando as possíveis causas de $\mathrm{MIH}$ ao período perinatal e pós natal.

É um estudo de execução complexa, uma vez que foi realizado primeiramente um trabalho de levantamento de dados em escolas, com exame bucal de um número considerável de crianças; em uma segunda etapa, procedeu-se à coleta de dados dos prontuários médicos no hospital onde as crianças havia nascido. Finalmente, pelo cruzamento de dados obtidos anteriormente, foi possível uma análise qualitativa e quantitativa das informações.

É importante salientar a relevância da reflexão sobre o tema proposto, pois a identificação de possíveis fatores etiopatogênicos pode levar a uma intervenção precoce, quando não à prevenção primária, preservando-se a saúde bucal de jovens brasileiros. 


\subsection{AMOSTRA}

O projeto foi submetido à apreciação do Comitê de Ética em Pesquisa com Seres Humanos do Centro Universitário de Brasília - UNICEUB, com parecer favorável no 1.018.756/2015. (ANEXO A)

Este foi um estudo de coorte retrospectivo, com uma amostra de conveniência, conduzido em 2 escolas públicas da regional do Gama /DF e no HRG/DF, Brasil, por médico e dentistas pediátricos.

O Distrito Federal (DF) é dividido em 31 regiões administrativas (RA). O Gama transformou-se em Região Administrativa - RA II em 1989, por meio da Lei n. .9 49/89 e do Decreto n. $11.921 / 89$ que fixou os novos limites das regiões administrativas do DF. O Gama localiza-se a $30 \mathrm{~km}$ de Brasília e possui uma população urbana estimada, para 2015, em 141.911 habitantes. A maioria da população é de classe média. A renda média é superior a seis salários mínimos por família, conforme pesquisa da Companhia de Planejamento do DF (Codeplan) em 2011.

Cerca de 50\% da população da RA Gama reside na região há 25 anos ou mais, seguido pelos que residem entre 15 a 24 anos, 18,75\%. (Fonte: Codeplan Pesquisa Distrital por Amostra de Domicílios - Gama - PDAD 2015)

A amostra do presente estudo foi constituída por 168 crianças entre 6 e 8 anos de idade, nascidas entre os anos 2007 e 2009 no HRG/DF e estudantes da rede pública de ensino da mesma região.

Segundo o censo escolar 2015, existem 39 escolas públicas de ensino fundamental no Gama, com 4.636 crianças, entre 6 e 8 anos, regularmente matriculadas e cursando o ensino fundamental (Censo 2015 Secretaria de Educação-DF). No presente estudo, o $\mathrm{N}=168$ equivale a $3,62 \%$ da população escolar na faixa etária pretendida.

Por randomização dois Centros Educacionais do Gama (CED ํo3 e 6), que fazem parte da rede pública de ensino do DF. Foram incluídas todas as turmas da $2^{\underline{a}}$

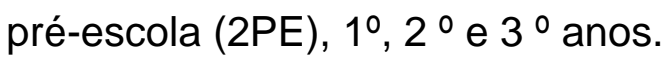


Para o experimento verificou-se, em trabalhos anteriores, uma estimativa da proporção de casos de crianças com $\mathrm{MIH}$, na ordem de 2,5\% na China a 40,2\% no Rio de Janeiro $(7,77)$. Supondo uma amostra aleatória simples, foi utilizada a fórmula abaixo para a cálculo da amostra ideal para a pesquisa:

$$
n=\frac{N \cdot Z^{2} \cdot p \cdot(1-p)}{Z^{2} \cdot p \cdot(1-p)+e^{2} \cdot(N-1)}
$$

Onde:

n: amostra calculada;

$\mathrm{N}$ : população;

Z- Variável normalmente padronizada associada ao nível de confiança;

p: probabilidade do evento

e: erro amostral 


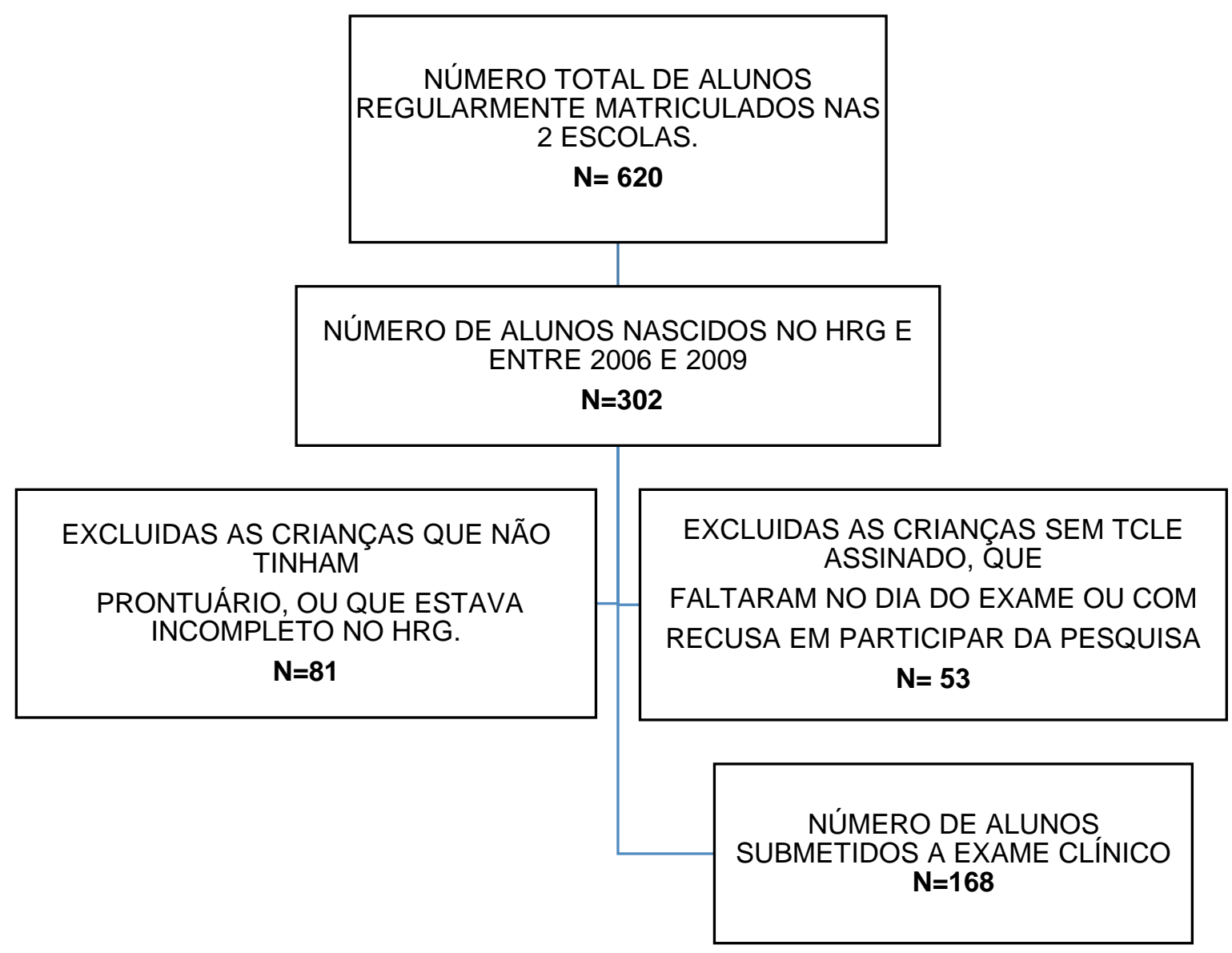

Figura 4 - Fluxograma de procedimentos e critérios de exclusão da pesquisa.

\subsection{CRITÉRIOS DE INCLUSÃO}

- Crianças cujo termo de consentimento livre e esclarecido tenha sido assinado pelos responsáveis legais;

- Crianças que possuíam pelo menos a metade da coroa dos 4 primeiros molares permanentes e os 8 incisivos permanentes erupcionados;; 
- Crianças nascidas no HRG/DF;

- Crianças na faixa etária entre 6 e 8 anos de idade;

- Crianças matriculadas e frequentando escola da rede pública do Gama /DF;

- Crianças cujo estado de saúde permitisse o exame odontológico;

- Crianças com responsáveis legais dentro do espaço geográfico delimitado pelo $D F$, vivendo em região de água tratada e fluoretada, com a proporção de 0,7 ppm de flúor ideal para a região.

\subsection{CRITÉRIOS DE EXCLUSÃO}

- Crianças não pertencentes da faixa etária definida;

- Crianças não matriculadas ou ausentes no dia previsto para a realização dos exames nas escolas e que ofereciam resistência ao exame clínico;

- Crianças com perda de dentes decíduos e ou permanentes de interesse para o estudo;

- Crianças cujo termo de consentimento livre e esclarecido não foi assinado pelo responsável legal.

\subsection{METODOLOGIA E COLETA DE DADOS}

Como no Brasil o acervo de pesquisa relacionado ao tema ainda é escasso, foram levados em consideração dados mundiais, que consideram uma larga faixa de prevalência; em diferentes estudos pelo mundo. A prevalência de $\mathrm{MIH}$ varia entre $2,5 \%$ na China a $40,2 \%$ no Rio de Janeiro $(7,77)$. Portanto foi escolhido uma taxa de $5 \%$ de prevalência de MIH para cálculo amostral, que foi trabalhado nas escolas. Sendo assim a amostra ideal (para um experimento supondo amostra aleatória simples) com $5 \%$ de erro seria de 200 , porém durante o período de estudo foram incluídos 168 indivíduos, resultando em um erro amostral de 7\% nas estimativas da pesquisa.

O trabalho foi realizado em etapas:

\section{Etapa 1 - Seleção das escolas}


As escolas selecionadas foram escolhidas levando-se em consideração a randomização. O sorteio foi realizado entre as 39 escolas da região. As escolas definidas para o estudo apresentavam um grupo participativo de nutricionista com acompanhamento da merenda escolar; recebiam assistência de instituição que faz a promoção de saúde bucal (Serviço Social do Comércio - SESC) e participavam de projeto educacional conjunto dos cursos de medicina e odontologia da FACIPLACDF (Faculdades Integradas da União Educacional do Planalto Central), provavelmente devido à proximidade geográfica das escolas com o HRG-DF.

\section{Etapa 2 - Seleção das crianças}

A seleção das crianças foi realizada na secretaria das escolas, com foco nas idades, entre 6 e 8 anos (através da data de nascimento constante na ficha de matrícula) e nascidas no HRG/DF (através da certidão de nascimento).

\section{Etapa 3 - Análise de prontuário médico}

Um levantamento de dados obtido de prontuários médicos (ficha do RecémNascido) foi realizado no HRG/DF. As informações de saúde das mães que realizaram o pré-natal durante os anos de 2005 a 2008, cujos filhos tem, em 2015, entre 6 (dentição decídua completa) e 8 anos de idade (incisivos e primeiros molares permanentes em boca). Os dados coletados dos prontuários das mães e das crianças foram registrados em fichas construídas para essa finalidade (APÊNDICE A).

\section{Etapa 4 - Contato com a escola e professores, entrega de TCLE e} questionário para as mães.

Pormenorizada explanação sobre a pesquisa foi fornecida aos diretores e professores de cada escola selecionada para o estudo.

As crianças selecionadas receberam o termo de consentimento livre e esclarecido (TCLE) (APÊNDICE B) e o questionário (APÊNDICE C), que foi respondido pelas mães. O questionário continha vários blocos de perguntas, possuindo questões sobre a história médica da mãe durante a gestação (fase pré natal), questões sobre o desenvolver do parto (fase perinatal), e sobre as condições de saúde da criança durante o primeiro ano de vida (fase pós natal). Não houve validação do questionário porque as questões contidas tinham o propósito do que se poderia incluir como uma anamnese.

Fase pré-natal: (desde a fecundação até as 40 semanas de vida intrauterina ou até o nascimento): realização do pré-natal e número de consultas; primiparidade, 
se a mãe fumou, bebeu, ou usou algum tipo de droga ilícita durante a gestação. Questionou-se se durante a gravidez houve hipertensão arterial, cardiopatia, diabete gestacional, anemia, infecção do trato urinário (ITU), ou outra comorbidade.

Fase perinatal (considerando o período neonatal que vai desde o nascimento até os 28 dias de vida incompletos): tipo de parto (vaginal ou cesariana), tempo de gestação (RNT, a partir de 37 semanas, ou RNPT, nascido antes das 37 semanas completas), de acordo com a Organização Mundial de Saúde (OMS 1999), classificação do $\mathrm{RN}$ de acordo com o seu desenvolvimento intra uterino, quanto ao peso $\mathrm{x}$ idade gestacional AIG ( adequado para a idade gestacional), PIG (pequeno para a idade gestacional) e GIG ( grande para a idade gestacional), classificação de acordo com o peso: BP ( peso ao nascer abaixo de 2,5 g), APGAR no primeiro e quinto minuto e internação na UTI neonatal.

Fase pós-natal (desde os 29 dias de vida até 1 ano de idade): Tempo de amamentação, dividida em 4 períodos: de 0 a 6 meses; 6 meses a 1 ano; 1 ano a 2 anos e $>2$ anos. Hospitalização durante o primeiro ano de vida, infecções, anemias, asma, pneumonia, febre alta, uso de amoxicilina e outras medicações.

\section{Etapa 5 - Exame clínico oral}

As crianças selecionadas foram submetidas a exame clínico intra-oral realizado por dois odontopediatras previamente treinados e calibrados anotados em ficha clínica elaborada para esse fim. (APÊNDICE D). Todas as crianças assinaram o termo de consentimento do menor (TCM) (APÊNDICE E).

A calibração entre os examinadores foi definida pelo estudo conjunto dos escores de acordo com a classificação da EAPD, através de fotografias representativas dos escores, até haver segurança quanto ao diagnóstico. Quando havia dúvidas durante o exame, a opinião do colega era solicitada, para se chegar a um consenso.

O exame clínico foi realizado na escola, com a criança sentada de frente para o examinador, sob luz natural, com a utilização de espelho odontológico e sonda exploradora. Todo o material clínico (sonda da OMS, gaze e espelho) utilizado no exame foram previamente esterilizados. O exame foi realizado em local iluminado, ventilado e limpo, obedecendo aos princípios de biossegurança. Os dados coletados foram anotados em fichas apropriadas, com a localização de opacidades e 
hipoplasias, de acordo com sua localização nos dentes incisivos e molares da dentição decídua e permanente.

Para o diagnóstico de $\mathrm{MIH}$, seguiram-se os critérios diagnósticos da European Academy of Paediatric Dentistry (EAPD) de 2008. O estudo foi realizado entre os meses de março a julho do ano de 2015.

\section{Etapa 6 - Análise de dados}

No questionário dirigido aos pais foram avaliadas as variáveis referentes às condições pré-natais, perinatais e pós-natais.

Os dados do período pré-natal e do nascimento do recém-nascido obtidos através do questionário foram comparados com os dados do prontuário médico, e, caso houvesse divergência de informações, foi considerada a informação do prontuário médico como verídica. Caso não houvesse informação no prontuário, foi considerada apenas a resposta do questionário.

No tratamento de dados foram considerados as variáveis provenientes de observações clínicas: ausência ou presença de opacidade demarcada em esmalte, dentes perdidos, dentes cariados e dentes obturados.

\subsection{ANÁLISE ESTATÍSTICA}

As estimativas geradas neste trabalho representam o universo de crianças que nasceram entre o ano de 2007 e 2009 e frequentam escolas públicas do Gama. Para isso foram utilizadas estimativas prévias baseada na bibliografia e na fórmula acima. Sendo assim constata-se que no mínimo deveriam ser pesquisados 89 pacientes e no máximo 289 pacientes, considerando um erro amostral de 5\% e um nível de confiança de 95\%. Foram coletadas informações de 168 indivíduos.

Para análise estatística foram utilizadas o software estatísticos IBM SPSS Software para imputação, organização e manipulação (criação de novas variáveis) de dados, como também a análise descritiva dos dados (análise univariada e bivariada). Para a realização dos testes de hipóteses, devido ao melhor nível de precisão, o software R: The R Project for Statistical Computing, com o auxílio do pacote $\mathrm{R}$ Commander foi empregado. O teste estatístico utilizado foi o teste exato de 
Fisher por ser 0 mais adequado para análises de tabelas cruzadas $2 \times 2$ e com valores esperados inferiores a 5 ou amostras pequenas com intervalo de confiança de variando de $1,95 \%$ a $14,1 \%$. 


\section{RESULTADOS}

\subsection{ANÁLISE DESCRITIVA DA AMOSTRA}

A prevalência de $\mathrm{MIH}$ foi de $\mathrm{N}=9$ ou $5,36 \%$ (IC95\%: $1,95 \%-14,1 \%$ ).

Tabela 1 - Distribuição das crianças pesquisadas nas escolas quanto a ocorrência de $\mathrm{MIH}$

\begin{tabular}{l|c|c}
\hline \multicolumn{1}{c|}{ Categoria } & № & $\%$ \\
\hline Não possui MIH & 159 & 94,64 \\
\hline Possui MIH & 9 & 5,36 \\
\hline Total & 168 & 100,00 \\
\hline
\end{tabular}

Um total de 168 crianças com idade entre 6-8 anos de idade participaram do estudo ( 6 anos $\mathrm{N}=27 ; 16,1 \%$ ), ( 7 anos $\mathrm{N}=58 ; 34,5 \%$ ) ( 8 anos $\mathrm{N}=83 ; 49,4 \%$ ), com uma idade média de 7,33 anos (Gráfico 1)

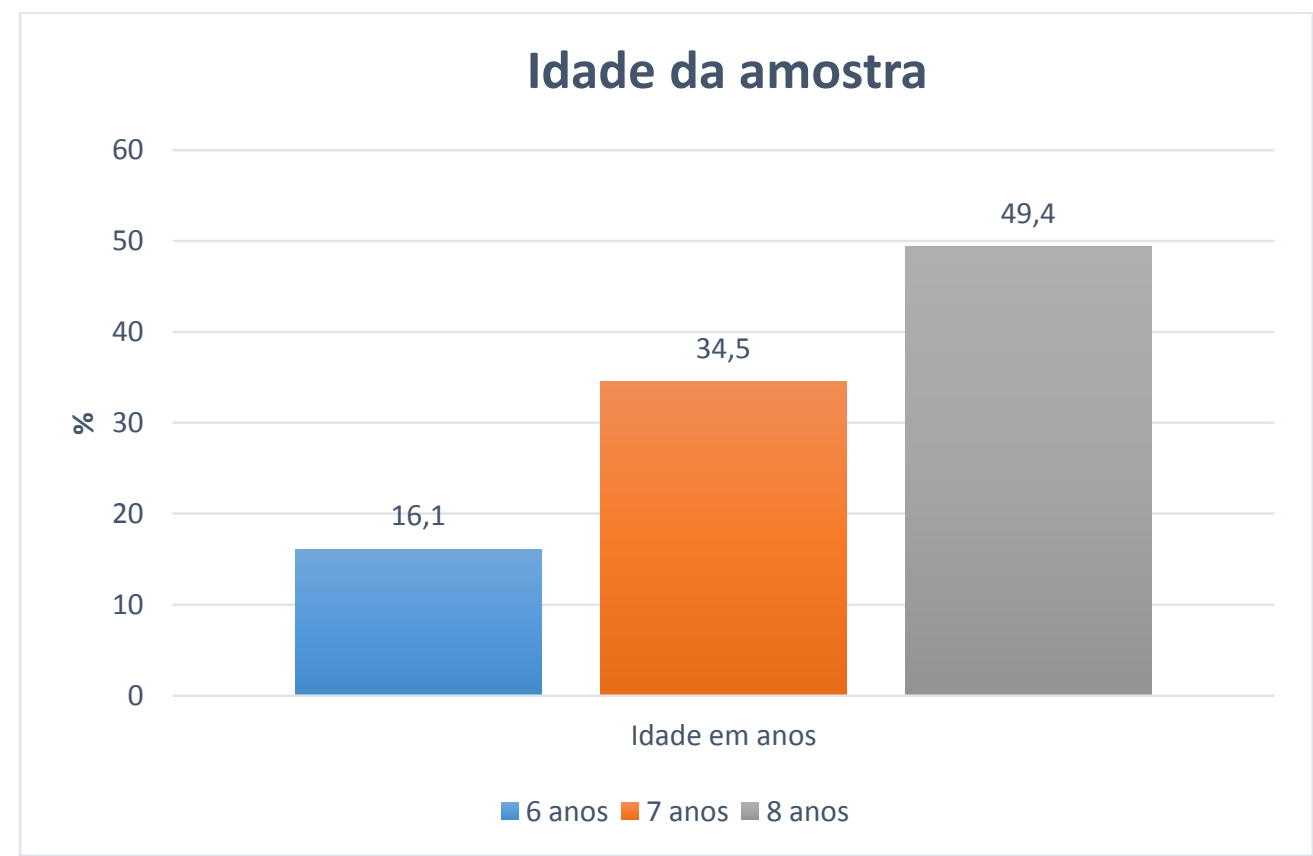

Gráfico 1 - Perfil da idade das crianças da amostra. 
Das 168 crianças 47,80 \% eram meninas e 52,20\% meninos. O gráfico abaixo ilustra o perfil da amostra em relação ao sexo.

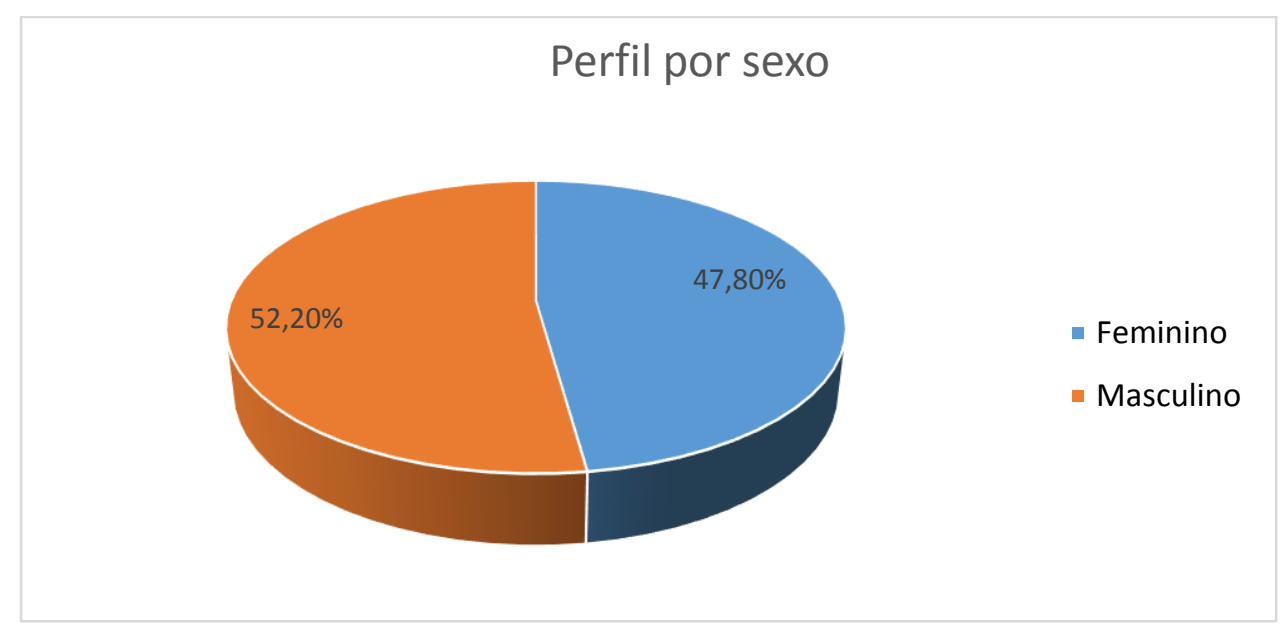

Gráfico 2: Distribuição da amostra por sexo

Quanto ao grau de instrução materna $32,7 \%$ tinham ensino fundamental completo e $45,8 \%$ haviam completado o ensino médio e apenas $7,7 \%$ possuíam ensino superior completo (Gráfico 3).

\section{Escolaridade Materna}

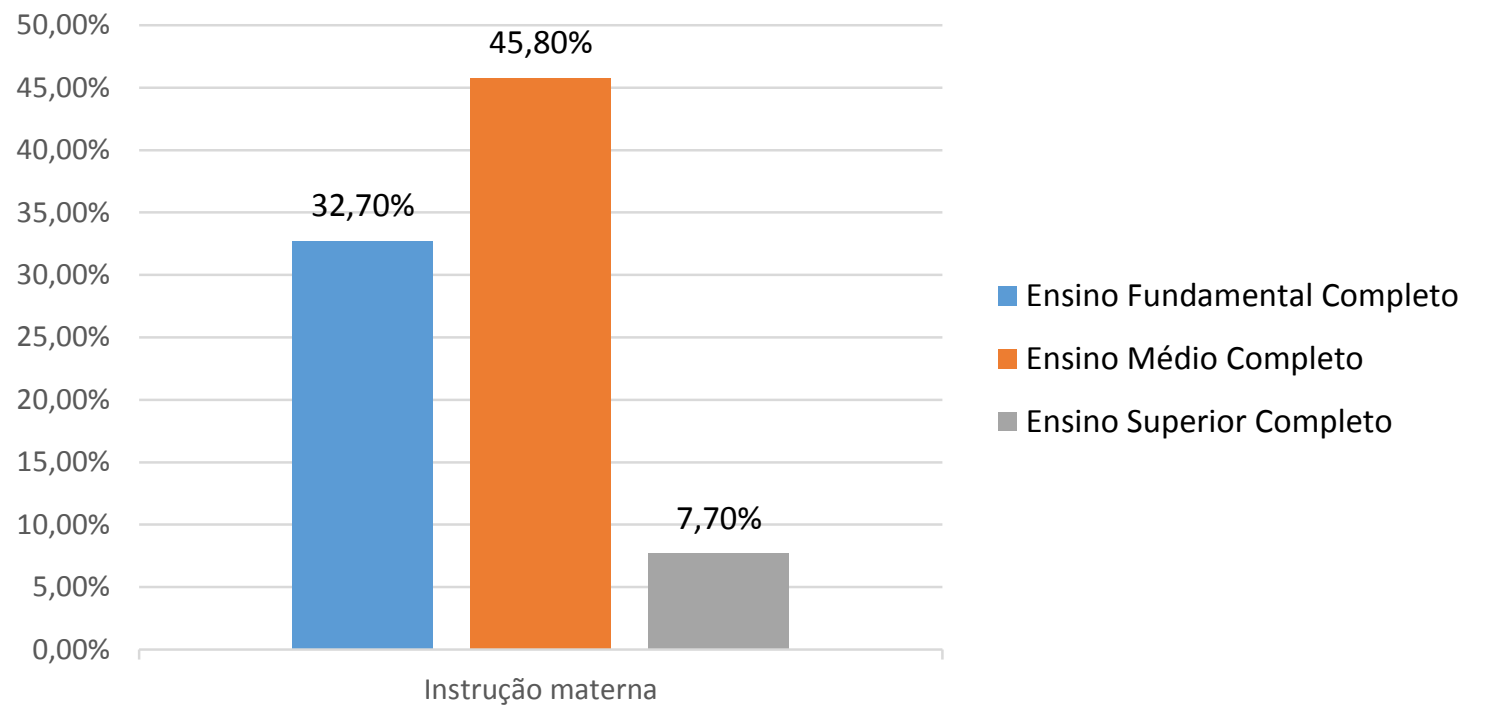

Gráfico 3: Perfil da escolaridade materna 
Das mulheres que responderam o questionário, 91,1\% haviam feito consulta de pré-natal, sendo que 69\% ( $\mathrm{N=116)}$ fizeram mais do que 6 consultas, o que é indicado pelo Ministério da Saúde (MS, Portaria nํ570, de 1ํ de junho de 2000- DO 110-E, de 08/06/2000) como o número mínimo de consultas para um bom acompanhamento durante a gestação (Gráfico 4).

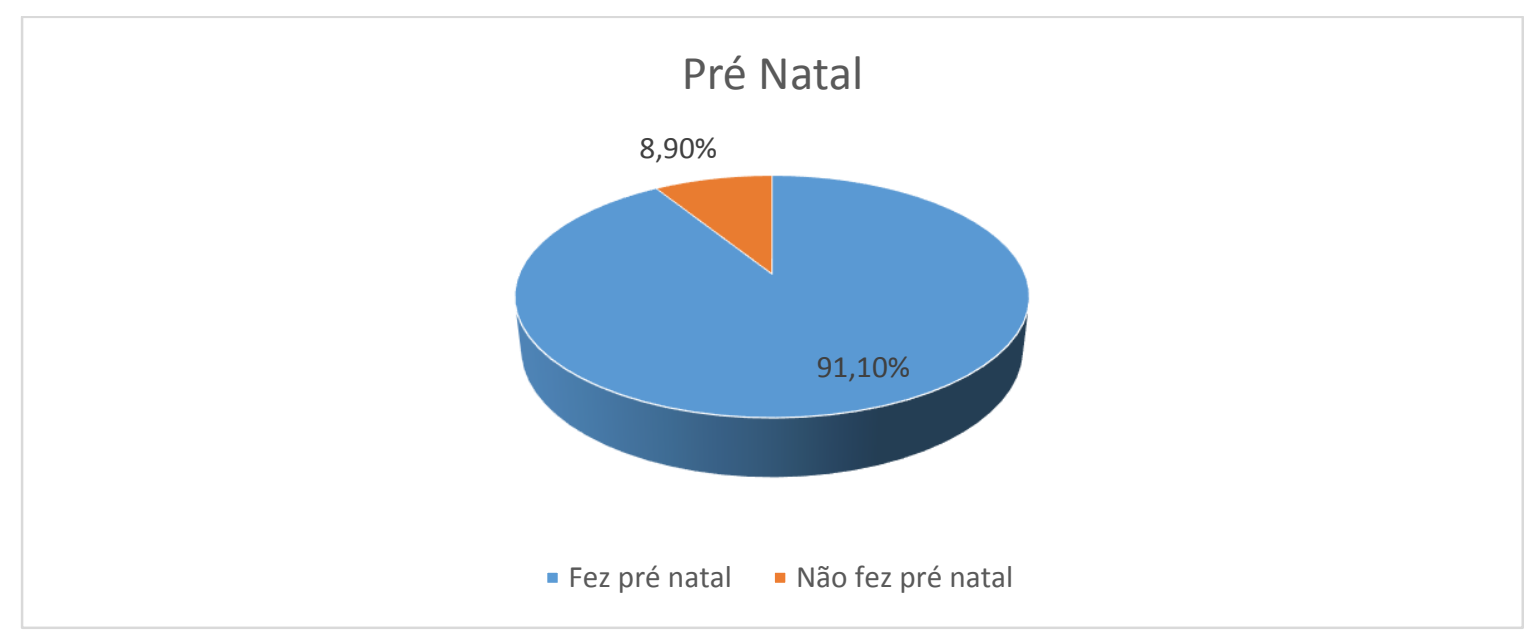

Gráfico 4: Realização de consultas de pré-natal

Foram pesquisados, no período pré-natal, aspectos que poderiam levar a anóxia ou hipóxia perinatal como: diabetes, hipertensão arterial, anemia, infecção materna, alcoolismo, tabagismo e uso de drogas ilícitas (Gráfico 5).

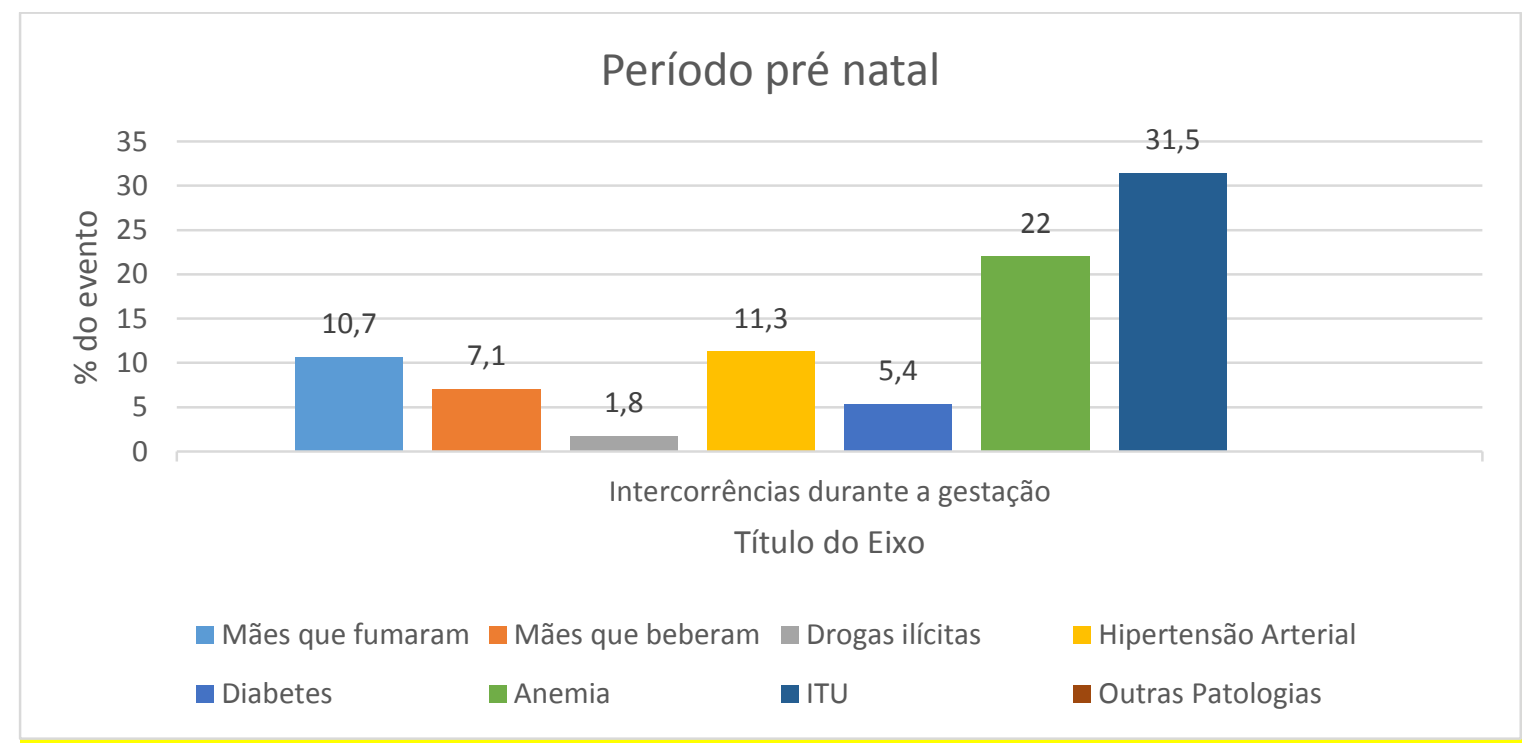

Gráfico 5: Intercorrências encontradas durante a gestação das mulheres estudadas. 
$\mathrm{Na}$ amostra, constatou-se uma porcentagem de $63,7 \%$ de parto normal e $36,3 \%$ de pardo cirúrgico (cesariana).

As variáveis consideradas no período neonatal foram: classificação de acordo com idade gestacional, peso ao nascer, APGAR no $1^{\circ}$ e $5 \stackrel{\circ}{\circ}$ minuto e classificação de acordo com a relação idade gestacional e peso. (Gráfico 6)

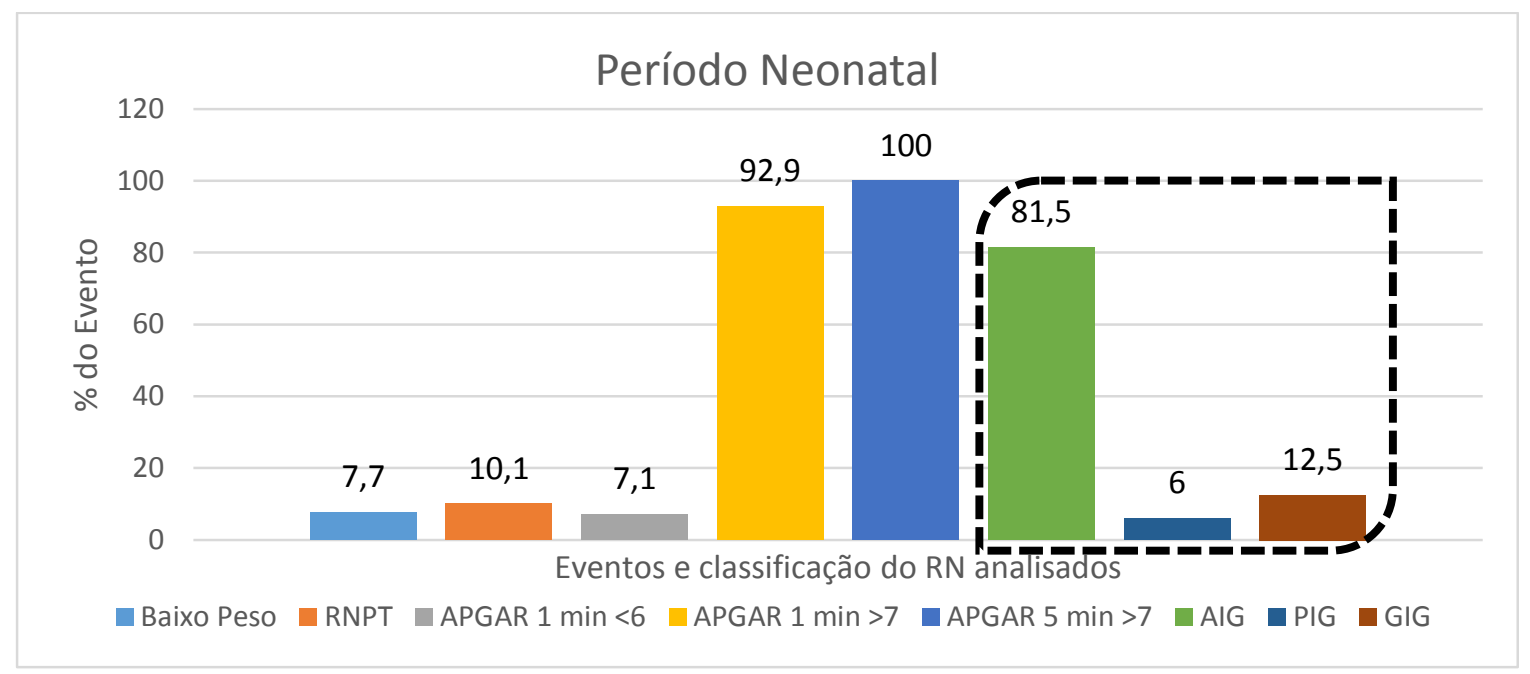

Gráfico 6: Intercorrências no período neonatal.

As principais e mais comuns intercorrências durante o primeiro ano de vida da criança foram: infecções, anemia, asma, pneumonia, febre alta, uso de amoxicilina e internação hospitalar. (Gráfico 7).

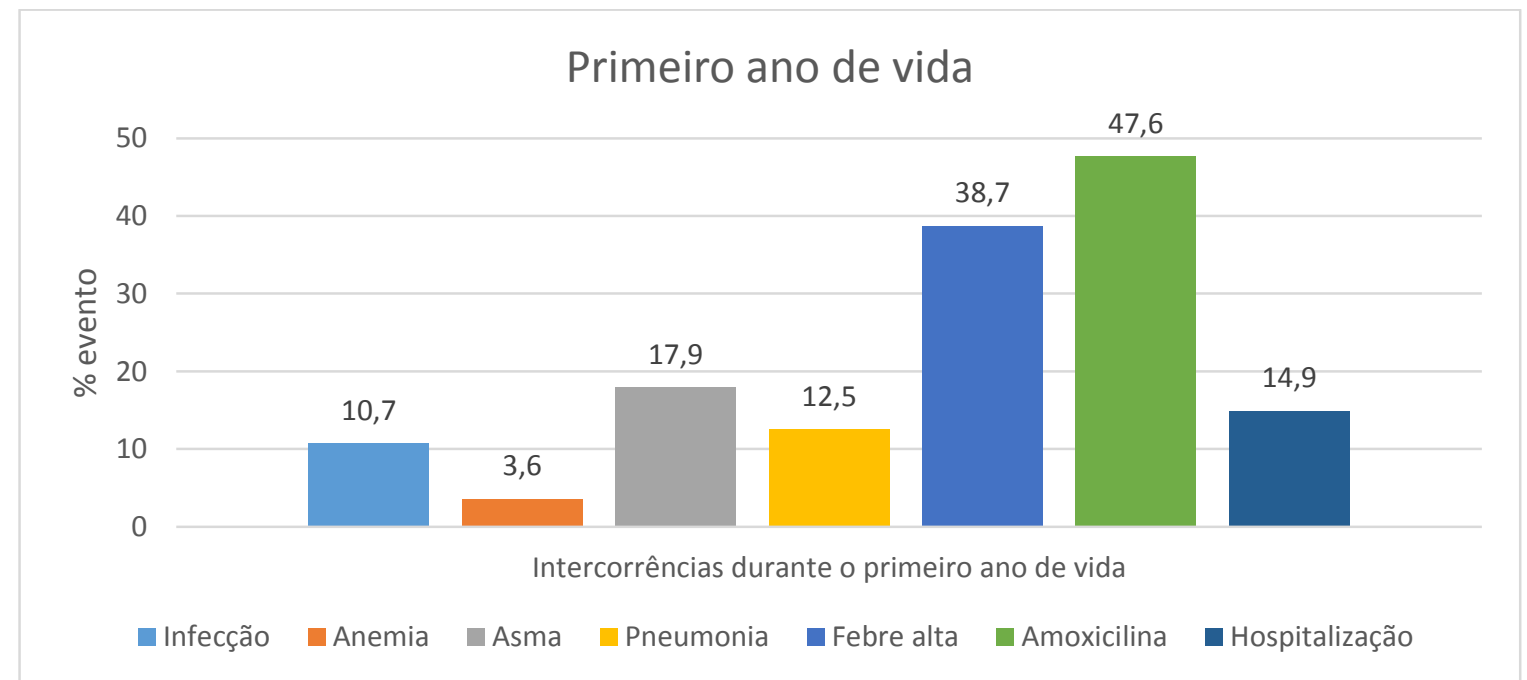

Gráfico 7: Intercorrências encontradas durante o primeiro ano de vida da criança 
O tempo de amamentação no seio materno mostrou uma grande percentagem de adesão das mães à lactação de seus filhos (Gráfico 8).

\section{Tempo de Aleitamento Materno}

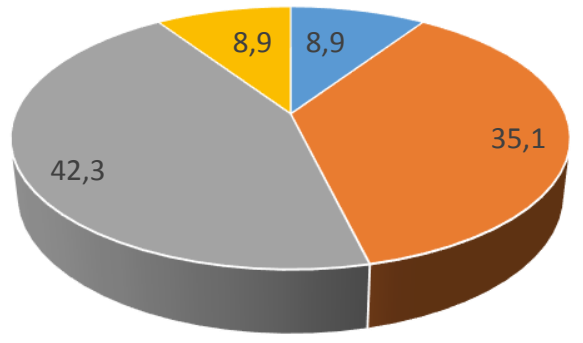

- Não mamou no peito

- $<6$ meses

- entre 6 meses e 2 anos

- $>2$ anos

Gráfico 8: Tempo de aleitamento materno.

Quanto ao perfil de higiene e cuidados com os dentes, as mães referiram que seus filhos usavam fio dental ( $\mathrm{N}=99,58 \%)$, possuíam escova de dente própria ( $N=166,98,8 \%)$, utilizavam creme dental $(\mathrm{N}=167,99,4 \%)$ e escovavam os dentes com uma frequência diária que variava, de 1 vez (14,3\%), 2 vezes (39,3\%), 3 vezes $(39,3 \%)$ e mais de 4 vezes $(6,5 \%)$ (Gráfico 9).

\section{Frequência diária de higiene bucal com escova de dente}

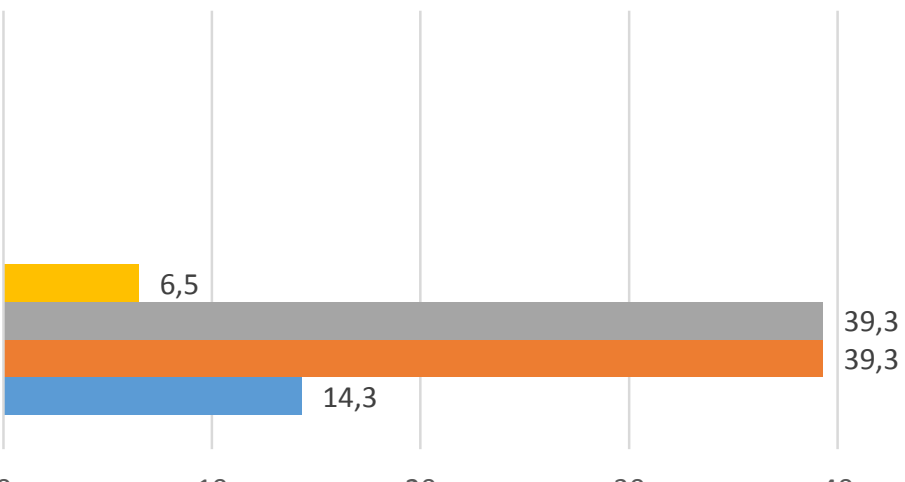

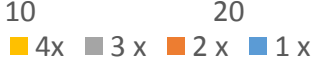

30

40

Gráfico 9: Perfil de cuidados com higiene oral. 
Ao se relacionar as informações socioeconômicas dos indivíduos pesquisados com $\mathrm{MlH}$, alguns aspectos devem ser destacados (Tabela 2).

Tabela 2: Informações socioeconômica dos indivíduos com MIH.

\begin{tabular}{|c|c|c|c|c|c|c|c|c|}
\hline \multirow{2}{*}{ Variável } & \multirow{2}{*}{ Categoria } & \multicolumn{2}{|c|}{ Não possui MIH } & \multicolumn{3}{|c|}{ Possui MIH } & \multicolumn{2}{|c|}{ Total } \\
\hline & & № & $\%$ & № & & $\%$ & № & $\%$ \\
\hline \multirow{3}{*}{$\begin{array}{l}\text { Sexo da } \\
\text { Criança }\end{array}$} & Masculino & 83 & 52,20 & & 3 & 33,33 & 86 & 52,20 \\
\hline & Feminino & 76 & 47,80 & & 6 & 66,67 & 82 & 47,80 \\
\hline & Total & 159 & 100,00 & & 9 & 100,00 & 168 & 100,00 \\
\hline \multirow{4}{*}{$\begin{array}{l}\text { Idade da } \\
\text { Criança }\end{array}$} & 6 & 25 & 15,72 & & 2 & 22,22 & 27 & 16,07 \\
\hline & 7 & 55 & 34,59 & & 3 & 33,33 & 58 & 34,52 \\
\hline & 8 & 79 & 49,69 & & 4 & 44,44 & 83 & 49,40 \\
\hline & Total & 159 & 100,00 & & 9 & 100,00 & 168 & 100,00 \\
\hline \multirow{3}{*}{$\begin{array}{c}\text { Idade } \\
\text { Materna }\end{array}$} & Até 26 anos & 93 & 58,49 & & 4 & 44,44 & 97 & 57,74 \\
\hline & Após 26 anos & 65 & 40,88 & & 5 & 55,56 & 70 & 41,67 \\
\hline & Total & 158 & 99,37 & & 9 & 100,00 & 167 & 99,40 \\
\hline \multirow{6}{*}{$\begin{array}{l}\text { Instrução } \\
\text { Materna }\end{array}$} & $\begin{array}{l}\text { Não possui instrução } \\
\text { formal }\end{array}$ & 1 & 0,64 & & 0 & 0,00 & 1 & 0,60 \\
\hline & 1a a 4aㅗ série & 19 & 12,10 & & 1 & 11,11 & 20 & 11,90 \\
\hline & 5a a 8ª série & 51 & 32,48 & & 4 & 44,44 & 55 & 32,74 \\
\hline & Nível médio & 73 & 46,50 & & 4 & 44,44 & 77 & 45,83 \\
\hline & Nível superior & 13 & 8,28 & & 0 & 0,00 & 13 & 7,74 \\
\hline & Total & 157 & 100,00 & & 9 & 100,00 & 166 & 98,81 \\
\hline \multirow{5}{*}{ Renda Familiar } & 500 a 1000 & 49 & 30,82 & & 3 & 33,33 & 52 & 30,95 \\
\hline & 1000 a 2000 & 66 & 41,51 & & 4 & 44,44 & 70 & 41,67 \\
\hline & 2000 a 4000 & 33 & 20,75 & & 2 & 22,22 & 35 & 20,83 \\
\hline & $>4 \mathrm{mil}$ & 11 & 6,92 & & 0 & 0,00 & 11 & 6,55 \\
\hline & Total & 159 & 100,00 & & 9 & 100,00 & 168 & 100,00 \\
\hline
\end{tabular}

Quanto ao sexo verificou-se que foi bem próximo o número de crianças do sexo masculino e do sexo feminino, porém percebe-se um número maior de crianças do sexo feminino portadoras de $\mathrm{MIH}(66,67 \%)$.

O número de indivíduos com MIH aumentou com o incremento da faixa etária.

A idade materna média foi de aproximadamente 26 anos. Filhos de mães mais velhas apresentaram maior índice de $\mathrm{MlH}$, porém essa informação não pode ser considerada estatisticamente significativa.

O salário médio das pessoas pesquisadas foi de $R \$ 1.809,00$ (um mil e oitocentos e nove reais), o que equivalia aproximadamente 2,3 salários mínimos. Percebe-se que o número de indivíduos com $\mathrm{MIH}$ cai à medida que a faixa salarial aumenta. 
Quanto à relação de variáveis no período pré-natal e $\mathrm{MIH}$, os aspectos em destaque são descritos na tabela 3 .

Tabela 3: Relação de MIH com intercorrências no período pré-natal

\begin{tabular}{|c|c|c|c|c|c|c|c|c|c|}
\hline \multirow{2}{*}{ Variável } & \multirow{2}{*}{ Categoria } & \multicolumn{2}{|c|}{ Não possui MIH } & \multicolumn{2}{|c|}{ Possui MIH } & \multicolumn{2}{|c|}{ Total } & \multirow{2}{*}{ p-valor } & \multirow[t]{2}{*}{ OR } \\
\hline & & № & $\%$ & № & $\%$ & № & $\%$ & & \\
\hline \multirow{3}{*}{ Fez pré-natal } & Sim & 146 & 91,82 & 7 & 77,78 & 153 & 91,07 & \multirow{3}{*}{0,19} & \multirow{3}{*}{$\begin{array}{c}3 \\
\text { (IC:0,29-19) }\end{array}$} \\
\hline & Não & 13 & 8,18 & 2 & 22,22 & 15 & 8,93 & & \\
\hline & Total & 159 & 100,00 & 9 & 100,00 & 168 & 100,00 & & \\
\hline \multirow{4}{*}{$\begin{array}{l}\text { Número de } \\
\text { consultas }\end{array}$} & $\begin{array}{l}\text { Não fez pré } \\
\text { natal }\end{array}$ & 12 & 7,55 & 2 & 22,22 & 14 & 8,33 & \multirow{4}{*}{-} & \multirow{4}{*}{ - } \\
\hline & $\begin{array}{l}1 \text { a } 5 \\
\text { consultas }\end{array}$ & 33 & 20,75 & 2 & 22,22 & 35 & 20,83 & & \\
\hline & $\begin{array}{l}>\text { de } 5 \\
\text { consultas }\end{array}$ & 111 & 69,81 & 5 & 55,56 & 116 & 69,05 & & \\
\hline & Total & 159 & 100,00 & 9 & 100,00 & 168 & 100,00 & & \\
\hline \multirow{3}{*}{ Fumou } & Sim & 16 & 10,26 & 2 & 25,00 & 18 & 10,98 & \multirow{3}{*}{0,21} & \multirow{3}{*}{$\begin{array}{c}0,34 \\
(I C: 0,06-3,78)\end{array}$} \\
\hline & Não & 140 & 89,74 & 6 & 75,00 & 146 & 89,02 & & \\
\hline & Total & 156 & 100,00 & 8 & 100,00 & 164 & 100,00 & & \\
\hline \multirow{3}{*}{ Bebeu } & Sim & 17 & 10,69 & 1 & 11,11 & 18 & 10,71 & \multirow{3}{*}{1} & \multirow{3}{*}{$\begin{array}{c}0,96 \\
\text { (IC:0,12-44,96) }\end{array}$} \\
\hline & Não & 142 & 89,31 & 8 & 88,89 & 150 & 89,29 & & \\
\hline & Total & 159 & 100,00 & 9 & 100,00 & 168 & 100,00 & & \\
\hline \multirow{3}{*}{ Drogas } & Sim & 3 & 1,90 & 0 & 0,00 & 3 & 1,81 & \multirow{3}{*}{1} & \multirow{3}{*}{-} \\
\hline & Não & 155 & 98,10 & 8 & 100,00 & 163 & 98,19 & & \\
\hline & Total & 158 & 100,00 & 8 & 100,00 & 166 & 100,00 & & \\
\hline \multirow{3}{*}{$\begin{array}{l}\text { Hipertensão } \\
\text { arterial }\end{array}$} & Não & 142 & 89,31 & 7 & 77,78 & 149 & 88,69 & \multirow{3}{*}{0,26} & \multirow{3}{*}{$\begin{array}{c}2,37 \\
\text { (IC:0,22-13,89) }\end{array}$} \\
\hline & Sim & 17 & 10,69 & 2 & 22,22 & 19 & 11,31 & & \\
\hline & Total & 159 & 100,00 & 9 & 100,00 & 168 & 100,00 & & \\
\hline \multirow{3}{*}{ Diabete } & Não & 150 & 94,94 & 8 & 88,89 & 158 & 94,61 & \multirow{3}{*}{0,4} & \multirow{3}{*}{$\begin{array}{c}2,32 \\
\text { (IC:0,04-21,59) }\end{array}$} \\
\hline & $\operatorname{Sim}$ & 8 & 5,06 & 1 & 11,11 & 9 & 5,39 & & \\
\hline & Total & 158 & 100,00 & 9 & 100,00 & 167 & 100,00 & & \\
\hline \multirow{3}{*}{ Anemia } & Não & 125 & 78,62 & 6 & 66,67 & 131 & 77,98 & & \\
\hline & Sim & 34 & 21,38 & 3 & 33,33 & 37 & 22,02 & 0,41 & $\begin{array}{c}1,83 \\
\text { (IC:0.28-9.11) }\end{array}$ \\
\hline & Total & 159 & 100,00 & 9 & 100,00 & 168 & 100,00 & & \\
\hline & Não & 111 & 69,81 & 4 & 44,44 & 115 & 68,45 & & \\
\hline ITU & Sim & 48 & 30,19 & 5 & 55,56 & 53 & 31,55 & 0,14 & $\begin{array}{c}2,87 \\
\text { (IC:0,58-15,12) }\end{array}$ \\
\hline & Total & 159 & 100,00 & 9 & 100,00 & 168 & 100,00 & & \\
\hline
\end{tabular}

Dos indivíduos pesquisados, que possuem $\mathrm{MIH}, 77,78 \%$ das mães informaram ter feito consulta pré-Natal. 
A maioria das mães informaram que não fumaram, beberam ou ingeriram bebida alcoólica durante a gestação, bem como que não apresentaram: hipertensão arterial, diabetes, anemia ou infecção do trato urinário (ITU).

Quanto a variável infecção urinária (ITU), percebe-se que 68,45\% não apresentaram ITU. No entanto, ao se analisar o grupo que possuem $\mathrm{MIH}, 55,56 \%$ deles tiveram ITU em algum momento da gestação.

Apesar de ser possível observar algumas relações/tendências entre o $\mathrm{MIH} \mathrm{e}$ algumas variáveis do período Pré-Natal, percebe-se que nenhuma delas foi estatisticamente significativa ao nível de 95\% de confiança.

Dentre as variáveis estudadas, a que se aproximou da significância estatística foi o questionamento sobre a consulta de pré-natal e a presença de $\mathrm{MIH}$ ( $p$-valor $0,19$ OR $=3)$.

Quanto a relação de intercorrências no período perinatal e $\mathrm{MIH}$, os principais aspectos são descritos na tabela 4.

Tabela 4: Relação de MIH com intercorrências no período perinatal

\begin{tabular}{|c|c|c|c|c|c|c|c|c|c|c|c|}
\hline \multirow{2}{*}{ Variável } & \multirow{2}{*}{ Categoria } & \multicolumn{2}{|c|}{ Não possui MIH } & \multicolumn{2}{|c|}{ Possui MIH } & \multicolumn{2}{|c|}{ Total } & \multirow{2}{*}{ p-valor } & \multirow{2}{*}{ Inf } & \multirow{2}{*}{ Sup } & \multirow{2}{*}{$\begin{array}{l}\text { ODDS } \\
\text { RATIO }\end{array}$} \\
\hline & & № & $\%$ & № & $\%$ & № & $\%$ & & & & \\
\hline \multirow{3}{*}{$\begin{array}{c}\text { Tipo de } \\
\text { parto }\end{array}$} & Normal & 101 & 63,52 & 6 & 66,67 & 107 & 63,69 & \multirow{3}{*}{1} & \multirow{3}{*}{0,13} & \multirow{3}{*}{4,26} & \multirow{3}{*}{0,87} \\
\hline & Cesariana & 58 & 36,48 & 3 & 33,33 & 61 & 36,31 & & & & \\
\hline & Total & 159 & 100,00 & 9 & 100,00 & 168 & 100,00 & & & & \\
\hline \multirow{3}{*}{ Baixo Peso } & Sim & 12 & 7,55 & 1 & 11,11 & 13 & 7,74 & \multirow{3}{*}{0,52} & \multirow{3}{*}{0,07} & \multirow{3}{*}{31,36} & \multirow{3}{*}{0,65} \\
\hline & Não & 147 & 92,45 & 8 & 88,89 & 155 & 92,26 & & & & \\
\hline & Total & 159 & 100,00 & 9 & 100,00 & 168 & 100,00 & & & & \\
\hline \multirow{3}{*}{ UTI Neo } & Sim & 6 & 3,80 & 1 & 11,11 & 7 & 4,19 & \multirow{3}{*}{0,32} & \multirow{3}{*}{0,03} & \multirow{3}{*}{16,32} & \multirow{3}{*}{0,31} \\
\hline & Não & 152 & 96,20 & 8 & 88,89 & 160 & 95,81 & & & & \\
\hline & Total & 158 & 100,00 & 9 & 100,00 & 167 & 100,00 & & & & \\
\hline \multirow{3}{*}{$\begin{array}{l}\text { Idade } \\
\text { Gestacional }\end{array}$} & RNT & 143 & 90,12 & 8 & 88,89 & 151 & 89,88 & \multirow{3}{*}{1} & \multirow{3}{*}{0,02} & \multirow{3}{*}{9,49} & \multirow{3}{*}{1,14} \\
\hline & RNPT & 16 & 9,88 & 1 & 11,11 & 17 & 10,11 & & & & \\
\hline & Total & 159 & 100,00 & 9 & 100,00 & 168 & 100,00 & & & & \\
\hline \multirow{3}{*}{ APGAR } & $>7$ & 117 & 73,58 & 5 & 55,56 & 122 & 72,62 & \multirow{3}{*}{0,25} & \multirow{3}{*}{0,42} & \multirow{3}{*}{10,84} & \multirow{3}{*}{2,22} \\
\hline & $<=7$ & 42 & 26,42 & 4 & 44,44 & 46 & 27,38 & & & & \\
\hline & Total & 159 & 100,00 & 9 & 100,00 & 168 & 100,00 & & & & \\
\hline
\end{tabular}

Dos partos realizados, 63,69\% foram do tipo normal e não houve diferença entre a quantidade de $\mathrm{MIH}$ e o tipo de parto ( $p$-valor = 1). 
Dos pacientes que internaram na UTI Neonatal no primeiro mês de vida (um total de 7 crianças) 6 não apresentaram $\mathrm{MIH}$ (3,80\% dos que não tinham $\mathrm{MIH})$ e 1 apresentava $\mathrm{MIH}(11,11 \%$ dos que apresentavam $\mathrm{MIH})$.

Quando se analisa o APGAR, percebe-se que o grupo de crianças que não possuem $\mathrm{MIH}, 26,42 \%$, recebeu APGAR $</=7$. Ao observar o grupo que possui $\mathrm{MIH}$, percebe-se que houve um aumento de $44,44 \%$ de pessoas que tiveram $\mathrm{MIH}(<=7)$. Houve uma leve tendência de crianças com APGAR baixo serem portadoras de $\mathrm{MIH}$, mas não passível de consideração estatística, por não alcançar o índice mínimo de 95\% de confiança no grupo pesquisado.

A grande maioria das crianças da amostra foi classificada como AIG ao nascer ( $N=140,83,5 \%)$, sendo GIG (N=18, 10,69\%) e PIG (N=10, 5,66\%). Foi observado que dentro do universo das crianças com MIH 44,44\% eram AIG, 44,44\% eram GIG e 11,11 \% eram PIG. O grupo dos RN GIG apresentou mais dentes afetados com MIH (proporcionalmente) do que os RN AIG e RN PIG. (Gráfico 10)

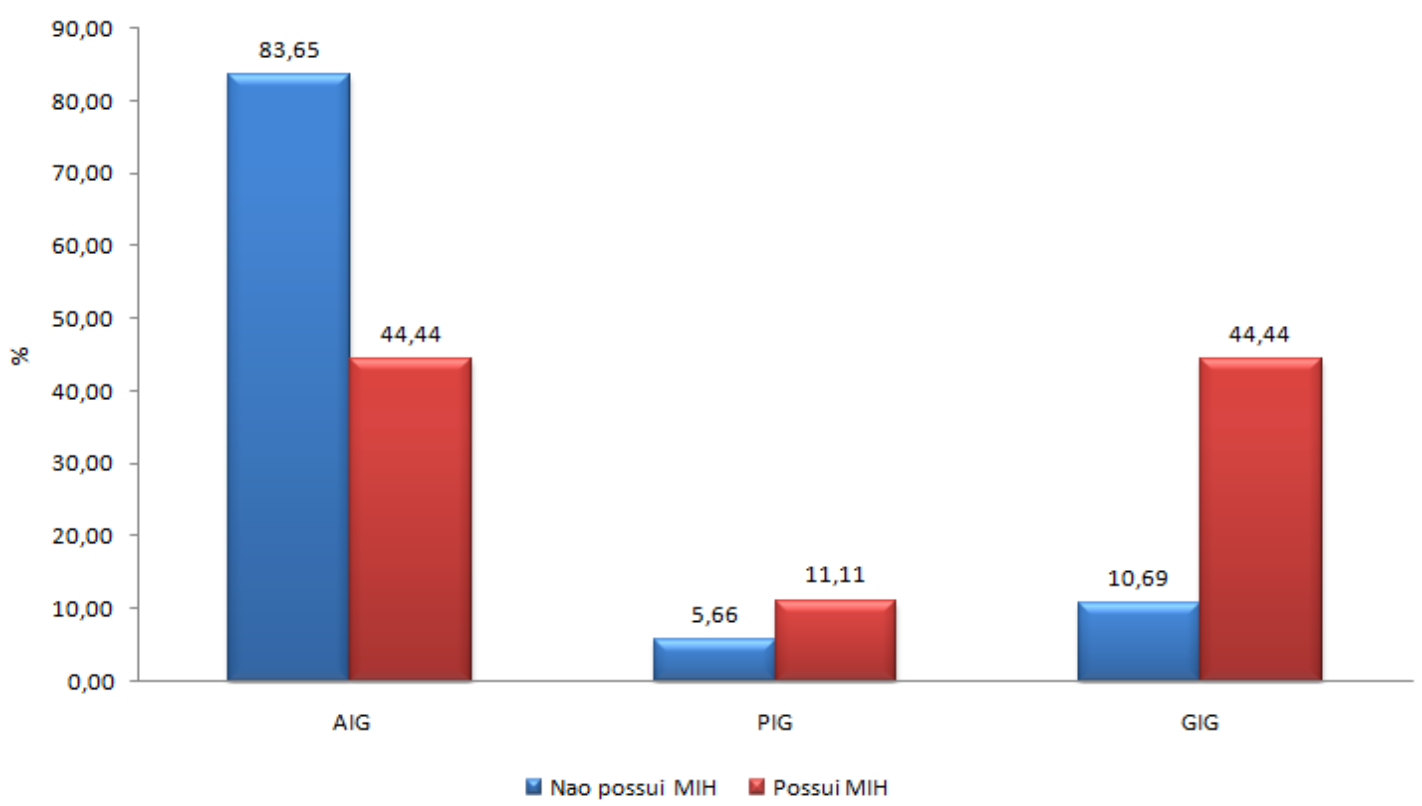

Gráfico 10: Relação entre a classificação do RN (peso x idade gestacional) e nível de $\mathrm{MIH}$

Quanto a relação de intercorrências no primeiro ano de vida e $\mathrm{MIH}$, os principais aspectos são descritos na tabela 5 . 
Tabela 5: Relação de MIH com intercorrências no $1^{\circ}$ ano de vida.

\begin{tabular}{|c|c|c|c|c|c|c|c|c|c|}
\hline \multirow{2}{*}{ Variável } & \multirow{2}{*}{ Categoria } & \multicolumn{2}{|c|}{ Não possui MIH } & \multicolumn{2}{|c|}{ Possui MIH } & \multicolumn{2}{|c|}{ Total } & \multirow{2}{*}{ p-valor } & \multirow{2}{*}{ ODDS RATIO } \\
\hline & & № & $\%$ & № & $\%$ & № & $\%$ & & \\
\hline \multirow{3}{*}{$\begin{array}{c}\text { Criança foi } \\
\text { hospitalizada } \\
\text { (1ㅇano) }\end{array}$} & Sim & 33 & 20,89 & 1 & 11,11 & 34 & 20,36 & \multirow{3}{*}{0,68} & \multirow{3}{*}{$\begin{array}{c}2,1 \\
\text { (IC:0,26-96,47) }\end{array}$} \\
\hline & Não & 125 & 79,11 & 8 & 88,89 & 133 & 79,64 & & \\
\hline & Total & 158 & 100,00 & 9 & 100,00 & 168 & 100,60 & & \\
\hline \multirow{3}{*}{ Infecção } & Sim & 18 & 11,39 & 0 & 0,00 & 18 & 10,91 & \multirow{3}{*}{0,60} & \multirow{3}{*}{-} \\
\hline & Não & 139 & 87,97 & 8 & 100,00 & 147 & 89,09 & & \\
\hline & Total & 158 & 100,00 & 8 & 100,00 & 165 & 100,00 & & \\
\hline \multirow{3}{*}{ Anemia } & & 6 & 3,80 & 0 & 0,00 & 6 & 3,57 & \multirow{3}{*}{1} & \multirow{3}{*}{-} \\
\hline & Não & 152 & 96,20 & 8 & 100,00 & 160 & 95,24 & & \\
\hline & Total & 158 & 100,00 & 8 & 100,00 & 166 & 98,81 & & \\
\hline \multirow{3}{*}{ Asma } & Sim & 29 & 18,35 & 1 & 12,50 & 30 & 18,07 & \multirow{3}{*}{1} & \multirow{3}{*}{$\begin{array}{c}1,56 \\
\text { (IC:0,18-73,31) }\end{array}$} \\
\hline & Não & 129 & 81,65 & 7 & 87,50 & 136 & 81,93 & & \\
\hline & Total & 158 & 100,00 & 8 & 100,00 & 166 & 100,00 & & \\
\hline \multirow{3}{*}{ Pneumonia } & Sim & 21 & 13,21 & 0 & 0,00 & 21 & 12,57 & \multirow{3}{*}{0,59} & \multirow{3}{*}{-} \\
\hline & Não & 138 & 86,79 & 8 & 100,00 & 146 & 87,43 & & \\
\hline & Total & 159 & 100,00 & 8 & 100,00 & 167 & 100,00 & & \\
\hline \multirow{3}{*}{ Febre alta } & Sim & 61 & 38,61 & 4 & 50,00 & 65 & 39,16 & \multirow{3}{*}{0,71} & \multirow{3}{*}{$\begin{array}{c}0,63 \\
\text { (IC: } 0,11-3,51)\end{array}$} \\
\hline & Não & 97 & 61,39 & 4 & 50,00 & 101 & 60,84 & & \\
\hline & Total & 158 & 100,00 & 8 & 100,00 & 166 & 100,00 & & \\
\hline \multirow{3}{*}{$\begin{array}{c}\text { Tomou } \\
\text { amoxicilina }\end{array}$} & Sim & 77 & 49,36 & 3 & 37,50 & 80 & 48,78 & \multirow{3}{*}{0,72} & \multirow{3}{*}{$\begin{array}{c}1,61 \\
\text { (IC:0,3-10,57) }\end{array}$} \\
\hline & Não & 79 & 50,64 & 5 & 62,50 & 84 & 51,22 & & \\
\hline & Total & 156 & 100,00 & 8 & 100,00 & 164 & 100,00 & & \\
\hline \multirow{3}{*}{$\begin{array}{l}\text { Mamou no } \\
\text { peito }\end{array}$} & Não & 14 & 9,21 & 1 & 14,29 & 15 & 9,43 & \multirow{3}{*}{0,5} & \multirow{3}{*}{$\begin{array}{c}0,61 \\
\text { (IC: } 0,06-29,97)\end{array}$} \\
\hline & Sim & 138 & 90,79 & 6 & 85,71 & 144 & 90,57 & & \\
\hline & Total & 157 & 100,00 & 7 & 100,00 & 159 & 100,00 & & \\
\hline
\end{tabular}

As crianças que não foram hospitalizadas no primeiro ano de vida perfazem um total de $79,64 \%$. Mais de $80 \%$ das crianças não apresentaram infecção, anemia, asma ou pneumonia.

Crianças que apresentaram febre e tomaram medicação totalizou $40 \%$ dos pesquisados. Nos indivíduos com $\mathrm{MIH}$, esse valor aumenta para $50 \%$.

Não houve relação entre a variável "Mamou no peito" e MIH, nos indivíduos pesquisados. Daqueles que possuíam $\mathrm{MIH}, 66,67 \%$, mamaram mais de 1 ano o seio materno, sendo essa relação estatisticamente significativa ao nível de $95 \%$ de confiança.

A saúde bucal da amostra foi analisada de acordo com o nível de cuidado com a higiene oral e com a quantidade de dentes cariados, perdidos e obturados. Foi observado que quase $60 \%$ das crianças usavam fio dental e praticamente todas 
as crianças tinham sua própria escova dental. Aproximadamente $60,12 \%$ das crianças estavam livres de carie. Ao se analisar os indivíduos com MIH, houve um aumento de indivíduos com dentes cariados, ou seja, $77,78 \%$ possuíam dentes cariados, verificando-se uma relação significativo entre $\mathrm{MIH}$ e dentes cariados ( $\mathrm{p}$ valor $=0,03)$. (Tabela 6)

Tabela 6: Informações sobre a saúde oral e relação com MIH

\begin{tabular}{|c|c|c|c|c|c|c|c|c|c|}
\hline \multirow{2}{*}{ Variável } & \multirow{2}{*}{ Categoria } & \multicolumn{2}{|c|}{ Não possui MIH } & \multicolumn{2}{|c|}{ Possui MIH } & \multicolumn{2}{|c|}{ Total } & \multirow{2}{*}{ p-valor } & \multirow{2}{*}{$\begin{array}{l}\text { ODDS } \\
\text { RATIO }\end{array}$} \\
\hline & & № & $\%$ & № & $\%$ & № & $\%$ & & \\
\hline \multirow[t]{3}{*}{ Higiene oral } & Sim & 83 & 55,33 & 6 & 75,00 & 89 & 56,33 & \multirow{3}{*}{0,46} & \multirow{3}{*}{$\begin{array}{l}0,42 \\
(I C: 0,04- \\
2,41)\end{array}$} \\
\hline & Não & 67 & 44,67 & 2 & 25,00 & 69 & 43,67 & & \\
\hline & Total & 150 & 100,00 & 8 & 100,00 & 158 & 100,00 & & \\
\hline \multirow{3}{*}{$\begin{array}{ll}\text { Usa } & \text { fio } \\
\text { dental? } & \end{array}$} & & 94 & 59,49 & 5 & 55,56 & 99 & 59,28 & \multirow{3}{*}{1,00} & \multirow{3}{*}{$\begin{array}{l}1,17 \\
(I C: 0,22- \\
5,68)\end{array}$} \\
\hline & Não & 64 & 40,51 & 4 & 44,44 & 68 & 40,72 & & \\
\hline & Total & 58 & 100,00 & 9 & 100,00 & 167 & 100,00 & & \\
\hline \multirow{3}{*}{$\begin{array}{l}\text { Possui } \\
\text { escova de } \\
\text { dentes } \\
\text { própria? }\end{array}$} & Sim & 57 & 98,74 & 9 & 100,00 & 166 & 99,40 & \multirow{3}{*}{1,00} & \multirow{3}{*}{0,00} \\
\hline & Não & 1 & 0,63 & 0 & 0,00 & 1 & 0,60 & & \\
\hline & Total & 58 & 99,37 & 9 & 100,00 & 167 & 100,00 & & \\
\hline \multirow{3}{*}{$\begin{array}{l}\text { Usa creme } \\
\text { dental? }\end{array}$} & $\operatorname{Sim}$ & 58 & 99,37 & 9 & 100,00 & 167 & 99,40 & \multirow{3}{*}{1} & \multirow{3}{*}{0} \\
\hline & Não & 0 & 0,00 & 0 & 0,00 & 0 & 0,00 & & \\
\hline & Total & 159 & 00,00 & 9 & 100,00 & 68 & 100,00 & & \\
\hline \multirow{3}{*}{$\begin{array}{l}\text { Quantas } \\
\text { escovações } \\
\text { por dia? }\end{array}$} & Até 2 & 86 & 54,09 & 4 & 44,44 & 90 & 53,57 & \multirow{3}{*}{0,73} & \multirow{3}{*}{$\begin{array}{l}1,46 \\
\text { (IC:0,3- } \\
7,69)\end{array}$} \\
\hline & Acima de 2 & 73 & 45,91 & 5 & 55,56 & 78 & 46,43 & & \\
\hline & Total & 159 & 100,00 & 9 & 100,00 & 168 & 100,00 & & \\
\hline \multirow{3}{*}{$\begin{array}{l}\text { Possui } \\
\text { dentes } \\
\text { cariados? }\end{array}$} & Não & 99 & 62,26 & 2 & 22,22 & 101 & 60,12 & \multirow{3}{*}{0,03} & \multirow{3}{*}{$\begin{array}{l}5,71 \\
(I C: 1,04- \\
58,07)\end{array}$} \\
\hline & $\operatorname{Sim}$ & 60 & 37,74 & 7 & 77,78 & 67 & 39,88 & & \\
\hline & Total & 159 & 100,00 & 9 & 100,00 & 168 & 100,00 & & \\
\hline \multirow{3}{*}{$\begin{array}{l}\text { Possui } \\
\text { dentes } \\
\text { perdidos? }\end{array}$} & Não & 140 & 88,05 & 5 & 55,56 & 145 & 86,31 & \multirow{3}{*}{0,02} & \multirow{3}{*}{$\begin{array}{l}5,79 \\
(I C: 1,05- \\
29,63)\end{array}$} \\
\hline & Sim & 19 & 11,95 & 4 & 44,44 & 23 & 13,69 & & \\
\hline & Total & 159 & 100,00 & 9 & 100,00 & 168 & 100,00 & & \\
\hline \multirow{3}{*}{$\begin{array}{l}\text { Possui } \\
\text { dentes } \\
\text { obturados? }\end{array}$} & Não & 141 & 88,68 & 6 & 66,67 & 147 & 87,50 & \multirow{3}{*}{0,08} & 3,86 \\
\hline & Sim & 18 & 11,32 & 3 & 33,33 & 21 & 12,50 & & (IC:0,57- \\
\hline & Total & 159 & 100,00 & 9 & 100,00 & 168 & 100,00 & & $20,10)$ \\
\hline & Até 16 & 70 & 44,03 & 5 & 55,56 & 75 & 44,64 & & \\
\hline $\begin{array}{l}\text { Número de } \\
\text { dentes }\end{array}$ & $\begin{array}{l}\text { Acima de } \\
16\end{array}$ & 89 & 55,97 & 4 & 44,44 & 93 & 55,36 & 0,51 & $\begin{array}{l}0,63 \\
\text { (IC:0,12- }\end{array}$ \\
\hline & Total & 159 & 100,00 & 9 & 100,00 & 168 & & & \\
\hline
\end{tabular}


Dos indivíduos pesquisados, nenhum apresentou MIH nos dentes incisivos e 2,34\% apresentaram MIH nos dentes molares. (Tabela 7)

Tabela 7: Distribuição quanto aos dentes com MIH

\begin{tabular}{|c|c|c|c|c|c|c|c|c|}
\hline \multirow[b]{2}{*}{ Categoria } & \multicolumn{2}{|c|}{ Dentes Incisivos } & \multicolumn{2}{|c|}{ Dentes Molares } & \multicolumn{2}{|c|}{ Dentes decíduos } & \multicolumn{2}{|c|}{ Total } \\
\hline & № & $\%$ & № & $\%$ & № & $\%$ & № & $\%$ \\
\hline $\begin{array}{c}\text { Indivíduos com } \\
\text { MIH }\end{array}$ & 0 & 0 & 4 & 2,38 & 5 & 3,0 & 9 & 5,36 \\
\hline $\begin{array}{c}\text { Indivíduos sem } \\
\mathrm{MIH}\end{array}$ & 168 & 100 & 164 & 97,62 & 163 & 97,0 & 159 & 94,64 \\
\hline Total & 168 & 100 & 168 & 100,00 & 168 & 100,0 & 168 & 100,00 \\
\hline
\end{tabular}

Do total de dentes com MIH, 4 são molares, ou seja, 44,44\%. No grupo pesquisado, $50 \%$ dos dentes com $\mathrm{MIH}$ encontrados foram primeiros molares permanentes, sendo que os elementos de número 36 foram os mais afetados, e os de número 46 os que menos defeitos apresentaram. (Gráfico 11)

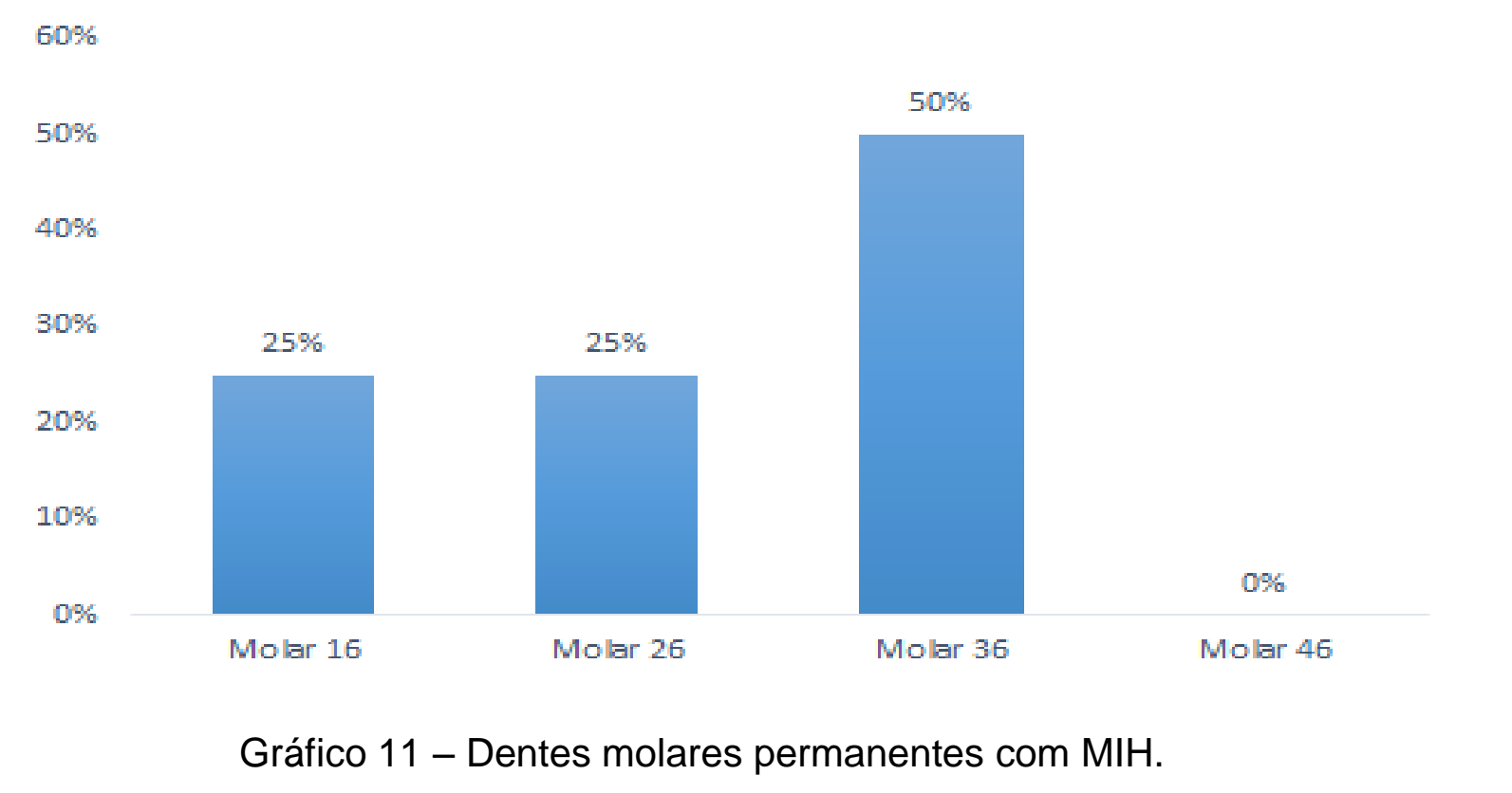

Realizou-se a análise de variáveis por período e sua relação com MIH. Para o período pré-natal foram eleitas as características: "Não fez pré-natal" e "Fumou"; 
para o período Perinatal foi escolhido as características: APGAR < 7 e ser AIG; e para o período Pós-natal: "Sim, teve febre" e "Tomou Amoxicilina. (Gráfico 12)

No período pré-natal percebeu-se que todas as mães que se declararam fumantes fizeram o número de consultas estabelecidas para o período gestacional.

Das 35 crianças com APGAR $<7$ e classificadas como AIG 5,7\% tiveram $\mathrm{MIH}$. Observa-se o alto nível de variabilidade nesse período, mostrando um desvio padrão de $8,8 \%$.

No período pós-natal, 51 crianças tiveram febre e tomaram Amoxicilina, nesse grupo, 3,9\% delas apresentaram $\mathrm{MIH}$.

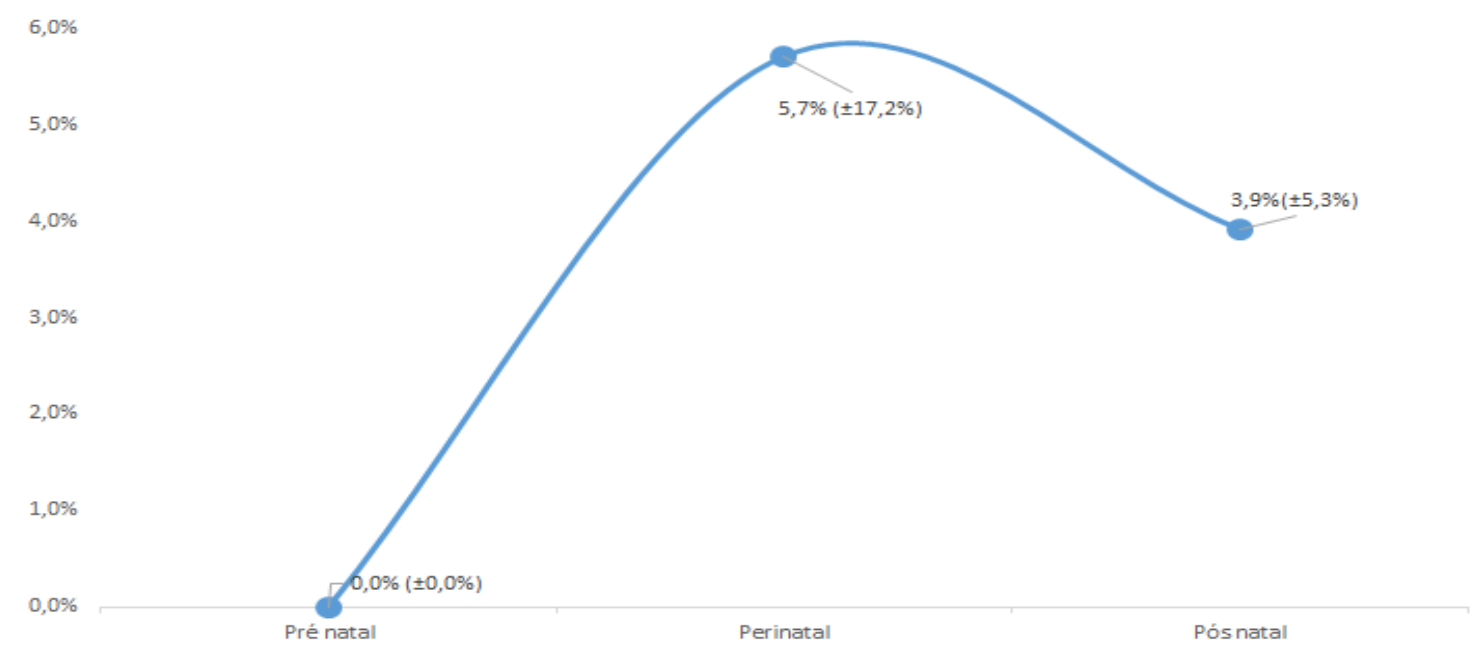

Gráfico 12: Análise de acometimento de MIH por período. 


\section{DISCUSSÃO}

O presente estudo de coorte retrospectivo analisou possíveis fatores etiológicos associados a presença de $\mathrm{MIH}$ em uma população de escolares do Gama - Brasília/DF - Brasil.

A amostra incluiu 168 crianças nascidas no HRG, com residência fixa e frequência escolar na mesma região. Foram relacionadas possíveis variáveis pré e pós-natais que poderiam estar incluídas como fatores etiológicos da $\mathrm{MIH}$.

Foi possível observar que em um universo de 168 crianças, 9 apresentaram $\mathrm{MIH}$, com uma prevalência de 5,36\% (IC95\%: 1,95\% - 14,1\%), porcentagem maior do que o que foi observado em estudos realizados na Ásia (2,8\%) (7) e na Bulgária $(3,58 \%)(89)$ e próximo ao que foi observado na Alemanha $(5,6 \%)$ e na Índia $(6,31)$ $(81,91)$; porém muito inferior aos $19,8 \%$ e 40,2\% encontrados em estudos realizados no Brasil $(7,8)$ e em outros trabalhos publicados em todo o mundo (Quadro 3). Essas variações podem ser devidas às diferenças étnicas e regionais, à faixa etária investigada ou mesmo aos aspectos culturais e sociais dos diferentes grupos.

Jalevik et al, 2010, recomendam que, em um estudo de $\mathrm{MIH}$, o mínimo de indivíduos examinados seja de 100. Porém, há vários estudos com amostras extremamente discrepantes na literatura mundial. Os estudos realizados na Lituânia, por exemplo, com 1.277 crianças (101), ou na Grécia, com 3.518 crianças (52), apresentam a vantagem de possuir uma maior representatividade da população. Porém a maioria inclui um número menor de indivíduos na pesquisa, o que pode justificar, em parte, a grande variedade nos percentuais da prevalência de $\mathrm{MIH}$. (Quadro 3).

Para se realizar o diagnóstico de MIH os dentes devem ser limpos com gaze, segundo os critérios referenciados pela EAPD em 2003. No presente estudo, esse critério foi observado, porém nota-se que existe uma grande variação em relação a essa conduta em vários outros estudos $(93,101)$, ou então essa questão não foi suficientemente abordada e descrita na metodologia $(81,98)$, o que dificulta a comparação entre eles. 
De acordo com recomendações da FDI (1992), os defeitos menores que 1 $\mathrm{mm}$ de diâmetro não devem ser registrados. Em algumas pesquisas não foram observados tais parâmetros $(52,58)$, enquanto que em outros, esses aspectos não foram sequer mencionados $(7,85)$.

Uma questão que pode, por sua vez, influenciar a prevalência obtida em diferentes estudos é o treino ou calibração do examinador ou examinadores entre si. No presente estudo, a calibração entre os examinadores foi definida pelo estudo conjunto dos escores de acordo com a classificação da EAPD, através de fotografias representativas dos escores, até haver segurança quanto ao diagnóstico. Quando havia dúvidas, durante o exame era solicitada a opinião do colega para se chegar a um consenso. Alguns estudos não fazem referência sobre calibração. (Quadro 3).

O intervalo etário da presente amostra, entre 6-8 anos de idade, com uma idade média de 7,33 anos (Gráfico 1) (Tabela 2), seguiu os critérios da EAPD, que sugerem a idade próxima aos 8 anos como a melhor para se realizar a observação relacionada a $\mathrm{MIH}$, pois nessa faixa etária há um menor risco de que defeitos do esmalte já tenham evoluído para lesões de cárie, além dos primeiros molares permanentes já estarem, em grande parte dos casos, erupcionados e presentes na cavidade bucal.

No entanto, observa-se uma heterogeneidade nos estudos quanto à faixa etária, variando dos 6 até os 17 anos de idade. (15, 81, 83) (Quadro 3).

No que se refere a diferenças entre sexos, não houve diferença significativa entre meninos e meninas em relação a $\mathrm{MIH}$, o que se assemelha aos números encontrados em grande parte dos estudos. $(77,90,98)$ (Tabela 2).

Condições socioeconômicas mais baixas e pouca instrução materna geralmente apresentam uma associação positiva com níveis mais altos de $\mathrm{MIH}$ e de carie, como também dificultam o acesso a tratamento odontológico, com piora da saúde como um todo. Dados encontrados no presente estudo que podem confirmar essa tendência. (Tabela 2).

O salário médio das pessoas pesquisadas foi de $R \$ 1.809,00$ (total equivalente a 2,29 salários mínimos em 2015), e foi possível inferir que à medida que a renda familiar aumenta, o número de indivíduos com MIH diminui. (Tabela 2). Para se afirmar tal relação, teria sido necessário a utilização de um formulário com questões para deduzir o padrão socioeconômico da família, como preconizado pelo 
Instituto Brasileiro de Geografia e Estatística. Além disso, não se pode determinar o nível socioeconômico de determinada família baseando-se apenas no fato de que suas crianças estudam no sistema público de educação. Outro fator que deve ser considerado é o número restrito do $\mathrm{N}$ amostral. Entretanto outros estudos poderão com uma amostra maior mostrar significância estatística relacionando renda e $\mathrm{MIH}$.

Quanto à questão da instrução das progenitoras, o índice educacional está demonstrado no Gráfico 3. Nenhuma das mães com ensino superior teve filhos portadores de MIH. (Tabela 2). Tal informação, entretanto, carece de significado estatístico.

Estudos relacionam condições socioeconômicas mais baixas e pouca instrução materna com o aparecimento de $\mathrm{MlH}$; e apontam, também, o papel de possíveis deficiências nutricionais com as alterações no desenvolvimento normal do esmalte dentário. (102, 103, 111). Estudo que provocou desnutrição em ovelhas demonstrou a associação desse estado com a presença de defeitos no esmalte, sugerindo uma relação entre mal nutrição com a ocorrência de MIH (111).

Levando-se em consideração os fatores pré-natais como possíveis agentes etiológicos do $\mathrm{MIH}$, observou- se que das mulheres que responderam 0 questionário, 91,82\% alegaram ter feito consulta de pré-natal, sendo que 69,81\% ( $\mathrm{N}=111$ ) fizeram mais do que 6 consultas de pré-natal, como indicado pelo Ministério da Saúde (MS, Portaria no 570, de 1ํo de junho de 2000- DO 110-E, de 08/06/2000), como o número mínimo de consultas para um bom acompanhamento durante a gestação. (Gráfico 4)

Dos indivíduos pesquisados que possuíam $\mathrm{MIH}(\mathrm{N}=9), 22,22 \%$ das mães informaram não ter feito pré-Natal, ( $p$-valor 0,19; OR:3).

As variáveis consideradas durante a gestação (período pré-natal) foram: uso de fumo, bebida ou drogas ilícitas; doenças presentes na gravidez como HAS, diabetes, anemia e ITU. (Gráfico 5)

Poucos casos de MIH foram relacionados com distúrbios no período prénatal, quando comparado com outros períodos. Não foi encontrada relação estatística significativa entre mães que referiram problemas médicos no período prénatal com MIH (Tabela 3), o que pode indicar que as crianças estariam protegidas no útero. Entretanto, estudo realizado por Fréden et al refere que mães com infecções urinárias durante o último trimestre de gravidez tinham maior probabilidade de ter filhos afetados por $\mathrm{MIH}$ (104). Outra pesquisa incluindo 33 crianças com MIH 
(37), mostrou que 15\% dessas crianças tinham uma relação com doenças crônicas durante a gestação como sífilis, hipertensão arterial, diabete e uso prolongado de drogas. No entanto em estudo posterior do mesmo grupo não foram obtidas as mesmas relações (56).

Outros estudos referem que mães com problemas médicos na gravidez têm maior probabilidade de terem filhos com $\mathrm{MIH}$, apesar de não ser encontrado nenhum problema médico específico e definido. (52; 62).

$\mathrm{Na}$ amostra foi encontrada uma porcentagem de $63,7 \%$ de parto normal e $36,3 \%$ de parto cirúrgico (cesariana). Dos 9 indivíduos diagnosticados com $\mathrm{MIH}$, $66,67 \%$ nasceram de parto normal, porém não mostraram uma relação significativa (p-valor=1) com a presença de $\mathrm{MIH}$. (Tabela 4). A literatura refere que a hipóxia neonatal é mais frequente em partos cesarianos (52).

Os problemas médicos relacionados ao parto prolongado ou cesariana com possível complicações, que podem levar a hipóxia nos ameloblastos, quase sempre levam a um escore de APGAR baixo, são citados em uma série de trabalhos. (39, $47,70,104,105)$.

A maioria das crianças recebeu APGAR no $1^{\circ}$ minuto $>7(92,9 \%)$, sendo que, no $5^{\circ}$ minuto, todas alcançaram no mínimo 7 (Gráfico 6). Houve 4 crianças que apresentavam APGAR $<7$ no $1^{\circ}$ minuto, mas não com valores que indicavam asfixia grave, e sem relação com a presença de $\mathrm{MIH}$.

No que se refere à idade gestacional e prematuridade, na amostra, 9 crianças afetadas por $\mathrm{MIH}$, apenas uma foi RNPT (11,11\%), dado sem valor estatístico (pvalor=1 IC: 0,02-9,49 - OR: 1,14) (Tabela 4). O que difere muito de estudo realizado na Suécia (50), que mostrou uma prevalência duas vezes maior de MIH em crianças prematuras (38\%) quando comparada a um grupo controle (16\%). Uma baixa idade gestacional e um baixo peso ao nascimento foram considerados fatores concomitantes ao aparecimento de $\mathrm{MIH}$ (37).

O nascimento prematuro tem sido considerado um grande responsável pela maior prevalência de defeitos de esmaltes na dentição permanente $(47,105)$. Em um estudo com 40 crianças prematuras com baixo peso ao nascimento, observou-se percentual altamente significante de defeitos nos primeiros molares permanentes (17\%) em comparação com crianças que nasceram com peso normal (8\%) (105). Crianças com $\mathrm{HMI}$ (48\%) apresentaram problemas médicos relacionados ao nascimento, seja prematuridade, duração prolongada do parto ou cianose (39). Por 
outro lado, vários autores não associam problemas perinatais com a $\mathrm{MIH}$. $(58,62$, 85). Semelhante com achados do presente estudo, onde apenas $11 ; 11 \%(\mathrm{~N}=1)$ das crianças com MIH foi prematuro, dado sem significado estatístico.

Os RN GIG apresentaram mais dentes afetados com MIH do que os RN AIG e RN PIG. (Gráfico 10). O nascimento de um RN GIG muitas vezes está associado com parto cesariano ou com APGAR baixo no $1^{\circ}$ minuto, mas nos dados desse trabalho não houve relação positiva entre essas variáveis. (Tabela 4)

O Boletim de APGAR é utilizado para verificar a condição vital do RN ao nascer. Alguns trabalhos mostram a relação de valores baixos do APGAR no 1ํ e 5ำ minutos de vida com defeitos do esmalte (112). No presente estudo não houve resultados significativos entre essa relação de variáveis.

O terceiro período considerado foi do nascimento até o primeiro ano de vida completo onde algumas variáveis foram analisadas: infecções, anemia, asma, pneumonia, febre alta, uso de amoxicilina e tempo de amamentação. (Gráfico 7)

$\mathrm{Na}$ infância o leite materno é a principal fonte de nutrientes e o aleitamento materno é uma vantagem para a saúde da criança. Contudo, existe uma recente preocupação sobre o conteúdo de contaminantes ambientais no leite materno.

Quando questionadas sobre a duração de aleitamento materno, percebe-se que os grupos estão proporcionalmente divididos em "até 1 ano" (51,03\%) e "mais de um ano" (48,97\%). (Gráfico 8). Ao se analisar o grupo que não possui $\mathrm{MIH}$, verifica-se que também são proporcionalmente parecidos $(52,9 \%$ e $47,1 \%$ respectivamente). (Tabela 5).

Entretanto ao se analisar as crianças afetadas pela MIH verifica-se que $66,67 \%$ mamaram mais de um ano, sendo essa relação estatisticamente significativa ( $p$-valor=0,05) (95\% de confiança). Resultado semelhante foi encontrado em estudo com crianças iranianas (86). Outros estudos não mostram diferenças entre o tempo de amamentação e MIH (62). Dois estudos europeus não encontraram correlação entre uma amamentação de longa duração e a MIH (56).

Na Finlândia a amamentação materna foi associada à MIH (106). Os autores supõem que esse fato pode estar relacionado com as dioxinas e os poluentes presentes no leite materno, mas a quantidade e qualidade desses poluentes é desconhecida. De qualquer forma esse aspecto gera uma preocupação, pois não se pode rejeitar a importância do leite materno nos seis primeiros meses de vida, sendo reconhecidamente fundamental. 
Apesar dos resultados destes estudos, a OMS recomenda a amamentação materna até os dois anos, uma vez que o leite materno é a maior fonte de energia na infância e que este protege as crianças de infecções, prevenindo alergias e reforçando o desenvolvimento cognitivo (106).

Ainda com a finalidade de se encontrar fatores que possam ter relação com $\mathrm{MIH}$, as intercorrências nos primeiros anos de vida em relação a saúde das crianças tem sido uma preocupação. Em estudo recente, verificou-se que crianças com HIM têm uma história médica, durante os primeiros três anos de vida, com um número maior de intercorrências em relação às outras crianças. (85).

Especial atenção tem sido dada a doenças infecciosas, febre alta, pneumonia $(37,38)$, asma (37), infecções do trato urinário (107), devido à sua relação com HIM, apesar de existirem resultados controversos relativamente a algumas doenças específicas $(37,62)$.

Aqui não foi encontrada relação entre $\mathrm{MIH}$ e doenças no $1^{\circ}$ ano de vida. (Tabela 5) Crianças que apresentaram febre e tomaram algumas medicações remédio foram $40 \%$ das pesquisadas. Nos indivíduos com $\mathrm{MIH}$, esse valor aumenta para 50\%, porém sem significância estatística. (Tabela 5). Tem sido sugerido que qualquer intercorrência que leve a uma deficiência de oxigênio ao ameloblasto pode ser responsabilizada pela formação de MIH. Doenças respiratórias são comuns nesse período, sendo as mais comuns as infecções de ouvido, pneumonias, asma, acompanhadas ou não por febre alta podendo levar a alterações da amelogênese. $(10,104)$. A febre é um sintoma comum a várias infecções na infância, tornando muito difícil afirmar ou distinguir-se o causador do defeito do esmalte, a infecção, a febre alta ou mesmo a medicação. (104).

Isolar cada uma das doenças, como fator etiológico é difícil, uma vez que, a mesma criança pode apresentar mais que um fator etiológico (10), ou seja, mais de um tipo de doença em períodos diferentes durante a primeira infância. Também, verifica-se alguma confusão por parte dos autores, se é a doença em si ou o tratamento que causam HIM. (22,62). Portanto, essas variáveis podem ser consideradas fatores confundidores ou vieses que podem distorcer ou alterar os resultados do estudo.

Alguns autores referem que a amoxicilina induz a formação precoce do esmalte. Outra possibilidade é que a amoxicilina interfira com a função dos 
ameloblastos, antecipando a iniciação da amelogênese ou acelerando a taxa de deposição do esmalte. (22).

Uma porcentagem de $49,36 \%$ de crianças do presente estudo usou amoxicilina no primeiro ano de vida, sendo que, das 9 crianças com $\mathrm{MIH}$, em 5 não foi relatado o uso do antibiótico (Tabela 5). A amoxicilina é o antibiótico mais utilizado pela pediatria clínica e o seu uso é indicado para uma grande parte de infecções desse período, além do que essa droga é de distribuição gratuita na rede pública pelo SUS. Esses fatos fazem com que o seu uso entre a população pediátrica seja, de uma certa maneira, indiscriminado. Seria interessante fazer a comparação com outras classes de antibióticos. Outro fato a ser considerado, e muito discutido na literatura, é se a indução da formação da MIH está relacionada diretamente ao uso da droga ou por febre alta ou pela doença de base, ou ainda por todo o processo inflamatório e infeccioso.

No presente estudo observou-se uma relação estatística significativa ( $p$-valor 0,03 OR:5,71 IC:1,04-58,07) entre dentes cariados e presença de $\mathrm{MIH}$; das 168 crianças examinadas 37,74\% (N=60) apresentavam lesões de cárie; sendo que das crianças com MIH 77,7\% ( $\mathrm{N}=7)$ apresentavam cárie. A relação de dentes perdidos com MIH também apresentou significância estatística (p-valor 0,02 OR:5,79 IC:1,0529,63). (Tabela 6)

Estudos demonstram que as características clínicas da HMI têm um impacto negativo sobre a higiene bucal diária dos indivíduos, resultando em aumento da prevalência de cárie e uma maior necessidade de tratamento. (97)

Estudo realizado por Oliveira et al. (2012), avaliou a prevalência, severidade da HMI e sua relação com a cárie dentária em 248 crianças entre 8 e 12 anos no município de Patrocínio Paulista - SP obtendo uma prevalência da $\mathrm{HMI}$ de $14 \%$. A prevalência de cárie dentária foi de $67 \%$ e o valor do índice CPO-D para as crianças examinadas foi de 1,04. Foi observada correlação entre HMI e cárie dentária, uma vez que as crianças com HMI apresentaram valor médio significativamente mais alto de índice CPO-D $(1,66)$ do que as crianças que não apresentaram a alteração no esmalte dentário $(0,94)$

Dos indivíduos pesquisados, não houve dentes incisivos afetados por $\mathrm{MIH}$ e 2,34\% apresentaram $\mathrm{MIH}$ em primeiros molares permanentes e $3 \% \quad(\mathrm{~N}=5)$ apresentaram MIH em dentes decíduos $(55,75,84,85)$ (Tabela 7$)$. 
Em estudos realizados em países tão diversos como Alemanha, Bósnia e Brasil, as alterações apenas em molares permanentes estavam presentes em $57,8 \%, 7,59 \%$ e $48,6 \%$ respectivamente. $(9,81,99)$

Do total de dentes com MIH, 4 são molares permanentes, ou seja, 44,44\%. No grupo pesquisado $50 \%$ dos dentes com $\mathrm{MIH}$ encontrados nos $1^{\circ}$ Molares permanentes estavam no 36 , e o menos envolvido foi o 46 . Sendo que uma mesma criança apresentava dois primeiros molares superiores permanentes com $\mathrm{MIH}$. (Gráfico 11) Diferindo do estudo de Kotsanos et al (108) onde o dente mais afetado foi o 26 e de Kuscu et al (85) onde o mais afetado foi o 16. Entretanto, essas relações não foram objeto de maior aprofundamento em função do tamanho amostral. Talvez se houvesse um número maior de indivíduos fosse interessante conhecer as diferenças e preferencias da MIH por algum dente especificamente.

Também, não houve diferença entre arcadas afetadas, seja superior ou inferior, o que também foi observado em alguns estudos. $(15,16,56,85)$. Entretanto no trabalho de Shiu-yin Cho et al (77) os molares superiores foram mais afetados (Gráfico 11). E, ao que se sabe, não existe uma explicação para que uma arcada dentária seja mais acometida do que outra, uma vez que o período de mineralização dos primeiros molares é idêntico tanto na maxila como na mandíbula.

$\mathrm{Na}$ amostra examinada, observou-se que houve uma significância estatística entre a relação de dentes cariados ( $p$-valor 0,03 ), perdidos ( $p$-valor 0,02) e obturados (p-valor 0,08) e MIH. (Tabela 6). Existe uma relação entre altos índices de cárie em crianças com MIH. $(68,98)$. Sabe-se que a presença de $\mathrm{MIH}$ em um elemento dentário poderia ser um fator de risco para o desenvolvimento de carie, até pelo fato do defeito de esmalte causar desconforto e dor durante a escovação o que pode levar a um aumento do índice de biofilme e consequentemente desmineralização.

No desenho deste estudo houve a preocupação de se diminuir os possíveis vieses. As escolas incluídas no estudo possuíam acompanhamento por grupo de nutricionistas (com dieta balanceada) e anualmente por odontólogos, com orientações de higiene oral e aplicação de flúor tópico. As duas escolas incluídas nesse estudo possuem parceria com instituição de nível superior, com cursos de odontologia e medicina onde são realizadas palestras e oficinas com objetivo de promoção de saúde geral e bucal das crianças regularmente matriculadas. 
Todas as crianças que participaram desse estudo residem em áreas com fluoretacão na água de abastecimento na proporção ideal para a região 0,7ppm.

Vale ressaltar algumas limitações dessa pesquisa como o fato de que algumas das informações dos possíveis fatores etiológicos basearam-se na memória das mães, durante o preenchimento dos questionários, com possível viés de memória. Outra dificuldade foi o levantamento de dados dos prontuários médicos, que se apresentavam em grande parte incompletos. Apenas os dados do pré-natal e do período neonatal puderam ser pareados e confirmados com os dados dos questionários. $\mathrm{O}$ amostral foi também uma preocupação pois, apenas 2 escolas foram selecionadas.

O profissional de saúde, de maneira geral, deve estar atento para o diagnóstico precoce da $\mathrm{MIH}$ principalmente durante a fase eruptiva, tanto dos molares decíduos e permanentes quanto dos incisivos permanentes. A detecção de um elemento dentário com esmalte defeituoso estará sujeito a um ambiente repleto de microrganismos capazes de, quando na presença de outros fatores associados, causar lesões cáries e o tratamento imediato certamente evitará maiores complicações.

Orientações adequadas fornecidas tanto aos pais quanto à criança afetada, interfere no sucesso do tratamento. Com um acompanhamento multidisciplinar, o pediatra pode perceber, com exame simples e direto, a alteração dentária, com imediato encaminhamento ao odontopediatra. Por isso, uma boa anamnese, que permita o conhecimento da história clínica e pregressa da criança, com a identificação de possíveis fatores etiológicos relacionados com o surgimento de $\mathrm{MIH}$ no período perinatal e nos primeiros anos de vida, é fundamental.

Estudos prospectivos, com o acompanhamento da criança desde o nascimento até a erupção dos molares permanentes, parecem ser os mais recomendados para a avaliação do impacto de fatores sistêmicos na etiologia do $\mathrm{MIH}$.

Através da projeção dos resultados do presente estudo, e da comparação com 0 de outros trabalhos, infere-se que a prevalência de $\mathrm{MIH}$ nas escolas estudadas seja de 5,33\%. Tais dados, quando estimados para a população em geral, mostram a necessidade de atenção para a adequada assistência da população brasileira. 


\section{CONCLUSÔES}

De acordo com a metodologia empregada e os resultados obtidos pode-se concluir que:

- A prevalência da MIH, neste grupo de crianças foi de 5,36\%;

- Não foi possível encontrar qualquer resultado significante entre os eventos analisados no período pré-natal ou perinatal das progenitoras com a $\mathrm{MIH}$ encontrada nas crianças;

- O índice CEOD e CPOD foi alto na população estudada e com relação estatisticamente significativa com $\mathrm{MIH}$;

- Embora as intercorrências durante o primeiro ano de vida pouco tenham influenciaram a relação com a $\mathrm{MIH}$, o aleitamento além do primeiro ano de vida mostrou significância estatística. Entretanto, esse dado que deve ser analisado de maneira muito cuidadosa, pois os benefícios da amamentação ao seio materno até os 2 anos de idade são inquestionáveis. 


\section{REFERÊNCIAS BIBLIOGRÁFICAS}

1- Weerheijm KL. Molar incisor hypomineralization (MIH): clinical presentation aetiology and management. Dental Update. 2004; 31(1):9-12.

2- Weerheijm KL. Molar incisor hypomineralization (MIH). Eur J of Paediat Dent. 2003; 4:114-20.

3- Jasulaityte L, Veerkamp JS, Weerheijim KL. Molar Incisor hypomineralization: review and prevalence data from a study of primary school children in Kaunas /Lithuania. Eur Arch Paediatr Dent. 2007; 8(2):87-94.

4- Gomez PM, Jimeno FG, Dalmau LJB, Tarrida LG. Prevalence of molar-incisor hypomineralization using transillumination in a group of children from Barcelona (Spain). Int JPaediatr Dent. 2012; 22(2):100-9.

5- Balmer R, Toumba J, Godson J, Duggal M. The prevalence of molar incisor hypomineralization in Northern England and its relationship to socioeconomic status and water fluoridation. Int J Paediatr Dent. 2012; 229(4):250-7.

6- Gravina DB, Cruvinel VR, Azevedo TD, Toledo AO, Bezerra AC. Prevalence of dental caries in children born prematurely or at full term. Braz Oral Res. 2006; 20(4):353-7.

7- Soviero V, Haubek D, Trindade C, Da Matta T, Poulsen S. Prevalence and distribution of demarcated opacities and their sequelae in permanent 1st molars and incisors in 7 to 13-year-old Brazilian children. Acta odontologica Scandinavica. 2009; 67(3):170-5.

8- Da Costa-Silva CM, Jeremias F, Souza JF, Cordeiro RC, Santos Pinto L. e Zuanon AC. Molar incisor hypomineralization: prevalence, severity and clinical consequences in Brazilian children. Int J Paediatr Dent. 2010; 20(6):426-34.

9- Jeremias F, Souza JF, Costa Silva CM, Cordeiro RCL, Zuanin ACC, Santos Pinto LAM. Dental caries experience and molar - incisor hypomineralization. Acta Odont Scand. 2013; 71(3-4):870-876.

10-Crombie FA, Manton DJ, Weerheijm KL, Kilpatrick NM. Molar incisor hypomineralization: a survey of members of the Australian and New Zealand Society of Paediatric Dentistry. Australian Dental J. 2008; 53(2):160-6. 
11-Mangum JE, Crombie FA, Kilpatrick N, Manton D J, Hubbard MJ. Surface integrity governs the proteome of hypomineralized enamel. $J$ Dent Resear. 2010; 89(10):1160-5.

12-Baroni C, Marchionni S. MIH supplementation strategies: prospective clinical and laboratory trial. J Dent Resear. 2011; 90(3):371-6.

13-Weerheijm KL, Duggal M, Mejare I, Papagiannoolis L, Koch G, Martens LC, Hallonsten AL. Judgement criteria for molar incisor hypomineralization $(\mathrm{MIH})$ in epidemiologic studies: a summary of European meeting on $\mathrm{MIH}$ held in Athens, 2003.Eur J Paed Dent. 2003; 4(3):110-3.

14-Elfrink MEC, Schuller AA, Weerheijim KL, Veerkamp JSJ. Hypomineralized second primary molars: prevalence data in Dutch 5-years -olds. Caries Res. 2008; 42:282-5.

15-Koch G, Hallonsten AL, Ludwigsson N, Hansson BO, Holst A, Ulbro C. Epidemiologic study of idiopatic enamel hypomineralization in permanent teeth of Swedish children. Comm Dent Oral Epidemiol. 1987; 15(5):279-85.

16-Weerheijm KL, Groen HJ, Beentjes VEVM, Poorterman JHG. Prevalence of the cheese molars in eleven-year-old Dutch children. J Dent Child. 2001; 68(4):25662.

17-Kraus BS, Jordan RE. The human dentition before birth. Philadelphia: Lea e Febiger Publ.1965.

18-Bönecker MJS, Ferreira SLM, Birman E. Prevalência de anomalias dentárias em crianças de 0 a 36 meses de idade. J Bras Odontopediatria Odontol Bebê. 2002; 5:425-31.

19-Corrêa MSNP, Martins ALCF, Fazzi L, Fazzi R. Erupção dentária. In: Corrêa MSNP. Odontopediatria na primeira infância. São Paulo: Livraria Santos.1998; p.117-29.

20-MC Donald RE, Avery DR, Dean JA. Odontologia para crianças e adolescentes. 9 ed. Rio de Janeiro: Elsevier. 2011. p.46.

21-Corrêa-Faria P, Martins-Júnior PA, Vieira-Andrade RG, Marques LS, RamosJorge ML. Perinatal factors associated with developmental defects of enamel in primary teeth: a case-control study. Braz Oral Resear. 2013; 27(4):363-8.

22-Laisi S, Sahlberg C, Arvio P, Lukinmaa PL, Alaluusua A. Amoxicillin may cause molar incisor hypomineralization. J Dent Res. 2009; 88(2):132-6..

23-Nanci A. Histologia Oral. 8.ed. Rio de Janeiro: Elsevier. 2013. 
24- Nicodemo RA, Moraes LC, Médici Filho E. Tabela cronológica da mineralização dos dentes permanentes, entre brasileiros. Rev. Fac. Odontol.1974;3(1):55-6.

25- FDI Comisssion on Oral Health, Research and Epidemiology. An epidemiological index of developmental defects of dental enamel (DDE Index). Int Dent J. 1982; 32(2):159-67.

26-Suclking GW. Developmental defects of enamel: historical and present day perspectives of their pathogenesis. Adv Dent Res. 1989; 3(2):87-94.

27-Suga S. Enamel hypomineralization view from the pattern of progressive mineralization of human and monkey developing enamel. Adv Dent Res. 1989; 3(2):188-98.

28-Cruvinel VRN, Gravina DBL, Azevedo TDPL et al. Prevalence of enamel defects and associated risk factors in both dentitions in preterm and full term born children. Journal of applied oral science : revista FOB. 2011; 20(3): 310-7.

29-Council O. Guideline on dental management of heritable dental developmental anomalies. Pediatric dentistry. 2013; 35(5):179-84.

30-Vianna LS, Parreira MLJ, Santos Filho JL, Menezes JTA. Estudo da sequência da erupção dos dentes permanentes em crianças do sexo feminino. Arq Cent Est Cur Odontol. 1979; 16:69-82.

31-Parreira MLJ, Moraes VR, Santos Filho JL, Moraes CP. Estudo da sequência da erupção dos dentes permanentes em crianças do sexo masculino. Arq Cent Est Cur Odontol. 1982; 19:101-12.

32-Aguirre $A L$, Rosa JE. Fatores que interferem na cronologia e sequência da erupção dentária decídua. Rev. Catarinense Odontol. 1980; 7:13-8.

33-Baume LJ, Beckes H, Evan HM. Hormonal control of tooth eruption. J Dent Res. $1954 ; 33: 80-90$.

34-Alvarez JO, Eguren JC, Caceda J, Navia JM. The effects of nutritional status on the age distribution of dental caries in the primary teeth. J. Dent Res. 1990; 69(9):1564-6.

35-Welbury, 1997 cit in Lygidakis, N.A. et alli. Molar-Incisor-Hypomineralisation (MIH). Retospective clinical study in Greek children. I. Prevalence and defect characteristics. European Archives of Paediatric Dentistry. 2008; 9(4):200-6.

36-Weerheijm KL, Jalevik B, Alaluusua S. Molar incisor hypomineralization. Caries Res. 2001; 35:390-1. 
37-Jälevik B, Norén JG. Enamel hypomineralization of permanent first molars: a morphological study and survey of possible aetiological factors. Int J Paediatr Dent. 2000; 10(4):278-89.

38-Beentjes VE, Weerheijm KL, Groen HJ. Factors involved in the aetiology of Molar-Incisor Hipomineralization (MIH). Eur J Paediatr Dent. 2002; 3(1):9-13.

39-Amerongen Van WE, Kreulen CM. Cheese molars: a pilot study of the etiology of hypocalcifications in first permanent molars. J Dent Child. 1995; 62(4):266-9.

40-Kühnisch J, Mach D, Thiering et al. Respiratory diseases are associated with molar-incisor hypomineralizations. Swiss Dent J. 2014; 124(3):286-93.

41-Mathu-Muju K, Wright JT. Diagnosis and treatment of molar incisor hypomineralization. Compend Contin Educ Dent. 2009; 19:73-83.

42- Muñoz AJ, Meléndez JD, González CV, Sánches CZ. Frequency and Severity of the Molar Incisor Hypomineralization in Patients Treated at the Dental Clinic of the Universidad de La Frontera, Chile. Int J Odontostomat. 2011; 5(2):133-140.

43-Alam M, Raza SJ, Sherali AR, Aktar AS. Neonatal complications in infants born to diabetic mothers. J Coll Physicians Surg Pak. 2006; 16(3):2121-5.

44-Cyna AM, Andrew M, Emmett RS, Simmons SW. Techniques for preventing hypotension during spinal anaesthesia for caesarean section. Cochrane Database Syst Rev. 2006; 18(4):CD002251.

45-Seow WK. Effects of preterm birth on oral growth and development. Australian dental journal. 1997; 42(2):85-91.

46-Lai PY, Seow WK, Tudehope DI. Enamel hypoplasia and dental caries in verylow birthweight children: a case-controlled, longitudinal study. Ped Dent. 1997; $19(1): 42-9$.

47-Aine L, Backström MC, Mäki R, Kuusela AL, Koivisto AM, Ikonen RS et al. Enamel defects in primary and permanent teeth of children born prematurely. $J$ Oral Pathol Med. 2000; 29:403-9.

48-Franco KMD, Peres SR, Moura Ribeiro MVL. Prenatal and neonatal variables associated with enamel hypoplasia in deciduos teeth in low birth preterm infants. J Appl Oral Sci. 2007; 15(6):518-23.

49-Seow WK. A study of the development of permanent dentition in very low birth weight children. Paediatr Dent. 1996; 18:379-84. 
50-Brogardh-Roth S, Matsson L, Klingberg G. Molar-incisor hypomineralization and oral hygiene in 10-to-12-yr-old Swedish children born preterm. Eur J Oral Sci, $2011 ; 119: 33-9$.

51-Corrêa-Faria P, Martins-Júnior PA, Vieira-Andrade RG, Oliveira-Ferreira $F$, Marques LS, Ramos-Jorge ML. Developmental defects of enamel in primary teeth: prevalence and associated factors. Int. J. Paediatr Dent. 2013; 23(3):173-9 DOI: 10.1111/j.1365-263X.2012.01241.X., May 2012.

52-Lygidakis, NA, Dimou G, Marinou D. Molar-Incisor-Hypomineralisation (MIH). A retrospective clinical study in Greek children. II. Possible medical aetiological factors. Eur Arch Paediatr Dent. 2008; 9(4):207-17.

53-Hansen AK, Wisborg K, Uldbjerg N, Heriksen TB. Risk the respiratorymorbidity in term infants delivered by elective caesarean section: cohort study. $\mathrm{Br}$ Med J. 2008; 336:85-7.

54-Visweswar VK, Amarla LD, Veerabahu R. Prevalence of developmental defects of enamel in children and adolescents with asthma: a cross-sectional study. Indian journal of dental research : official publication of Indian Society for Dental Research. 2012; 23(5):697-8.

55-Crombie F, Manton D, Kilpatrick N. Aetiology of molar-incisor hypomineralization: a critical review. Int J Paediatr Dent. 2006; 27:604-10.

56-Jälevik B, Norén JG, Klingberg G, Barregard L. Etiologic factors influencing the prevalence of demarcated opacities in permanent first molars in a group of Swedish children. Eur J Oral Sci. 2001; 109:230-234.

57-Kaliner M, Lemanke R. Rhinitis and asthma. JAMA. 1992; 268(20):2808-9.

58-Wogelius P, Haubek D, Nechifor A, Norgaard M, Tvedebrink T, Poulsen S. Association between use of asthma drugs and prevalence of demarcated opacities in permanent first molars in 6-to-8-year-old Danish children. Community Dent. Oral Epidemiol. 2010; 38(2):145-51.

59-Welsh MJ, Ramsey BW, Accurso FJ, Cutting GR. Cystic fibrosis. Scriver CF, Beaudet AL, Sly WS, editors. The metabolic and molecular bases of inherited disease, $8^{\text {th }}$ ed. New York: McGraw- Hill. 2001; p.5122-88.

60-Ferrazzano GF, Sangianantoni G, Cantile T, et al. Dental enamel defects in Italian children with cystic fibrosis: anobservational study. Community Dent Health. 2012; 29(1):106-9. 
61-Avçar A.; Kalayci AG. The presence and distribution of dental enamel defects and caries in children with celiac disease. Turk. J. Pediatr. 2008; 50(1):45-50.

62-Whatling R, Fearne JM. Molar incisor hypomineralization: a study of aetiological factors in a group of UK children. Int J Paediatr Dent. 2008; 18:155-62.

63-Santos MM, Marques RA, Ditterich RG, Wanbier DS, Lopes CML, Baldani MH. Cárie dentária e defeitos não fluoróticos de esmalte em escolares nutridos e em risco nutricional. Rev. Odontol. UNESP. 2010; 39(5):277-83.

64-WhitfordGM, angman- Monnon B. Fluoroses-like effects of acidosis, but not $\mathrm{NH}$,on rat incisor enamel. Caries Res. 1995; 129:20.

65-Atar M, Körperich EJ. Systemic disorders and their influence on the development of dental hard tissues: a literature review. Journal of dentistry. 2010; 38(4):296306.

66-Willmott N.S. Molar-Incisor-Hypomineralization: a literature review. Eur. Arch. Paediatr. Dent. 2009; 9(4):172-9.

67-Fernandes AS, Mesquita P, Vinhas L. Hipomineralização incisivo-molar: uma revisão da literatura. Rev Port Estomatol Med Dent Cir Maxilofac. 2012; 53:25862.

68-Weerheijm KL, Mejàre I. Molar incisor hypomineralization: a questionnaire inventory of its occurrence in member countries of the European Academy of Paediatric Dentistry (EAPD). Int J Ped Dent. 2003; 13(6):411-6.

69-Costa-Silva CM, Ambrosano GM, Jeremias F, Souza JF, Mialhe FL. Increase in severity of molar-incisor hypomineralisation and its relationship with the colour of enamel opacity: a prospective cohort study. Int J Paediatr Dent. 2011; 21:333-41.

70-Lygidakis NA. Treatment modalities in children with teeth affected by molarincisor enamel hypomineralisation $(\mathrm{MIH})$ : A systematic review. Eur Arch Paediatr Dent. 2010; 11(2):65-74.

71-Muratbegovic A, Markovic N, Selimovic,M G. Molar Incisor Hypomineralisation in Bosnia and Herzegovina: aetiology and clinical consequences in médium caries activity population. Eur.Arch. Paediatr.Dent. 2007; 8(4):189-94.

72-Ruschel HC, Souza IPR, Froner AL, Laitemberg DE. Amelogênese imperfeita: uma abordagem clínica, genética e histológica. J Bras Odontop Odonto Bebê. $2001 ; 4(21): 367-74$. 
73-Canger EM, Çelenk P, Yenísey M, Odyakmaz SZ. Amelogenesis imperfecta, hypoplastic type associated with some dental abnormalities: A case report. Brazilian Dental Journal. 2010; 21(2):170-174.

74-Jälevik B, Klingberg GA. Dental treatment, dental fear and behaviour management problems in children with severe enamel hypomineralization of their first molars. Int J Paed Dent. 2002; 12:24-32.

75-Silva CMC, Mialhe FL. Considerations for clinical management of molar-incisor hypomineralization: A literature review. Rev Odonto Cienc. 2012; 27(4):333-8.

76-Fayle SA. Molar Incisor hypomineralization: restorative management. Eur. J. Paediatr. Dent. 2003; 2:121-6.

77-Cho SY, Ki Y, Chu V. Molar incisor hypomineralization in Hong Kong Chinese children. Int J Paediatr Dent. 2008; 18(5):348-52.

78-Lepäniemi A, Lukinmaa PL, Alaluusua S. Nonfluoride hypomineralizations in the permanent first molars and their impact on treatment need. Caries Res. 2001; 35(1):36-40.

79-Cordeiro RCL. Tratamento restaurador em molares afetados pela hipomineralização molar-incisivo: estudo longitudinal. Unesp, Araraquara, 2014.

80- Alaluusua S. Development defects associated wich log breast feeding. Eur $\mathrm{J}$ Oral Scie. 1996; 104:493-7.

81-Dietrich G, Sperling S, Heltzer G. Molar incisor hypomineralisation in a group of children and adolescents living in Dresden (Germany). Eur J Paediatr Dent. 2003; 4(3):133-7

82-Fteita D, Ali A, Alaluusua S. Molar-incisor hypomineralization (MIH) in a group of school-aged children in Benghazi, Libya. Eur Arch Paediatr Dent. 2006; 7(2):92-5.

83-Kemoli AM. Prevalence of molar incisor hypomineralisation in six to eight yearolds in two rural divisions in Kenia. East Afr Med J .2008; 85(10):514-9.

84- Jasulaityte L, Weerheijm KL, Veerkamp JS. Prevalence of molar-incisorhypomineralization among children participating in the Dutch National Epidmiological Survey (2003). Eur Arch Paediatr Dent. 2008; 9(4):218-23.

85-Kuscu OO, Caglar E, Aslan S, Durmusoglu E, Karademir A, Sandalli N. The prevalence of molar incisor hypomineralization $(\mathrm{MIH})$ in a group of children in a highly polluted urban region and windfarm-green energy island. Int $\mathrm{J}$ Paediatr Dent. 2009; 19(3):176-85. 
86-Ahmadi R, Ramazani N, Nourinasab R. Molar Incisor Hypomineralization: A study of Prevalence and Etiology in a Group of Iranian Children. Iran J Pediatr. 2012; 22(2):245-251.

87-Biondi AM, Lopez Jordi Mdel C, Cortese SG, Alvarez L. Salveraglio I, Ortolani AM. Prevalence of molar-incisor hypomineralization (MIH) in children seeking dental care at the Schools of Dentistry of the University of Buenos Aires (Argentina) and University of la Republica (Uruguay).Acta Odontol Latinoam. 2012; 25(2):224-30.

88-Parikh DR, Ganesh M, Bhaskar V. Prevalence and characteristics of molarincisor hypomineralization ( $\mathrm{MIH})$ in the child population residing in Gandhinagar , Gujarat, India. Eur Arch Paediatr Dent. 2012; 13(1):21-6.

89-Kukleva MP, Petrova SG, Kondeva VK, Nihtyanova TI. Molar incisor hypomineralisation in 7-to-14 years old children in Plovdiv, Bulgaria: an epidemiologic study. Folia Med (Plovdiv). 2008; 50(3):71-5.

90-Calderara PC, Gerthoux PM, Mocarelli P, Lukinmaa PL, Tramacere PL, Alaluusua S. Eur J Paediatr Dent. 2005; 2:79-83.

91-Mittal NP,Goyal A, Gauba K, Kapur A. Molar incisor hypomineralisation: prevalence and clinical presentation in school children of the norther region of India. Eur Arch Paediatr Dent. 2014; 15:11-19.

92-Balmer RC, Prevalence of enamel defects and $\mathrm{MIH}$ in non-fluoridated and fluoridated communitie. Eur J Paediatr Dent. 2005; 4:209-212.

93-Arrow P. Prevalence of developmental enamel defects of first permanent molars among school children in Western Australian. Australian dental J. 2008; 43:250259.

94-Martinez Gomez TP, Guinot Jimeno F, Bellet Dalmau LJ, Giner Tarrida L. Prevalence of molar incisor hypomineralisation observed using transillumination in a group of children from Barcelona (Spain). Int J Paediatr Dent. 2012; 22(2):100-9.

95-Kuscu OO, Caglar E, Sandalli N. The prevalence and aetiology of molar incisor hypomineralization in a group of children in Istambul. Eur J Paediatr Dent. 2008; 9:139-144.

96-Zawaideh $\mathrm{FI}, \mathrm{Al}$-Jundl $\mathrm{SH}$, Al-Jaljoli $\mathrm{MH}$. Molar incisor hypomineralization in Jordanian children and clinical characteristics. Eur Arch Paediatr Dent. 2011; 12:31-36. 
97-Ghanim A, Morgan M, Marino R, Bailey D. Molar incisor hypomineralization prevalence and defects characteristics. Int J Paediatr Dent. 2011; 21:413-421.

98-Leppaniemi A, Lukinmaa PL, Alaluusua S. Nonfluoride hypomineralization in the first permanent molars and their impact on the treatment need. Caries Res. 2011, 35:36-40.

99-Muratbegovic A, Markovik N, Ganlbegovic SM. Molar incisor hypomineralization in Bosnia and Herzegovlnal aetiology and clinical consequences in medium caries activity population. Eur Arch Paediatr Dent. 2007; 8:189-194.

100- Preusser SE, Ferring V. Prevalence and severity of molar incisor hypomineralization in a region of Germany-a brief communication.J Public Health Dent. 2007; 67:148-150.

101- Jasulaityte L, Veerkamp JS, Weerheijm KL. Molar-incisor-hypomineralization review and prevalence data from the study of primary school children in Kaunas/Lithuania. Eur Arch Paediatr Dent. 2007; 8:87-94.

102- Psoter WJ, Reid BC, Katz RV. Malnutrition and dental caries: a review of literature. Caries Res 2005; 39:441-7.

103- Rugg-Gunn AJ, al-Moahammadi SM, Butler TJ. Malnutrition and developmental defects in 2 to 6-year-old Saudi boys. Caries Res. 1998; 32:18192.

104- Alaluusua S. Etiology of molar incisor hypomineralization: a systematic review. Eur Arch Paediatr Dent. 2010; 11(2):53-8.

105- Seow W K. Clinical diagnosis of enamel defects: pitfalls and practical guidelines. Int Dent J. 1997; 47(3):173-82.

106- Alaluusua S, Lukinmaa $P$, Vartiainen T, Partanen M, Torppa J, TuomistoJ. Polychlorinated dibenzo-p-dioxins and dibenzofurans via mother's milk may cause developmental defects in the child's teeth. Environmental Toxocology and Pharmacology. 1996; 1(3):193-197.

107- Tapias-Ledesma MA, Jimenez R, Lamas F, Gonzalez A, Carrasco P, Gil de Miguel A. Factors associated with first molar dental enamel defects: a multivariate epidemiological approach. J Dent Child. 2003; 70(3):215-20.

108- Kotsanos N, Kaklamanos EG, Arapostathis K. Treatment management of first permanent molars in children with Molar-Incisor Hypomineralisation. Eur $\mathrm{J}$ Paediatr Dent. 2005; 4:179-184. 
109- Smith CE. Celular and chemical events during enamel maturation. Crit Ver Oral Biol Med. 1995; 9:128-161.

110- World Health Organization. International Statistical Classification of Diseases and Related Health Problems, 10th revision. Volume 3: alphabetical index, Geneva, WHO.1994.

111- Suckling G, Elliott DC, Thurley DC. The production of developmental defects of enamel in the incisor teeth of penned sheep resulting from induced parasitism. Arch Oral Biol. 1983; 28:393-399.

112- Needleman HL, Allred E, Bellinger D, Leriton A, Rabinowitz M, Iverson K. Antecedent and correlates of hypoplast defects of primary incisors. Pediatric Dent 1992; 14(3):158-66. . 


\section{APÊNDICE A - FICHA DO PRONTUÁRIO}

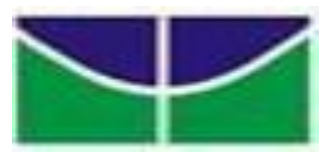

UNIVERSIDADE DE BRASILIA

PROGRAMA DE PÓS-GRADUAÇÃO EM CIÊNCIAS DA SAÚDE - MESTRADO

1) Identificação:

\begin{tabular}{|l|l|}
\hline 1- Nome da criança: & \\
\hline 2- Nome da mãe: & \\
\hline 3- Data de nascimento:(dia/mês/ano) & Criança: \\
\hline 4- Sexo: (1) masculino (2) feminino & \\
\hline
\end{tabular}

\section{2) Dados socioeconômicos e ambientais}

\begin{tabular}{|l|l|}
\hline A- Educação materna e paterna & \\
\hline MÃE: Até que série cursou? & Sim Não \\
\hline $\begin{array}{l}\text { Trabalha fora? } \\
\text { Profissão? }\end{array}$ & \\
\hline PAl: Até que série cursou? & Sim Não \\
\hline $\begin{array}{l}\text { Trabalha fora? } \\
\text { Profissão? }\end{array}$ & \\
\hline
\end{tabular}

3) Fase pré natal:

\begin{tabular}{|l|l|}
\hline Quantas consultas de pré natal ? & \\
\hline G P C A & (1) Sim (2) Não \\
\hline Fumou durante a gravidez? & (1) Sim (2) Não \\
\hline Bebeu durante a gravidez? & (1) Sim (2) Não \\
\hline Drogas durante a gravidez? & \\
\hline Durante a gravidez apresentou uma das & \\
doenças abaixo? & \\
(1) Hipertensão arterial & \\
(2) Cardiopatia & \\
(3) Diabete & \\
(4) Anemia & \\
(5) Infecção urinária & Qual: \\
(6) Outras doenças & \\
\hline Medicação durante a gravidez? & \\
\hline
\end{tabular}

Anotações: 


\section{4) Dados perinatais:}

\begin{tabular}{|l|l|}
\hline Idade gestacional ao nascer & IG: \\
\hline Como foi o parto? & (1) Normal \\
\hline Peso de nascimento? & \multicolumn{2}{|c|}{ (2) Cesariana } \\
\hline Comprimento ao nascimento? & \multicolumn{2}{|c|}{} \\
\hline Ficou internado na UTI neonatal? & (1) Sim $\quad$ (2) Não \\
\hline APGAR: & (1) Sim $\quad$ (2) Não \\
\hline Fez fototerapia: & Mãe: Criança: \\
\hline Tipagem sanguinea: & \multicolumn{2}{|}{} \\
\hline Ventilação mecânica? & \\
\hline Parada cardio respiratória? & \\
\hline Mal formação congênita? & \\
\hline Distúrbio hidroeletrolítico? & \\
\hline
\end{tabular}

Anotações:

HOOD (tempo):

CPAP:

VM:

5) Condições de saúde da criança (primeiro ano de vida):

\begin{tabular}{|l|ll|}
\hline Foi hospitalizada? & (1) Sim & (2) Não \\
\hline Teve infeç̧ão? & (1) Sim & (2) Não \\
\hline Teve anemia? & (1) Sim & (2) Não \\
\hline Tem asma ou bronquite? & (1) Sim & (2) Não \\
\hline Teve pneumonia? & (1) Sim & (2) Não \\
\hline Teve febre alta? $\left(>38^{\circ}\right)$ & (1) Sim & (2) Não \\
\hline Tomou remédios? & (1) Sim & (2) Não \\
\hline Se tomou remédio, qual foi? & (1) Sim & (2) Não \\
\hline Tomou amoxacilina? & (1) Sim & (2) Não \\
\hline
\end{tabular}

Anotações: 


\title{
APÊNDICE B - TCLE \\ TCLE -TERMO DE CONSENTIMENTO LIVRE E ESCLARECIDO
}

\author{
"Correlação de fatores peri-natais e intercorrências na primeira infância e HMI". \\ Instituição das pesquisadoras: UniCEUB e UnB \\ Pesquisador(a) responsável: Andréa Lopes Ramires Kairala \\ Orientador: Ana Cristina Barreto Bezerra
}

Seu filho(a) está sendo convidado(a) a participar do projeto de pesquisa acima citado. O documento abaixo contêm todas as informações necessárias sobre a pesquisa que estamos fazendo. A colaboração dele(a) neste estudo será de muita importância para nós, mas se ele(a) desistir a qualquer momento, isso não causará nenhum prejuízo.

O nome deste documento que você está lendo é Termo de Consentimento Livre e Esclarecido (TCLE).

Antes de decidir se deseja que ele(a)participe (de livre e espontânea vontade) você deverá ler e compreender todo o conteúdo. Ao final, caso decida autorizar a participação, você será solicitado a assiná-lo e receberá uma cópia do mesmo.

Antes de assinar faça perguntas sobre tudo o que não tiver entendido bem. A equipe deste estudo responderá às suas perguntas a qualquer momento (antes, durante e após o estudo).

\section{Natureza e objetivos do estudo}

O objetivo específico deste estudo é explicar o porquê de algumas doenças na gravidez, e no primeiro ano de vida da criança, causarem defeitos nos dentes por volta dos 6 anos de idade.

Você está sendo convidado a participar exatamente porque os resultados advindos da pesquisa contribuirão para o entendimento de possíveis causas de malformações dentárias na criança decorrentes do período da gestação.

\section{Procedimentos do estudo}

Sua participação consiste em permitir que sejam coletados dados através dos prontuários médicos do Hospital Regional do Gama -DF, das crianças e das mães no período da gravidez e do primeiro ano de vida. Em responder breve questionário enviado a você e também permitir o exame bucal da criança. $O$ exame dos dentes do seu filho será realizado na escola, em horário de aula, por dentista especialista em criança, sem custos para a criança ou responsável.

O procedimento é um exame bucal e as crianças receberão orientações sobre saúde bucal, técnicas de escovação e aplicação tópica de flúor, se necessário.

Não haverá nenhuma outra forma de envolvimento ou comprometimento neste estudo.

\section{Riscos e benefícios}

Este estudo possui baixo risco, pois a criança que participar da pesquisa será submetida ao exame bucal em consultório, respeitando-se a privacidade da criança. O exame será realizado por odontopediatra experiente, com capacidade técnica e psicológica para evitar qualquer tipo de desconforto, ansiedade ou constrangimento durante o exame clínico. Todo e qualquer dano decorrente da pesquisa será ressarcido pelo pesquisador. Os achados dessa pesquisa serão repassados para a escola, para se organizar um trabalho de prevenção de doenças bucais.

Medidas preventivas durante o exame serão tomadas para minimizar qualquer risco ou incômodo. 

realizá-lo.

Caso esse procedimento possa gerar algum tipo de constrangimento você não precisa

Sua participação poderá ajudar no maior conhecimento sobre o entendimento de possíveis causas de malformações dentárias na criança decorrentes do período da gestação.

\section{Participação, recusa e direito de se retirar do estudo}

Sua participação é voluntária. Você não terá nenhum prejuízo se não quiser participar.

Você poderá se retirar desta pesquisa a qualquer momento, bastando para isso entrar em contato com um dos pesquisadores responsáveis.

Conforme previsto pelas normas brasileiras de pesquisa com a participação de seres humanos você não receberá nenhum tipo de compensação financeira pela sua participação neste estudo.

\section{Confidencialidade}

Seus dados serão manuseados somente pelos pesquisadores e não será permitido o acesso a outras pessoas.

O material com as suas informações ficará guardado sob a responsabilidade da Professora/Médica /Cirurgiã Dentista Andréa Lopes Ramires Kairala, com a garantia de manutenção do sigilo e confidencialidade, e será destruído após a pesquisa.

Os resultados deste trabalho poderão ser apresentados em encontros ou revistas científicas, entretanto, serão apresentados apenas os resultados obtidos como um todo, sem revelar seu nome, instituição a qual pertence ou qualquer informação que esteja relacionada com sua privacidade ou a da criança.

Se houver alguma consideração ou dúvida referente aos aspectos éticos da pesquisa, entre em contato com o Comitê de Ética em Pesquisa do Centro Universitário de Brasília - CEP/UniCEUB, que aprovou esta pesquisa, pelo telefone 3966.1511 ou pelo e-mail cep.uniceub@uniceub.br. Também entre em contato para informar ocorrências irregulares ou danosas durante a sua participação no estudo.

Eu,

RG

após receber uma explicação completa dos objetivos do estudo e dos procedimentos envolvidos concordo voluntariamente em fazer parte deste estudo. Este Termo de Consentimento encontra-se impresso em duas vias, sendo que uma cópia será arquivada pelo pesquisador responsável, e a outra será fornecida ao senhor(a).

Brasília, de de

\section{Participante}

Andréa Lopes Ramires Kairala, celular 92394014, email kairalak@uol.com.br.

\section{Endereço dos(as) responsável(eis) pela pesquisa:}

Instituição: UnB

Endereço : Campus Universitário Darcy Ribeiro - Faculdade de Ciências em Saúde

Bairro: /CEP/Cidade: Brasília - DF, 70910-900

Telefones p/contato: (61) 3107-3300

Benefícios: Os participantes receberão orientações sobre como cuidar dos dentes e prevenir a cárie dental. Terão a garantia de receber respostas a qualquer pergunta ou 
esclarecimento sobre procedimentos, riscos, benefícios e outros relacionados com a pesquisa; a liberdade de retirar o consentimento a qualquer momento e deixar de participar do estudo sem que isso traga prejuízo ou dano ao atendimento no serviço; a segurança de que não será identificado e que será mantido o caráter confidencial da informação.

Caso existam custos adicionais, serão absorvidos pelo pesquisador responsável. Também será dada a garantia de orientação aos responsáveis das crianças pela informação da necessidade de tratamento.

As crianças que necessitarem tratamento dentário serão encaminhadas para o ambulatório de odontopediatria da SES-DF.

Ao final do exame bucal as crianças receberão orientações sobre saúde bucal, técnicas de escovação e aplicação tópica de flúor, se necessário.

Riscos: A criança que participar da pesquisa será submetida ao exame bucal em consultório respeitando-se a privacidade da criança; o exame será realizado por odontopediatra experiente, com capacidade técnica e psicológica para evitar qualquer tipo de desconforto, ansiedade ou constrangimento durante o exame clínico. Todo e qualquer dano decorrente da pesquisa será ressarcido pelo pesquisador.

Os achados dessa pesquisa serão repassados para a escola, para se organizar um trabalho de prevenção de doenças bucais.

No presente estudo, afirmamos que todo o processo transcorrerá de acordo com as diretrizes e normas regulamentadoras de pesquisas envolvendo seres humanos (Resolução 466/2012 CNS); e obedecerá aos rigores éticos do sigilo da identidade dos sujeitos e preservação de dados que possam comprometer a qualidade das interações.

Contato de urgência: Andréa Lopes Ramires Kairala Domicílio: SMPW Quadra 16 Conjunto 3 Lote 8 Casa F Bairro: Park Way /Telefone: 33802744 


\section{APÊNDICE C - QUESTIONÁRIO}

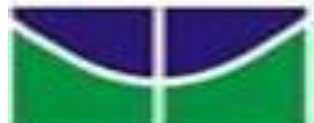 \\ UNIVERSIDADE DE BRASILIA \\ PROGRAMA DE PÓS-GRADUAÇÃO EM CIÊNCIAS DA SAÚDE - MESTRADO \\ QUESTIONÁRIO}

1) Identificação:

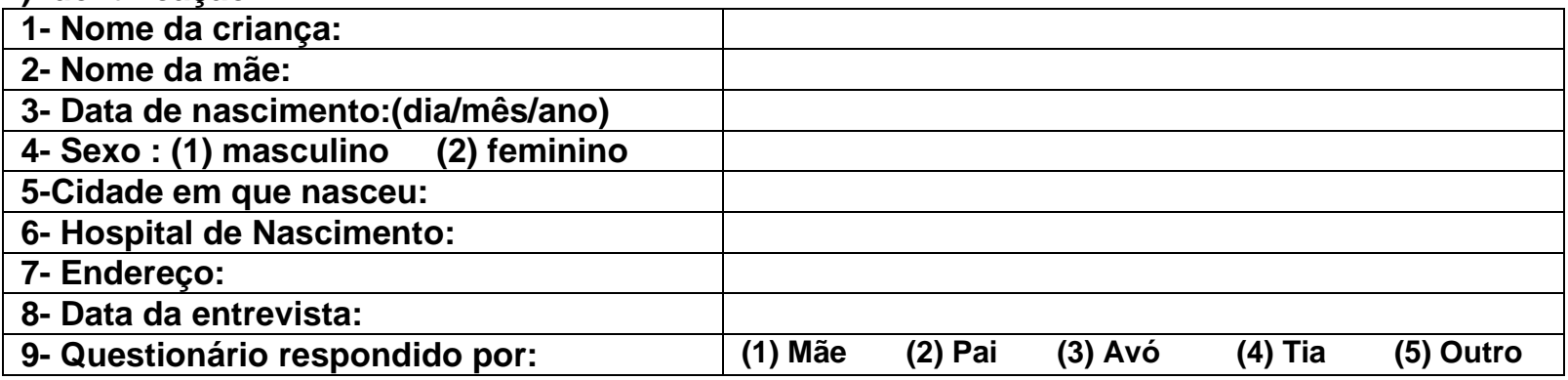

2) Dados socioeconômicos e ambientais

A- Educação materna e paterna

MÃE: Até que série cursou?

(1) Fundamental $1^{\circ}$ a $4^{\circ}$ série

(2) Fundamental $5^{\circ}$ a $8^{\circ}$ série

(3) Nível médio

(4) Nível superior

(5) Pós graduação

(6) Nunca foi à escola

(7) Não sabe informar

Trabalha fora?

Profissão?

PAl: Até que série cursou?

(1) Fundamental $1^{\circ}$ a $4^{\circ}$ série

(2) Fundamental $5^{\circ}$ a $8^{\circ}$ série

(3) Nível médio

(4) Nível superior

(5) Pós graduação

(6) Nunca foi à escola

(7) Não sabe informar

Trabalha fora?

(1)Sim (2)Não

Profissão?

B- Tamanho da família e renda familiar Quantas pessoas moram em casa (incluindo você e a criança):

(1) 1 a 4 pessoas

(2) 5 a 10 pessoas

(3) $>10$ pessoas

Qual a renda mensal da família:
(1) 500 a $1.000,00$
(2) $1.000,00$ a $2.000,00$
(3) 2000,00 a $4.000,00$
(4) $>4.000,00$ 


\begin{tabular}{|c|c|}
\hline C- Habitação e saneamento: & \\
\hline Voce mora em casa ou apartamento? & \\
\hline Quantos cômodos tem na casa? & (1) $\begin{array}{l}1 \text { a } 4 \\
(3)>8\end{array}$ \\
\hline $\begin{array}{l}\text { Destino do lixo: } \\
\text { (1) Coleta diária } \\
\text { (2) Coletor } \\
\text { (3) Enterrado } \\
\text { (4) Queimado } \\
\text { (5) Terreno baldio }\end{array}$ & \\
\hline $\begin{array}{l}\text { Você tem um desses aparelhos funcionando } \\
\text { em casa? }\end{array}$ & $\begin{array}{lll}\text { Fogão a gás: } & \text { (1) Sim } & \text { (2)Não } \\
\text { Geladeira: } & \text { (1) Sim } & \text { (2)Não } \\
\text { Radio: } & \text { (1) Sim } & \text { (2)Não } \\
\text { Televisão: } & \text { (1) Sim } \text { (2)Não } \\
\text { Computador: } & \text { (1) Sim } & \text { (2)Não }\end{array}$ \\
\hline
\end{tabular}

3) Fase pré natal:

\begin{tabular}{|c|c|}
\hline $\begin{array}{l}\text { Fez pré natal? } \\
\text { Quantas consultas de pré natal foram } \\
\text { realizadas? }\end{array}$ & $\begin{array}{ll}\text { (1) Sim (2) Não } & \\
\text { (0) Não fez pré natal } & \text { (1) Não sabe informar } \\
\text { (2) } 1 \text { a } 5 \text { consultas } & \text { (3) }>6 \text { consultas }\end{array}$ \\
\hline Este é o seu primeiro filho? & (1)Sim (2) Não \\
\hline $\begin{array}{l}\text { Considera ter tido uma boa alimentação } \\
\text { durante a gravidez? }\end{array}$ & (1) Sim (2) Não \\
\hline $\begin{array}{l}\text { Você fumou durante a gravidez? } \\
\text { Quantos cigarros /dia? }\end{array}$ & $\begin{array}{lll}\text { (1) Sim } & \text { (2) Não } & \text { (3) Não sabe informar } \\
\text { Total: } & & \end{array}$ \\
\hline Você bebeu durante a gravidez? & $\begin{array}{lcc}\text { (1) Sim } & \text { (2) Não } & \text { (3) Socialmente } \\
\text { (4) Não sabe informar } & \end{array}$ \\
\hline Usou drogas durante a gravidez? & $\begin{array}{lll}\text { (1) Sim } & \text { (2) Não } & \text { (3) Não sabe informar }\end{array}$ \\
\hline $\begin{array}{l}\text { Se sim, qual o tipo de droga consumida } \\
\text { durante a gravidez? }\end{array}$ & $\begin{array}{lrr}\text { (1) Crack } & \text { (2) Maconha } & \text { (3) Cocaína } \\
\text { (4) Outra } & \text { (5)Não sabe informar }\end{array}$ \\
\hline $\begin{array}{l}\text { Durante a gravidez apresentou uma das } \\
\text { doenças abaixo? } \\
\text { Hipertensão arterial } \\
\text { Cardiopatia } \\
\text { Diabete } \\
\text { Anemia } \\
\text { Infecção urinária } \\
\text { Outras doenças }\end{array}$ & $\begin{array}{ll}\text { (0)Não } & \text { (1) } \mathrm{Sim} \\
\text { (0)Não } & \text { (1) Sim } \\
\text { (0)Não } & \text { (1) Sim } \\
\text { (0)Não } & \text { (1) Sim } \\
\text { (0)Não } & \text { (1) Sim } \\
\text { (0)Não } & \text { (1) Sim }\end{array}$ \\
\hline $\begin{array}{l}\text { Tomou alguma medicação durante a } \\
\text { gravidez? }\end{array}$ & $\begin{array}{lll}\text { (1) Sim } & \text { (2) Não } & \text { (3) Não sabe informar } \\
\text { Qual: } & & \end{array}$ \\
\hline
\end{tabular}


4) Dados perinatais:

\begin{tabular}{|c|c|}
\hline Nasceu com quantas semanas de gestação & (1) RNT (2) RNPT \\
\hline Como foi o parto? & $\begin{array}{l}\text { (1) Normal } \text { (2) Cesariana } \\
\text { (4)Não sabe informar }\end{array}$ \\
\hline Qual o peso de nascimento? & (1)AIG (2) PIG (3)GIG \\
\hline Qual o comprimento ao nascimento? & \\
\hline Ficou internado na UTI neonatal? & (3) Não sabe informar \\
\hline APGAR? & \\
\hline Fez fototerapia? & (3) Não sabe informar \\
\hline
\end{tabular}

5) Condições de saúde da criança (primeiro ano de vida):

\begin{tabular}{|l|lll|}
\hline Foi hospitalizada? & (1) Sim & (2) Não & (3) Não sabe informar \\
\hline Teve infecção? & $(1) \operatorname{Sim}$ & (2) Não & (3) Não sabe informar \\
\hline Teve anemia? & (1) Sim & (2) Não & (3) Não sabe informar \\
\hline Tem asma ou bronquite? & (1) Sim & (2) Não & (3) Não sabe informar \\
\hline Teve pneumonia? & (1) Sim & (2) Não & (3) Não sabe informar \\
\hline Teve febre alta? $\left(>38^{\circ}\right)$ & (1) Sim & (2) Não & (3) Não sabe informar \\
\hline Tomou remédios? & (1) Sim & (2) Não & (3) Não sabe informar \\
\hline Se tomou remédio, qual foi? & (1) Sim & (2) Não & (3) Não sabe informar \\
\hline Tomou amoxacilina? & (1) Sim & (2) Não & (3) Não sabe informar \\
\hline
\end{tabular}

6) Amamentação:

\begin{tabular}{|c|c|}
\hline Mamou no peito? & $\begin{array}{ll}\text { (2) Não (3) Não sabe informar }\end{array}$ \\
\hline Se mamou no peito, quanto tempo? & $\begin{array}{l}\text { (0) Não respondeu } \\
\text { (1) Não mamou } \\
\text { (2) } 0 \text { a } 6 \text { meses } \\
\text { (3) } 6 \text { meses a } 1 \text { ano } \\
\text { (4) } 1 \text { ano a } 2 \text { anos } \\
\text { (5) }>2 \text { anos }\end{array}$ \\
\hline $\begin{array}{l}\text { Após a mamada era realizada a higiene } \\
\text { bucal? }\end{array}$ & $\begin{array}{lll}\text { (1) Sim } & \text { (2) Não (3) Não sabe informar }\end{array}$ \\
\hline
\end{tabular}

\section{7) Assistência à saúde da criança}

\begin{tabular}{|l|lll|}
\hline Tem algum problema de saúde? & (1) Sim & (2) Não & (3) Não sabe informar \\
\hline Toma algum remédio regularmente? & (1) Sim & (2) Não & (3) Não sabe informar \\
\hline Se toma algum remédio, qual? & & & \\
\hline Foi internado em hospital nos últimos anos? & (1) Sim & (2) Não & (3) Não sabe informar \\
\hline Se foi internado, porque? & & & \\
\hline
\end{tabular}

8) Assistência à saúde bucal da criança

\begin{tabular}{|l|lll|}
\hline $\begin{array}{l}\text { Quem cuidou da higiene bucal da criança até os } \\
\text { dois anos de idade? }\end{array}$ & (1) Sim & (2) Não & (3) Não sabe informar \\
\hline Possui escova de dente própria? & (1) Sim & (2) Não & (3) Não sabe informar \\
\hline Usa fio dental? & (1) Sim & (2) Não & (3) Não sabe informar \\
\hline Usa creme dental? & (1) Sim & (2) Não & (3) Não sabe informar \\
\hline $\begin{array}{l}\text { Escova os dentes quantas vezes } \\
\text { por dia? }\end{array}$ & \begin{tabular}{llll} 
(1) 1 & (2) 2 & (3) 3 & (4) mais de 4 \\
\hline
\end{tabular} & $\begin{array}{llll}\text { (5) não escova } & \text { (6) Não sabe informar }\end{array}$ \\
\hline
\end{tabular}




\section{APÊNDICE D - FICHA CLÍNICA}

Ficha de Avaliação Bucal Modificada da OMS

Para preenchimento da escola

Escola

Nome do aluno:

Data de nasc:

Idade em anos:

Sexo: H। $\mathrm{F}$ ( )

Para preenchimento da equipe odontológica

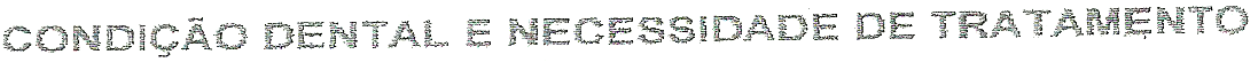
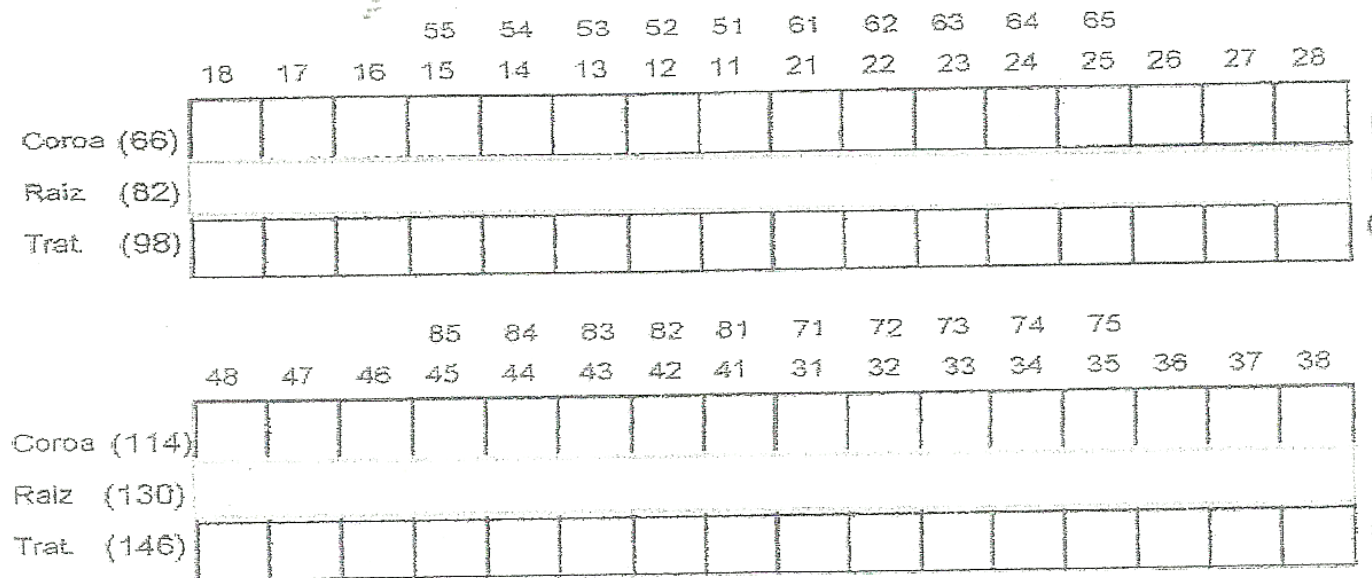

\begin{tabular}{|c|c|c|}
\hline Codigo & Descricao & Severidade \\
\hline 0 & Sem defeito & \\
\hline 1 & $\begin{array}{l}\text { Opacidades branco/ creme } \\
\text { demarcadas }\end{array}$ & \multirow[t]{2}{*}{ Leve } \\
\hline 2 & Opacidades amarelo/marrom & \\
\hline $3 a$ & Perda de esmalte & Moderado \\
\hline $3 b$ & Perda de esmalte e dentina & \multirow[t]{4}{*}{ Severo } \\
\hline $3 c$ & $\begin{array}{l}\text { Cavidades atipicas extendendo } \\
\text { na polpa e atingindo } 1 \text { ou }+ \\
\text { cuspides }\end{array}$ & \\
\hline 4 & Restauracoes atipicas & \\
\hline 5 & Dente extraido & \\
\hline
\end{tabular}




\title{
APÊNDICE E - TCM \\ TERMO DE ASSENTIMENTO DO MENOR
}

"Correlação de fatores peri-natais e intercorrências na primeira infância e HMI".

\author{
Instituição das pesquisadoras: UniCEUB e UnB \\ Pesquisadora responsável: Andréa Lopes Ramires Kairala \\ Orientadora: Ana Cristina Barreto Bezerra
}

Você está sendo convidado(a) a participar do projeto de pesquisa acima citado. Antes de decidir se quer participar, é importante que você entenda porque o estudo está sendo feito e o que ele envolverá.

Discutimos esta pesquisa com seus pais ou responsáveis e eles sabem que também estamos pedindo seu acordo. Se você vai participar na pesquisa, seus pais ou responsáveis também terão que concordar. Mas se você não desejar fazer parte da pesquisa, não é obrigado, até mesmo se seus pais concordarem.

Você pode discutir qualquer coisa deste formulário com seus pais, amigos ou qualquer um com quem você se sinta a vontade para conversar. Você pode decidir se quer participar ou não depois de ter conversado sobre a pesquisa e não é preciso decidir imediatamente.

Pode haver algumas palavras que não entenda, ou coisas que você queira que eu explique mais detalhadamente porque você ficou mais interessado(a) ou preocupado(a). Por favor, peça que eu explique melhor. Não tenha pressa de decidir se deseja ou não participar deste estudo.

É assegurado a você o direito a ressarcimento ou indenização no caso de quaisquer danos que possam ser causados pela pesquisa.

Os resultados estarão à sua disposição quando finalizada. Seu nome, ou o material que indique sua participação, não será liberado sem a permissão de seu responsável. Os dados e instrumentos utilizados na pesquisa ficarão arquivados com a pesquisadora responsável por um período de 5 anos, e após esse tempo serão destruídos.

Este Termo Assentimento encontra-se impresso em duas vias, sendo que uma cópia será arquivada pela pesquisadora responsável, e a outra será fornecida a você.

\section{Assentimento}

Eu, $R G$ (se

já tiver o documento), fui esclarecido (a) dos objetivos e procedimentos da presente pesquisa, de maneira clara e detalhada e esclareci minhas dúvidas. Fui informado(a) que posso solicitar novas informações a qualquer momento e que tenho liberdade de abandonar a pesquisa quando quiser, sem nenhum prejuízo para mim. O meu/a minha responsável poderá modificar a decisão de participar se assim o desejar. Tendo o consentimento do meu/da minha responsável já assinado, eu concordo em participar dessa pesquisa. As pesquisadoras me deram a oportunidade de ler e esclarecer as minhas dúvidas.

\section{Participante}

Andréa Lopes Ramires Kairala, celular 92394014. Email:kairalak@uol.com.br.

Se houver alguma consideração ou dúvida referente aos aspectos éticos da pesquisa, você e seus responsáveis podem entrar em contato com o Comitê de Ética em Pesquisa do Centro Universitário de Brasília - CEP/UniCEUB, que aprovou esta pesquisa, localizado na SEPN 707/907, campus do UniCEUB, bloco VI, sala 6110, CEP 70790-075, telefone 39661511, e-mail cep.uniceub@uniceub.br. 
ANEXO A - AUTORIZAÇÃO CEP

\section{CENTRO UNIVERSITÁRIO DE BRASÍLIA - UNICEUB}

\section{PARECER CONSUBSTANCIADO DO CEP}

DADOS DO PROJETO DE PESQUISA

Título da Pesquisa: CORRELAÇÃO DE FATORES PERI-NATAIS E INTERCORRÊNCIAS NA PRIMEIRA INFÂNCIA E HMI

Pesquisador: Andréa Lopes Ramires Kairala

Área Temática:

Versão: 1

CAAE: 43270515.1 .0000 .0023

Instituição Proponente: Centro Universitário de Brasília - UNICEUB

Patrocinador Principal: Financiamento Próprio

\section{DADOS DO PARECER}

Número do Parecer: 1.031 .828

Data da Relatoria: 10/04/2015

\section{Apresentação do Projeto:}

A pesquisa visa encontrar a correlação entre fatores peri-natais e intercorrências na primeira infância junto à ocorrência da hipomineralização incisivo molar (HMI). As causas da HMI não estão bem esclarecidas, a literatura recente sugere uma ampla variedade de fatores envolvidos no seu desenvolvimento. Conhecer os fatores etiológicos e seus efeitos é essencial para a compreensão do surgimento dos defeitos do esmalte e para a elaboração de modelos de comprovada eficácia na promoção da saúde. Entender estas causas são importantes pois clinicamente o esmalte hipomineralizado deteriora-se com facilidade, o que pode causar dor e aumento expressivo da propensão ao desenvolvimento de lesão cariosa. Outro fato importantíssimo é que com dor a criança apresenta dificuldade no processo de mastigação o que consequentemente vai levar a uma dificuldade na alimentação, podendo levar a processos de desnutrição de menor ou maior grau. As crianças atingidas têm seu tratamento complicado pela dificuldade em se anestesiâr os dentes afetados, gerando medo e ansiedade; além de problemas comportamentais, principalmente quando há envolvimento estético. Será realizada a técnica de correlação através de programa estatístico.

Os critérios de inclusão são crianças que estejam matriculadas e frequentando escola da rede pública; crianças na faixa etária de $5 / 6$ e $7 / 8$ anos de idade - crianças nascidas no Hospital

Endereço: SEPN 70/907 - Bloco 6, sala 6.110, $1^{\circ}$ andar

Bairro: Setor Universitário CEP: $70.790-075$

UF: DF Município: BRASILIA

Telefone: (61)3966-1200 Fax: (61)3966-1511 E-mail: comite.bioetica@uniceub.br 


\section{CENTRO UNIVERSITÁRIO DE Plotơformo BRASÍLIA - UNICEUB}

Continuação do Parecer: 1.031 .828

Regional do Gama; - crianças cujo Termo de Consentimento Livre e Esclarecido foi assinado pelos responsáveis legais; - crianças cujo estado de saúde permita o exame odontológico; - apresentar a erupção da metade do dente examinado,

e, os Critério de Exclusão são crianças não pertencentes à faixa etária definida;

- crianças que não nasceram no HRG; - crianças não matriculadas ou ausentes no dia previsto para a realização dos exames nas escolas e que ofereçam resistência ao exame clínico; - crianças com perda de dentes decíduos e ou permanentes; - crianças cujo termo de consentimento livre e esclarecido não foi assinado pelos responsáveis legais; - crianças que não colaboram com o exame oral.

\section{Objetivo da Pesquisa:}

O objetivo Primário é Identificar possíveis casos de molares e incisivos hipomineralizados em crianças nascidas no Hospital Regional do Gama e correlacionar os dados à história clínica das progenitoras durante os períodos pré e peri-natais, visando a obtenção de dados que esclareçam as causas da patologia estudada. Os objetivos secundário são: identificar as crianças matriculadas em escolas públicas da regional do Gama - DF, com idade entre 5 a 8 anos, que tenham alteração na formação do esmalte dentário; Analisar os prontuários médicos e correlacionar as intercorrências durante o pré natal e período perinatal de mães (das crianças identificadas na escola com alteração no esmalte dentário) acompanhadas durante a gestação no Hospital Regional do Gama - DF para detecção de prováveis fatores causais da HMI; - Avaliar questionário respondido pelos responsáveis pelas crianças, elaborado especificamente para esse fim, correlacionando as intercorrências e doenças na primeira infância, mais frequentes com possibilidade de interferência na amelogênese de molares e incisivos decíduos e permanentes.

\section{Avaliação dos Riscos e Beneficios:}

Os riscos apresentados pelo autores são baixos e se caracterizam por questões de privacidade, pois as crianças serão analisadas em consultórios por especialistas. O exame será realizad̆ por odontopediatra experiente, com capacidadé técnica e psicológica para evitar qualquer tipo de desconforto, ansiedade ou constrangimento durante o exame clínico. Todo e qualquer dano decorrente da pesquisa será ressarcido pelo pesquisador. Os achados dessa pesquisa serão repassados para a escola, para se organizar um trabalho de prevenção de doenças bucais. Quanto aos benefícios, as crianças identificadas como portadoras de necessidade de tratamento dentário serão orientadas e encaminhadas para receberem os cuidados necessários na rede pública de saúde do DF. Serão realizadas, se necessárias, aplicações tópicas de flúor. Serão transmitidas noções sobre cuidado e higiene bucal.

Endereço: SEPN 70/907 - Bloco 6, sala 6.110, $1^{\circ}$ andar

Bairro: Setor Universitário CEP: 70.790-075

UF: DF Município: BRASILIA

Telefone: (61)3966-1200 Fax: (61)3966-1511 E-mail: comite.bioetica@uniceub.br 


\section{CENTRO UNIVERSITÁRIO DE BRASÍLIA - UNICEUB}

Continuação do Parecer: 1.031.828

\section{Comentários e Considerações sobre a Pesquisa:}

A pesquisa possui benefícios reais e se encontra dentro dos padrões exigidos para aprovação, $O$ cronograma cumpre com o solicitado.

Considerações sobre os Termos de apresentação obrigatória:

O TCLE foi apresentado, a linguagem está clara, alertando sobre riscos e benefícios. Os procedimentos aparecem destacados. O termo de assentimento está apresentado com claridade.

\section{Recomendações:}

Recomenda-se uma revisão de critérios de inclusão e exclusão do trabalho de pesquisa que apresenta alguns fatores discordantes com o que a metodologia solicita.

\section{Conclusões ou Pendências e Lista de Inadequações:}

Apenas com a ressalva técnica do critério de inclusão e exclusão, porém sem nenhum fator que desabone a ética do projeto sugiro aprovação do mesmo.

O CEP-UniCEUB ressalta a necessidade de atenção às diretrizes éticas nacionais quanto aos incisos XI.1 e XI.2 da Resolução $n^{\circ}$ 466/12 CNS/MS concernentes às responsabilidades do pesquisador no desenvolvimento do projeto. Observação: Ao final da pesquisa enviar Relatório de Finalização da Pesquisa ao CEP. O envio de relatórios deverá ocorrer pela Plataforma Brasil, por meio de notificação de evento. O modelo do relatório encontra-se disponível na página do UniCEUB

http://www.uniceub.br/instituicao/pesquisa/ins030_pesquisacomitebio.aspx, em Relatório de Finalização e Acompanhamento de Pesquisa.

\section{Situação do Parecer:}

Aprovado

Necessita Apreciação da CONEP:

Não

Considerações Finais a critério do CEP:

Protocolo previamente avaliado por este CEP, com parecer $N^{\circ} 1.018 .756 / 2015$, tendo sido homologado na

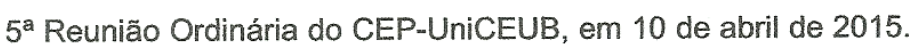

Endereço: SEPN 70/907 - Bloco 6, sala 6.110, $1^{\circ}$ andar

Bairro: Setor Universitário CEP: $70.790-075$

UF: DF Município: BRASILIA

Telefone: (61)3966-1200 Fax: (61)3966-1511 E-mail: comite.bioetica@uniceub.br 